\author{
Universidade de São Paulo \\ Faculdade de Filosofia, Letras e Ciências Humanas \\ Departamento de Linguística \\ Programa de Pós-graduação em Semiótica e Linguística Geral
}

Dissertação de Mestrado

Restrição de domínio, distributividade e a expressão kar em um dialeto da língua Kaingang

Michel P. Assis Navarro

São Paulo 


\title{
Restrição de domínio, distributividade e a expressão kar em um dialeto da língua Kaingang
}

\author{
Versão corrigida \\ De acordo: \\ Prof. Dr. Marcelo Barra Ferreira \\ Dissertação apresentada ao Programa de \\ Pós-Graduação em Semiótica e Linguística \\ Geral do Departamento de Linguística/USP \\ como requisito para a obtenção do título de \\ Mestre em Linguística.
}

Orientador: Marcelo Barra Ferreira

São Paulo 
Ao povo Kaingang 


\section{AGRADECIMENTOS}

Agradeço, antes de tudo, à Gilda Kuitá e Cristina Bandeira, amigas e informantes que trabalharam comigo durantes esta pesquisa, e sempre foram pacientes e dedicadas. Sem a contribuição delas esta pesquisa simplesmente seria inviável.

Agradeço também à comunidade Kaingang da reserva do Apucaraninha, em Tamarana, Paraná, pelo acolhimento.

Agradeço ao meu orientador, Prof. Marcelo Barra Ferreira, pela ética com que trabalha, respeitando a autonomia do orientando e sempre disposto em ajudar em todos os detalhes da pesquisa. Além disso, agradeço ao Marcelo pelos cursos e disciplinas que ministrou, nos quais me impressionou pela clareza de exposição, conhecimento profundo dos assuntos abordados e dedicação. Sem dúvida, o melhor professor com quem já tive aulas, e com o qual aprendi quase tudo do pouco que ainda sei sobre linguagem. E como não bastasse, tem sido uma pessoa amiga, auxiliando-me em vários assuntos.

Agradeço à prof(a). Luciana Storto, pela paixão e seriedade com que estuda as línguas indígenas, e por ser alguém em quem se espelhar. Obrigado pelas observações, críticas e conselhos que me deu no exame de qualificação.

Agradeço à Prof(a). Esmeralda Negrão pelas aulas de sintaxe e também pelas observações, críticas e conselhos que me deu no exame de qualificação.

Agradeço à prof(a). Ana Müller pela ajuda e contribuição importantíssima em parte da minha pesquisa.

Agradeço ao professor e amigo Roque Rocari, pelo companheirismo, pelas discussões sobre filosofia da linguagem e por ter sido a primeira pessoa que me apresentou a linguística formal.

Agradeço às amigas e amigos de curso, cujos trabalhos e debates têm me ajudado muito a crescer como pesquisador.

Agradeço aos meus pais, Dagoberto e Maria de Lourdes, por me apoiarem em todas as minhas decisões e sempre acreditarem em mim.

Agradeço às minhas irmãs, Luciana e Luana, pelo companheirismo e amizade.

Agradeço à minha sobrinha, Nina, por sempre me lembrar de que no mundo, apesar de tudo, sempre há espaço para o encanto e a beleza. 
"Las palabras son inciertas

Y dicen cosas incertas.

Pero digan esto o aquello

Nos dicen."

(Octavio Paz)

“...uma teoria satisfatória do significado deve dar uma explicação de como o significado das sentenças depende do significado das palavras"

(Davidson 2001 (1967): 17)

"O pensamento não existe antes da fala, nem a fala antes do pensamento; essas duas formas de um mesmo ato do cérebro humano nascem juntas. Assim, nada de pensamento sem fala. Mas o que é a fala? É a comunicação, é a conversação de um indivíduo humano com muitos outros indivíduos, e o homem animal só se transforma em ser humano, quer dizer, em ser pensante, pela conversação, na conversação."

(Mikhail Bakunin (1871)) 


\section{RESUMO}

NAVARRO, M, P, A. Restrição de Domínio, distributividade e a expressão kar em um dialeto da Língua Kaingang. 2012 - Dissertação (Mestrado), p.102 - Faculdade de Filosofia, Letras e Ciências Humanas, Universidade de São Paulo, São Paulo, 2012.

Esta dissertação apresenta uma análise semântica, no paradigma da Semântica Formal, da (i) restrição de domínio no DP e da (ii) expressão kar, que veicula a ideia de totalidade, no dialeto paranaense da língua Kaingang, do tronco Macro-Jê, família Jê, falada nas regiões sul e sudeste do Brasil. Num primeiro momento, o artigo definido parece ter, no Kaingang Paranaense, uma distribuição não trivial: aplica-se primeiro a um determinante quantificacional e restringe, via essa combinação, o domínio do quantificador, tal como no Basco, Grego e St'át'imcets (Giannakidou 2003, Etxeberria 2005 e Etxeberria \& Giannakidou 2009), línguas muito parecidas com o Kaingang no domínio nominal. Alguns dados, contudo, apontaram a análise em outra direção. Entendemos que certos padrões de comportamento semântico e sintático apresentado por kar nas sentenças, tal como sua neutralidade quanto à propriedade de distributividade e a possibilidade da conjunção de duas sequências de [NP+kar] sob um mesmo artigo definido (ao contrário do Basco, no qual a mesma estrutura é agramatical, sugerindo que os quantificadores universais em Basco criam um QP), são algumas das evidências que, no conjunto, dão suporte para a hipótese, defendida nesta dissertação, de que kar, no Kaingang Paranaense, parece ser um modificador - à la Lasersohn (1999) -, não tendo, por isso, uma força quantificacional própria. A função semântica de kar seria de controlar o quanto de desvio da verdade é pragmaticamente permissível. Como consequência desta análise, no Kaingang Paranaense o artigo definido não operaria sobre um determinante quantificacional, mas sim sobre um NP. O que aponta no sentido de que os artigos definidos ag/fag (os/as) no Kaingang Paranaense, em contextos em que eles co-ocorrem com kar, não perderiam a sua função max, i.e., de formadores de indivíduo a partir de um conjunto, para funcionar meramente como um operador preservador de tipo e restritor de domínio adjungido ao determinante quantificacional, como proposto por Giannakidou 2003, Etxeberria (2005) e Etxeberria \& Giannakidou (2009) para o Basco e o Grego. Ag/fag continuariam sendo artigos definidos clássicos ocupando o núcleo de uma projeção DP e kar um modificador. Também discutimos brevemente algumas das vantagens e problemas de se tentar estender esta análise para 0 Basco, Grego e St'át'imcets. E, por último, investigamos o comportamento de kar na sentença, as possíveis leituras quando da sua interação com indefinidos, numerais, tipos de predicados e o operador distributivo introduzido via reduplicação verbal. Com base nos dados, nossa proposta é de que - em função de a leitura distributiva, na maioria dos exemplos, ser permitida pelos informantes somente quando houve reduplicação verbal kar é neutro quanto à propriedade da distributividade e que o operador distributivo introduzido por reduplicação verbal tem escopo sobre todo o VP.

Palavras-chave: Kaingang; restrição de domínio; determinante; quantificação; modificador; distributividade. 


\begin{abstract}
NAVARRO, M, P, A. Domain restriction, distributivity and the expression kar in a dialect of the Kaingang language. 2012 - Thesis (Master's Degree), p.102 Faculdade de Filosofia, Letras e Ciências Humanas, Universidade de São Paulo, São Paulo, 2012.

This dissertation presents, in the paradigm of formal semantics, a semantic analysis of both (i) the phenomenon of domain restriction in the DP and (ii) the expression kar, which conveys the idea of totality, in a dialect of the Kaingang language, a Brazilian language from the Macro-Jê Stock, Jê family, spoken in southern and southeastern Brazil. Although, at first, the definite article in Kaingang seems to have a non-trivial distribution: it applies first to a quantificational expression, and via such combination restricts the domain of the quantifiers, such as in Basque, Greek and St'át'imcets (Giannakidou 2003, Etxeberria 2005 and Etxeberria \& Giannakidou 2009), some data pointed the analysis in another direction. Patterns of semantic and syntactic bevavior presented by $k a r$ in some sentences, such as its neutralite regarding the property of distributivity and the possibility of conjoining two [NP $+k a r]$ sequences under the same definite article (unlike Basque, which does not allow such structure, suggesting that in Basque the universal quantifier creats a QP), seem to be as a whole evidences for the hypothesis, advocated in this thesis, that the expression kar may be a modifier - à la Lasersohn (1999) - and as such does not have a quantificational force. The semantic function of kar would be to control how much deviation from the truth conditions of the sentences is pragmatically allowed. As a result of this analysis, the definite articles ag/fag in Kaingang do not operate on a quantificational expression, as in Basque and Greek, but on the NP. Such fact suggests that the definite articles in Kaingang, in contexts they co-occur with kar, do not lose their max function in order to work merely as a type preserver and a domain restrictor combined with a quantificational expression, as proposed by Giannakidou 2003, Etxeberria (2005) e Etxeberria \& Giannakidou (2009) for Basque and Greek. Ag/fag would still be a classical definite article occupying the head of a DP projection and kar a modifier, instead of a universal quantifier. We also discuss briefly some of the advantages and problems of trying to extend this analysis to the Basque, Greek and St'át'imcets languages. And lastly, we investigated the behavior of $k a r$ in the sentence, its interaction with indefinites, numerals, types of predicates and the distributive operator introduced via verbal reduplication. Based on such data, once distributive readings were permitted by the informants only via verbal reduplication, our proposal is that kar is neutral regarding the property of distributivity and that the distributive operator introduced via verbal reduplication has scope over the VP.
\end{abstract}

Key-words: Kaingang language; domain restriction; definite article; quantification; modifier; distributivity. 


\section{SUMÁRIO}

$\begin{array}{ll}\text { Abreviaturas } & 09\end{array}$

$\begin{array}{lr}\text { INTRODUÇÃO } & 10\end{array}$

Capítulo 1: Considerações sobre a língua 13

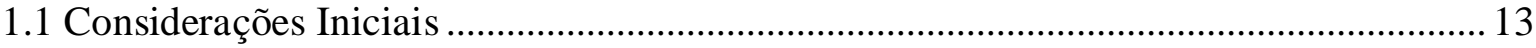

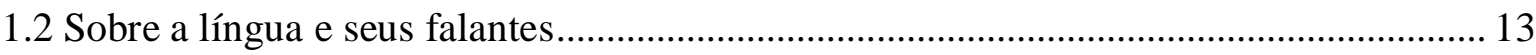

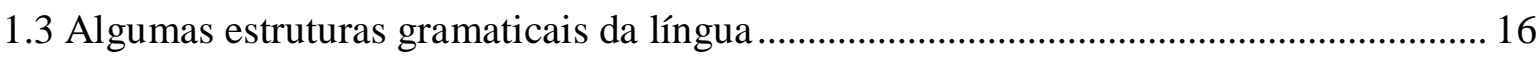

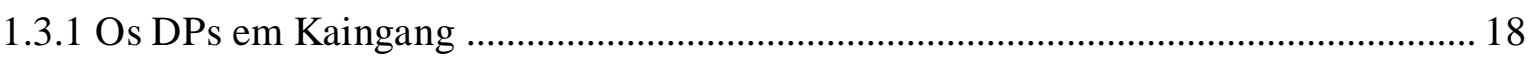

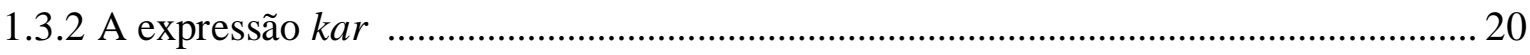

Capítulo 2: A estrutura interna dos DPs com kar em Kaingang 24

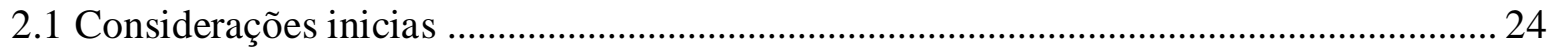

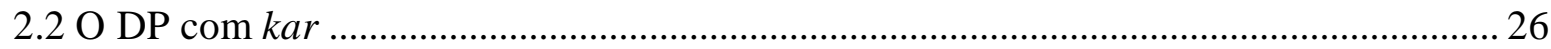

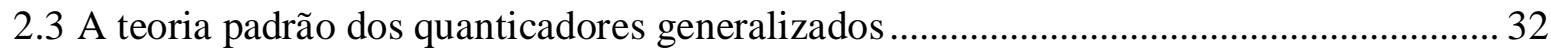

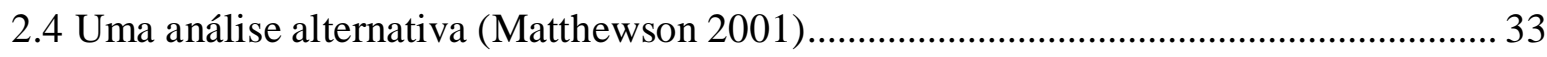

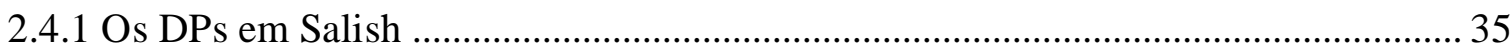

2.4.2 Alguns problemas com a hipótese de que o domínio de Q é de tipo e...................... 39

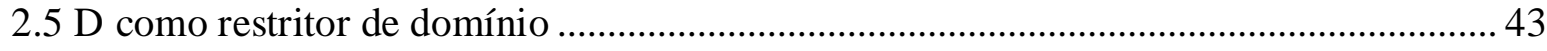

2.5.1 Salish explicado por Etxeberria \& Giannakidou (2009) ............................................ 46

2.6 Restrição de domínio em Kaingang: evidência para a hipótese de Etxeberria \&

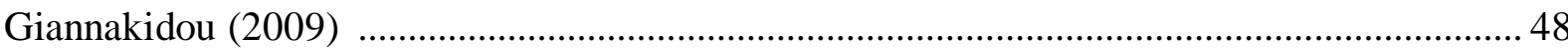

2.7 E se em Kaingang $N+k a r+a g$ form um DP e kar um modificador? .............................. 50

2.7.1 Duas propostas na literatura de interpretação de all como modificador .................... 53

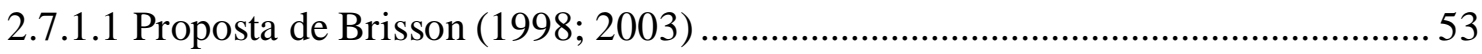

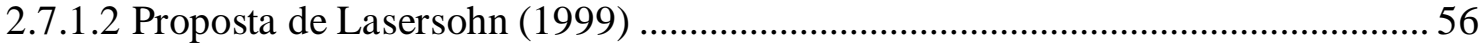

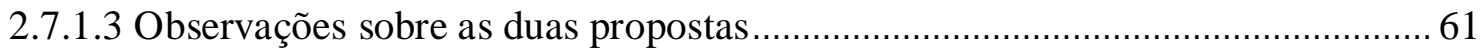

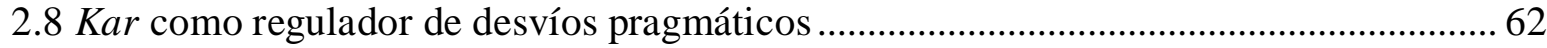

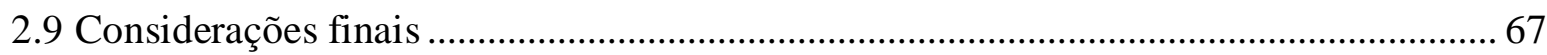

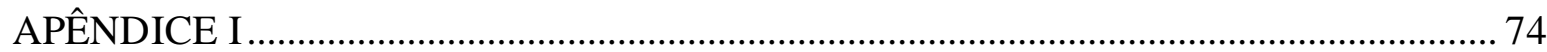




\section{Capítulo 3: O comportamento de kar na sentença e sua interação com o operador} distributivo introduzido via reduplicação verbal

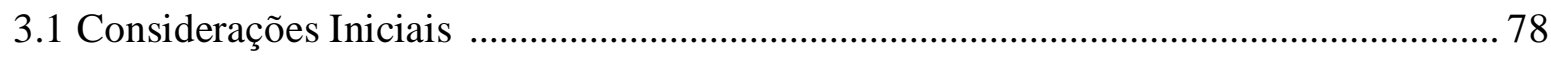

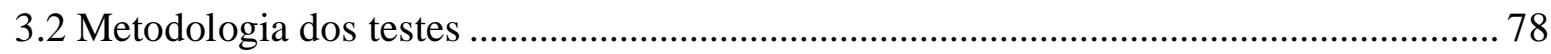

3.3 A expressão kar do Kaingang e sua interação com outros termos na sentença ............... 80

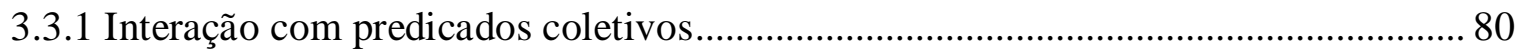

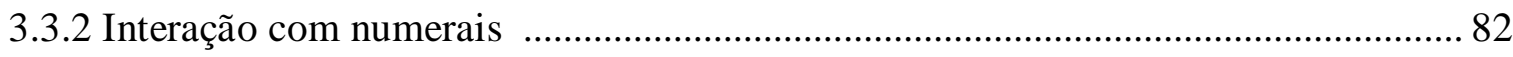

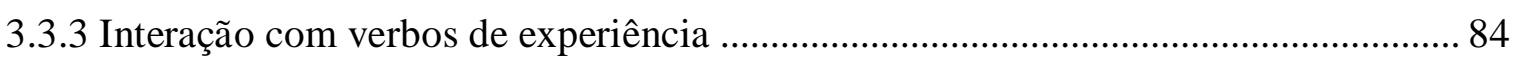

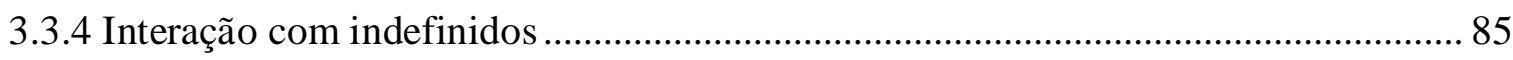

3.3.5 Interação com um operador de negação ....................................................................... 87

3.3.6 Número gramatical, variável ligada e distributividade verbal .................................. 88

3.4 Interpretando o operador distributivo e calculando as condições de verdade de uma sentença 


\section{Abreviaturas}

ASP - aspecto

ASP.hab - aspecto de habitualidade

cl - classificador

abs - absolutivo

$\mathrm{D}$ - determinante definido

D.sg - determinante definido singular

D.pl - determinante definido plural

DIST - operador distributivo

gen - genitivo

ind.circ - indicador de circunstância

$1 \mathrm{p}$ - primeira pessoa do singular

$3 p . p l$ - terceira pessoa do plural

m.s - marca de sujeito

PRES - presente

aux - auxiliar

NEG - negação

nom - nominativo

part - partitivo

part.fut - particular de futuro

PAST - pretérito perfeito

PLR - pluracionalidade

pron.pos.sg - pronome possessivo singular

pron. pos.pl - pronome possessivo plural

prep - preposição

$\mathrm{pl}$ - plural

sg - singular 


\section{INTRODUÇÃO}

Nas duas últimas décadas houve uma explosão de pesquisas sobre quantificação e definitude em línguas tipologicamente das mais diversas (Bach et AL. 1995, Matthewson 1998, 2001, 2008; Giannakidou 2004; Etxeberria 2005; Giannakidou \& Etxeberria 2009, dentre outros). Embora o programa de pesquisa em semântica formal centrado nas estruturas quantificacionais das línguas naturais tenha praticamente surgido junto com essa área da linguística, somente nas duas últimas décadas o foco translinguístico dos estudos permitiu que teorias padrões da quantificação fossem seriamente questionadas. Pesquisas em línguas tipologicamente das mais variadas apresentaram resultados e deram base para hipóteses de que alterações na teoria padrão precisavam ser realizadas para contemplar novos padrões de quantificação encontrados entre as línguas.

Este trabalho visa ser mais uma contribuição para os estudos sobre quantificação, definitude e restrição de domínio, a partir da análise desses fenômenos em um dialeto da língua Kaingang, do troco Macro-Jê, família Jê, falada por aproximadamente 25 mil pessoas, nas regiões Sul e Sudeste do Brasil. O dialeto em foco é o paranaense, falado predominantemente no norte e centro do Estado do Paraná.

O objetivo específico deste trabalho é, em primeiro lugar, descrever e analisar o comportamento semântico da expressão kar, que veicula a ideia de totalidade, e sua interação com expressões nominais cuja denotação é restringida, via artigo definido, a um conjunto de indivíduos salientes no contexto; em segundo lugar, investigaremos também a interação de kar, na sentença, com outros termos da língua, sobretudo com verbos cuja reduplicação parece introduzir um operador distributivo, de maneira a entender quando leituras distributivas e/ou coletivas são permitidas.

O objetivo geral é contribuir para os estudos translinguísticos, em semântica formal, sobre quantificação, definitude, restrição contextual de domínio e distributividade.

Esta dissertação está dividida em 3 capítulos. No capítulo 1, trato da língua e seu povo e de alguns pontos sobre a estrutura gramatical da língua relevantes para uma melhor compreensão dos dados presentes nos capítulos subsequentes. No capítulo 2 , dividido em 9 seções, focamos a estrutura interna dos DPs definidos em Kaingang. Na seção 2.2 trataremos da distribuição de kar no domínio nominal e as interpretações atribuídas às sentenças em que kar co-ocorre com o artigo definido e nas sentenças em 
que o artigo definido está ausente. Mas antes de analisar mais detalhadamente o papel de kar e o artigo definido no Kaingang Paranaense quando eles interagem na sentença e tentar resolver composicionalmente o fato de o artigo definido na língua se combinar com kar, e não diretamente com o nome, faz-se necessário olhar para propostas na literatura que tentaram dar uma solução composicional para línguas que parecem apresentar o mesmo problema e confrontar os dados dessas línguas com os dados do Kaingang expostos nesta seção. Para tanto, na próxima seção, 2.3, apresentaremos a análise que ficou conhecida por Teoria Padrão dos Quantificadores (em consonância com o cálculo de predicados), que entendemos ser importante apresentar ao leitor, pois as propostas de solução para o problema composicional em línguas em que o artigo definido parece primeiramente se combinar com uma expressão quantificacional fazem referência à teoria padrão e em grande medida procuram preservá-la. Após a seção 2.3, trataremos, na seção 2.4, da análise alternativa de Matthewson (1999) à teoria padrão, a partir de dados em St'át'imcets, língua da família Salish, falada no Canadá. E, então, na seção 2.5, abordaremos a proposta de Giannakidou (2004), Etxeberria (2004, 2005, 2009) e Giannakidou \& Etxeberria (2009) de que a restrição de domínio pode afetar abertamente o determinante quantificacional, formando com ele um constituinte, tal como no Grego e Basco, línguas em que o artigo definido parece também se combinar primeiramente com uma expressão quantificacional. Na análise dos autores ficará evidente a defesa que eles fazem da teoria padrão.

Na seção 2.6, argumentaremos que o Kaingang Paranaense parece fornecer, à primeira vista, evidências em apoio ao programa de que a restrição de domínio pode afetar abertamente o determinante quantificacional, formando com ele um constituinte, tal como no Grego e Basco. Entretanto, o comportamento de kar em determinados contextos sentenciais mostra, como verifico na seção 2.7 , que ele não apresenta sempre um padrão de comportamento que se espera de um determinante quantificacional. Kar parece se comportar mais como um modificador do que um quantificador quando em construções com um argumento nominal. Com base nessas evidências, hipotetizamos, seguindo a proposta de Lasersohn (1999) para all, que kar seja um operador com a função de regular os desvios pragmáticos das sentenças em relação às suas condições de verdade. Como resultado da proposta de que kar seja apenas um modificador, sustentaremos também na seção 2.7, que o artigo definido no Kaingang Paranaense, quando operando sobre $N$ kar não perde a sua função referencial, como no caso do Basco e Grego. De maneira que no Kaingang Paranaense o determinante definido não é 
ambíguo entre um artigo definido clássico e um mero restritor contextual de domínio, como proposto por Etxeberria e Giannakidou (2009) para o Basco e o Grego. Em estruturas $N P+k a r+a g$, o determinante também funciona como restritor contextual, mas continua sendo um operador de tipo <<et,>e>, i.e., formando indivíduo a partir de um conjunto. Por fim, nas considerações finais, além de retomar as hipóteses a que chegamos quanto ao modificador kar e o determinate definido ag, levantamos algumas reflexões quanto à possibilidade de se estender a análise do Kaingang para o Basco e o Grego.

No capítulo 3, investigaremos a interação da expressão kar com outros termos na sentença, i.e, as possíveis leituras que podem receber sentenças com DP nos quais ocorre kar. Observamos sentenças com $N P+k a r+a g$ em interação com indefinidos, numerais, operador de negação, assim como os tipos de predicados verbais com os quais $N$ kar ag pode co-ocorrer. Também olharemos para a interação de $N P+k a r+a g$ com um operador distributivo introduzido via reduplicação verbal, de forma a entender quando leituras distributivas e/ou coletivas são permitidas. O comportamento de kar nas sentenças apontou no sentido de que kar é neutro quanto à distributividade, i.e., não força leitura distributiva. As leituras distributivas foram atribuídas às sentenças quando houve reduplicação verbal. O fato de tais leituras atribuírem o predicado verbal aos indivíduos atômicas na extensão do DP sujeito, levou-nos a hipotetizar que a reduplicação verbal em Kaingang, ao menos para verbos accomplishments, introduz um operador distributivo que tem escopo sobre todo o VP. 


\section{CAPÍTULO 1: CONSIDERAÇÕES SOBRE A LÍNGUA.}

\subsection{Considerações iniciais.}

Neste capítulo, em primeiro lugar, discorreremos brevemente sobre a língua Kaingang, seus falantes, regiões em que é falada e suas variações dialetais. Em seguida, apresentaremos algumas características gramaticais da língua que entendemos ser importantes para facilitar a compreensão do leitor dos dados apresentados na dissertação e das hipóteses e generalizações que formularemos. Quanto a pontos gramaticais não mencionados, a respeito dos quais, por ventura, o leitor gostaria de saber, eles não constam basicamente por duas razões: (i) porque seriam irrelevantes para a compreensão dos dados apresentados e para as questões da língua tratadas nesta dissertação, e (ii) porque há vários pontos que não foram estudados ainda na língua, e que, por isso, qualquer afirmação sobre eles soaria nada científica.

\subsection{Sobre a língua e seus falantes.}

A língua Kaingang é uma das línguas da Família Jê, integrante do tronco linguístico Macro-Jê. Falada nas regiões Sul e Sudeste do Brasil pelo povo da etnia Kaingang, a língua, junto com o Xokleng, forma o conjunto meridional das línguas Macro-Jê. São as únicas, do conjunto das línguas Jê, faladas no sul do país ${ }^{1}$. O Kaingang não é somente a língua da família Jê com maior número de falantes, mas também é uma das línguas indígenas mais faladas no Brasil ${ }^{2} 3$, com aproximadamente 25 mil falantes, distribuídos em mais de 30 terras indígenas, nos Estados de São Paulo, Paraná, Santa Catarina e Rio Grande do Sul (TABOSA 2006). Segundo a classificação em Wiesemann (1971), foram identificados cinco dialetos. São eles:

\footnotetext{
${ }^{1}$ A maioria das línguas e povos da família Jê está bem mais ao norte: os Xavante (Mato Grosso), os Parakatéye (Pará), os Mebengokre, conhecidos como Kayapó (Pará e Mato Grosso), os Xerente, os Krahô, os Apinayé (Tocantins), os Apaniekrá, os Pukobyé, os Krinkati (Maranhão) e alguns outros.

${ }^{2}$ Dados da Enciclopédia das Línguas do Brasil: http://www.labeurb.unicamp.br/elb/indigenas/kaingang.htm .

${ }^{3}$ Estima-se que aproximadamente $60 \%$ dos Kaingangs, de uma população entre 25 e 30 mil, sejam falantes da língua. Em função da controvérsia quanto ao número exato de falantes nativos da língua, preferimos não apresentar nenhum número determinado.
} 
- Dialeto de São Paulo, falado ao norte do rio Paranapanema, no Estado de São Paulo;

- O dialeto Paranaense, falado na área entre os rios Paranapanema e Iguaçu;

- O dialeto Central, falado na área entre os rios Iguaçu e Uruguai;

- O dialeto Sudoeste, falado ao sul do rio Uruguai e ao oeste do rio Passo Fundo;

- O dialeto Sudeste, falado ao sul do Rio Uruguai e ao leste do rio Passo Fundo.

Todos os dados do Kaingang nesta dissertação são sentenças no dialeto Paranaense. Os informantes são moradores da reserva indígena do Apucaraninha, situada no Município de Tamarana, próximo à cidade de Londrina, na confluência dos rios Apucarana e Apucaraninha com o Rio Tibagi, no Estado do Paraná ${ }^{4}$ O mapa abaixo localiza a reserva ${ }^{5}$ :

(1)

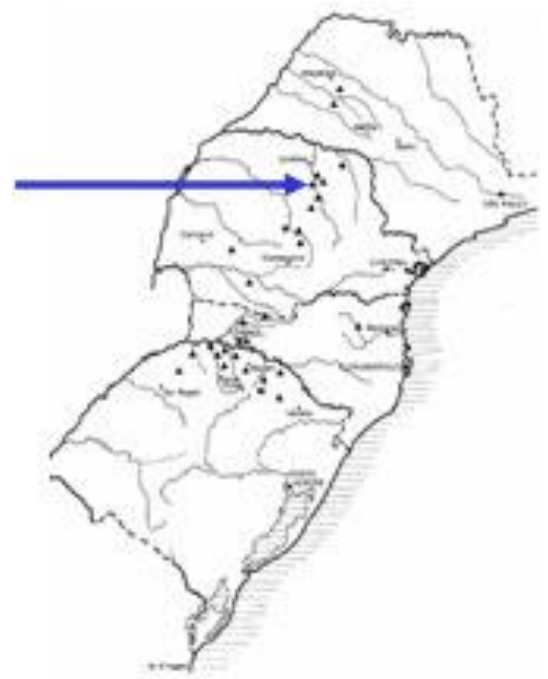

Desde já queremos deixar bem claro que as hipóteses e generalizações formuladas - embora possam ser estendidas a outros dialetos da língua - são sobre o dialeto Paranaense. Apesar de ao longo de quase toda a dissertação empregarmos, por

\footnotetext{
${ }_{5}^{4}$ Fonte: http://www.portalkaingang.org/index_apucaraninha.htm\#.

${ }^{5}$ Mapa retirado na mesma fonte.
} 
motivo de simplificação, apenas o termo Kaingang, o leitor deve sempre manter em mente que estamos nos referindo ao dialeto Paranaense.

Como quase todas as línguas indígenas brasileiras, o Kaingang tem sido relativamente pouco estudado. Entre os estudos realizados, alguns importantes são:

i. Um estudo importante de descrição fonológica da língua: D’ANGELIS 1998. Traços de modo e modos de traçar geometrias: línguas Macro-Jê \& teoria fonológica. Tese de Doutorado. Campinas: IEL-Universidade estadual de Campinas (Unicamp);

ii. Dois estudos interessantes sobre tempo e aspecto na perspectiva funcionalista: GONÇALVES, Solange A. A expressão do tempo na língua Kaingang. In: ESTUDOS LINGUÍSTICOS, São Paulo, 38 (1): 249-258 jan.-abr. 2009; GONÇALVES, Solange A. Aspecto no Kaingang. Dissertação de Mestrado. Universidade Estadual de Campinas (Unicamp)

iii. Um estudo no paradigma gerativista a respeito da estrutura sintática da língua: NASCIMENTO, S.H.L (1995). Aspectos Morfológicos e Sintáticos e Marcação de Caso da Língua Kaingang. Dissertação de Mestrado, Universidade Federal de Santa Catarina (UFSC);

iv. Um trabalho sobre construções causativas na língua: TABOSA, L.P (2006). Construções Causativas na Língua Kaingang. Dissertação de Mestrado, Universidade Estadual de Londrina (UEL).

Até onde sabemos, nosso estudo é o primeiro na perspectiva da semântica formal realizado sobre aspectos da língua Kaingang. 


\subsection{Algumas estruturas gramaticais da língua.}

A estrutura oracional padrão do Kaingang é SOV, como em (2).

$\begin{array}{lcllll}\text { 2. Jũm } & \text { vỹ } & \text { mĩg } & \text { tén } & \emptyset^{6} & \text { SOV } \\ \text { João } & {\mathrm{m} . \mathrm{s}^{7}}^{7} & \text { onça } & \text { matar } & \text { ASP } & \\ \text { 'João matou onça' } & & & & \end{array}$

Contudo, em sentenças com sujeito pronominal, como em (3), o sujeito pode aparecer posposto ao verbo:

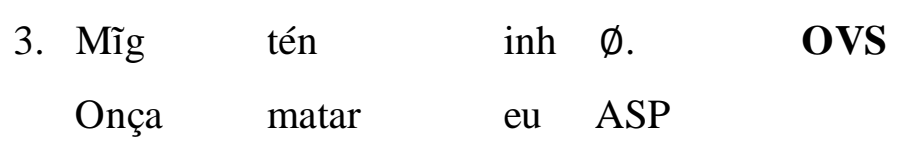

'Eu matei onça.'

O que não muda são as posições do objeto direto e do verbo, sempre adjacentes, na ordem OV.

O Kaingang parece se comportar, em linhas gerais, como uma língua núcleofinal, i.e., os núcleos são frequentemente posicionados no final do sintagma do qual são membros e cujo tipo sintático determinam, como exemplificado com a sentença abaixo ${ }^{8}$ :

\footnotetext{
${ }^{6} \mathrm{O}$ símbolo $\varnothing$ no final das sentenças exemplificadas nesta dissertação consiste na categoria de aspecto representada pelo morfema zero. A categoria de aspecto é expressa na língua por meio do uso de partículas aspectuais posposicionadas ao verbo. A ausência de marcas morfológicas de aspecto indica que o aspecto da ação descrita é perfectivo, ou seja, acabado, não durativo. Assumiremos, no esteio de Nascimento (1995), que aspecto é uma categoria funcional em Kaingang. O Kaingang é uma língua rica em partículas aspectuais, mas não conhecemos nenhum estudo que tente formalizar as possíveis leituras resultantes da interação entre adjuntos temporais e partículas aspectuais em Kaingang.

7 m.s: marcador de sujeito. Em Kaingang, há várias partículas posposicionadas aos substantivos, pronomes ou frases substantivas em função de sujeito, e ainda há pouco estudo sobre as funções dessas partículas. De acordo com a definição padrão das línguas de sistema ergativo/absolutivo, tais partículas deveriam ocorrer como marcadores de caso ergativo do DP argumento externo dos verbos transitivos. Em contrapartida, o sujeito dos verbos intransitivos deveria receber o caso absolutivo. Contudo, em Kaingang, como bem demonstrado em Nascimento (1995), não é bem assim: partículas ergativas podem também ocorrer posposicionadas aos sujeitos de verbos monoargumentais, de maneira que o Kaingang pode ser enquadrado no padrão das línguas de ergatividade cindida. O que significa que, como uma língua cindida, pode fazer uma escolha misturada: ora o sujeito dos verbos monoargumentais se distribui como objeto (no caso do Kaingang, antecede diretamente o verbo, sem nenhuma partícula entre eles) ora apresenta a mesma forma do sujeito dos verbos transitivos. Assim, decidimos usar o rótulo m.s como um artifício que permite contornar as dúvidas sobre a caracterização tipológica do Kaingang. Além do mais, na maioria dos exemplos apresentados na dissertação (quase todos de sentenças declarativas) que têm uma partícula de sujeito, ela é a partícula $v \tilde{y}$, $e$ não a partícula $t \tilde{y}$, classificada por Wiesemann (2002) como marcadora de ergatividade.

${ }^{8}$ Por causa de alguns problemas (levantados na literatura sobre o assunto) presentes em uma tentativa rígida de classificar de forma dicotômica as línguas entre núcleo-inicial e núcleo final, como a dificuldade de classificar consitentemente toda uma língua (em vez de áreas da sua gramática) como sendo de um tipo
} 


\section{Pã’i ũ vỹ kanhgág ag mỹ garĩnh fi fẽg $\emptyset$. cacique um m.s kaingang D.pl para galinha D.pl dar ASP \\ 'Um cacique deu a galinha para os kaingangs.'}

O Tempo em Kaingang é indicado prioritariamente por adjuntos adverbiais, pois a maioria dos seus verbos tem uma forma básica sem flexão de tempo. ${ }^{9}$ Por exemplo, em (5) e (6), rãáté (ontem) e $\tilde{\boldsymbol{a}} \boldsymbol{h} \tilde{\boldsymbol{a}}$ (recentemente), respectivamente, localizam os eventos em relação de anterioridade ao momento de fala e como contidos no momento de referência:

\begin{tabular}{|c|c|c|c|c|c|}
\hline 5. Inh & panh & vỹ & rãkétá & jun & $\varnothing$. \\
\hline 1p.sing & pai & $\mathrm{m} . \mathrm{s}$ & ontem & chegar & ASP \\
\hline \multicolumn{6}{|c|}{ 'Meu pai chegou ontem'. } \\
\hline 6. Jũm & vỹ & mĩg & tén & $\tilde{\mathbf{a}} \mathbf{h} \tilde{\mathbf{a}}^{10}$ & $\varnothing$. \\
\hline João & $\mathrm{m} . \mathrm{s}$ & onça & matar & recentemente & ASP \\
\hline
\end{tabular}

\footnotetext{
ou de outro, não nos comprometemos em sustentar que o Kaingang seja uma língua núcleo-final. Apenas nos limitamos a apontar que ao menos os dados apresentados nesta dissertação e em outros estudos mostram que o núcleo frequentemente se localiza no final do sintagma.

${ }^{9}$ Alguns verbos possuem uma forma própria (supleção) para o passado, como vyr (foi), que é o passado de $\boldsymbol{t} \tilde{\boldsymbol{i}}$ (ir). Há também alguns verbos que apresentam uma forma para o futuro, como $\boldsymbol{v} \boldsymbol{e j}$ (verá), futuro de ve (ver). Para a expressão temporal de posteridade ao momento de fala, pode ser usada também a partículas $\boldsymbol{k e}$, posposta ao verbo, como indicação de tempo futuro. Para indicar concomitância entre o momento do evento e o momento de fala, o Kaingang possui um advérbio de tempo ha (agora). Ao contrário do advérbio hur (agora), que permite que o momento do evento preceda (num intervalo curto de tempo) o momento de fala, $\boldsymbol{h} \boldsymbol{a}$ faz referência a um a um evento no presente, "coincidindo o momento do evento com o momento de fala" (Solange 2007).

${ }^{10}$ Em Kaingang, uma sentença com o verbo na sua forma básica e sem realização fonológica de uma partícula aspectual será uma sentença no pretérito perfeito, sem a necessidade de especificação (por meio de advérbios temporais) de um momento de referência anterior ao momento de fala. Como ficará claro no decorrer desta dissertação, a maioria dos dados apresentados serão de sentenças descritivas no pretérito perfeito.
} 


\subsubsection{Os DPs em Kaingang e o artigo definido.}

A ordem dos constituintes dentro dos DPs em Kaingang é nome-determinante:
7. [Kanhgág ag] vỹ [ĩn ti] $]$ han $\emptyset$.
kaingang D.pl m.s casa D.sg fazer ASP
'Os kaingangs fizeram a casa.'

Os determinantes definidos em Kaingang são termos que assumem as formas fonéticas - $t i$ e - $f i$ para masculino e feminino singular, respectivamente. Já no plural, a forma masculina é -ag e a feminina -fag:
8. a. Kanhgág
ti/fi ter
$\emptyset$.
kaingang
D.sg morrer
ASP
'O/A kaingang morreu.'
b. Kanhgág
ag/fag
kãgter
$\emptyset 11$.
kaingang
D.pl
morrer-PLR ASP
'Os/As kaingangs morreram.'

Os artigos definidos retomam informação previamente introduzida. Note o exemplo abaixo, em que a informante narra um fato passado:

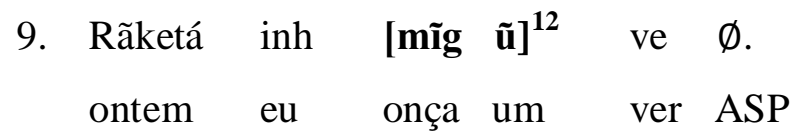

\footnotetext{
${ }^{11}$ Em Kaingang, como fica claro nos exemplos (8a-b), os substantivos não possuem marca de número.

${ }^{12} \mathrm{O}$ uso apenas do nome nu $\boldsymbol{m i} \boldsymbol{g}$ também pode ser empregado com leitura existencial. Além disso, os nomes nus em Kaingang também podem expressar leituras genéricas, como em (i) e (ii) abaixo:
}

i. Kanhgág vỹ kanhró nỹtĩ.

kaingang m.s inteligente ASP

'Kaingang é inteligente.'

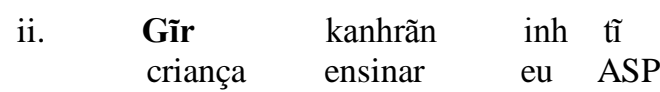

'Eu ensino criança.' 
'Ontem eu vi uma onça'

$\begin{array}{llllllll}\text { [Mĩg fi] } & \text { tóg } & \text { inh } & \text { in } & \text { rã } & \text { jẽ } & \text { ja } & \text { nĩ. } \\ \text { onça } & \text { D.sg } & \text { m.s } & \text { 1pron.pos } & \text { casa } & \text { perto } & \text { ASP } & \text { ASP } \\ \text { 'A onça estava perto da minha casa.' } & & & & \end{array}$

Os determinantes definidos são homófonos com os pronomes pessoais e os possessivos de terceira pessoa, o que poderia sugerir que, na verdade, em sentenças como (8a-b), o que teríamos seriam pronomes pessoais posposicionados aos nomes. Em tais sentenças eles se comportariam de forma semelhante ao uso de pronomes pessoais em sentenças do português como os kaingangs, eles morreram. Contudo, há muitas evidências que, a nosso ver, corroboram a hipótese de que $\boldsymbol{t} \boldsymbol{i} / \boldsymbol{f} \boldsymbol{i}$ e $\boldsymbol{a g} / \boldsymbol{f a g}$ se comportam também como artigos definidos.

Em construções possessivas, um termo possuidor (abaixo a mãe que possui a casa o kaingang que possui a casa e o kaingang que possui a galinha) pode também aparecer com artigo. Observem:

$\begin{array}{lllllll}\text { 10. Inh } & \underline{\mathbf{n}} \mathbf{f} \mathbf{f i} & \text { in } & \text { ra } & \text { inh } & \text { vyr } & \emptyset . \\ \text { minha } & \text { mãe D.sg } & \text { casa } & \text { para } & \text { eu } & \text { ir } & \text { ASP }\end{array}$

'Eu fui para casa da minha mãe'

(Abreu , E, R(46))

\begin{tabular}{|c|c|c|c|c|c|}
\hline 11. Jũm & vỹ & kanhagág ti & & & han $\varnothing$. \\
\hline
\end{tabular}

12. Maria fi vỹ fóg ti mỹ kanhgág ti garinh fi maria D.sg m.s homem-branco D.sg para kaingang D.sg galinha D.sg

feg $\varnothing$.

dar ASP

'A Maria deu a galinha do kaingang para o homem branco' 
Outros pronomes pessoais, como os de segunda pessoa, são agramaticais quando posposicionados aos nomes, como em (13) e (14) abaixo:
13. *Fóg
$\tilde{\mathbf{a}}$
vỹ goj
kygvénh
$\emptyset$.
homem-branco 2.p.poss.sg
m.s rio
sujar-PLR
ASP
'Homens brancos vocês sujaram os rios.'

\begin{tabular}{|c|c|c|c|c|}
\hline 14. *Fóg & ãjag & vỹ & goj & kygvénh \\
\hline homem-branco & 2.p.poss.pl & m.s & rio & sujar-PLR \\
\hline
\end{tabular}

\subsubsection{A expressão kar}

O termo kar é um constituinte que sempre carrega a ideia de totalidade. A sua presença na sentença parece exigir que todos os indivíduos de um conjunto tomem parte em uma ação. Considere o par de sentenças abaixo:
15. a. Kanhgág kar ag vỹ prefeito ti ve jé mũ $\varnothing$. kaingang $\operatorname{total}^{14}$ D.pl m.s prefeito D.sg visitar ASP
'Todos os kaingang visitaram o prefeito'

$\begin{array}{rllllll}\text { b. Kanhgág } & \text { ag } & \text { vỹ } & \text { prefeito } & \text { ti } & \text { ve jé mũ } & \emptyset . \\ \text { kaingang } & \text { D.pl } & \text { m.s } & \text { prefeito } & \text { D.sg } & \text { visitar } & \text { ASP }\end{array}$

\footnotetext{
${ }^{13}$ A única distribuição aceita pelas informantes foi de ajjag no inicio da sentença, com uma partícula, talvez de topicalização, entre ãjag e fóg, como abaixo:

$\begin{array}{llllll}\text { i. } & \text { ãjag tỹ(tỹ) } & \text { fóg } & \text { goj } & \text { kygvénh } \emptyset . & \\ \text { vocês ? } & \text { homem-branco } & \text { rio } & \text { sujar-PLR } & \text { ASP. } \\ \text { 'Vocês homens brancos sujaram os rios.' } & & \end{array}$

${ }^{14}$ Para evitar pré-julgamentos, que levem, de forma precipitada, o leitor a interpretar kar como um quantificador universal, optamos por, na glosa, traduzi-lo com total. E essa opção em muito se deve ao fato de nesta disseratação, em grande parte, investigarmos justamente o estatuto gramatical de kar.
} 
'Os kaingangs visitaram o prefeito'

Embora (15a), com kar, (15b), sem kar, sejam intuitivamente próximas no significado, elas parecem não ser identicas. As informantes foram mais enfáticas na exigência de que (15a) descreva uma situação em que todos os kaingangs em um dado contexto tomam parte na ação de visitar o prefeito. Já (15b) parece ser, por assim dizer, mais flexível quanto à exigência de que todos os kaingangs em um dado contexto tomem parte na ação de visitar o prefeito. Essa diferença sutil entre ambas as sentenças nos colocam a seguinte questão: seriam (15a) e (15b) semanticamente equivalentes, isto é, teriam elas as mesmas condições de verdade, e sua diferença apenas sendo de condições de uso, ou teriam elas condições de verdade distintas? Essa é uma questão que trataremos nesta dissertação, mais especificamente na seção 2.7 do capítulo 2. Contudo, por ora, o leitor deve apenas manter em mente que, a partir de paradigmas como (15a-b), verificamos que $\boldsymbol{k a r}$ veicula um sentido de completude, i.e, "expressa a totalidade da expressão nominal com a qual ele se combina (Etxeberria 2005: 251).

A expressão kar, assim como os numerais, tanto pode aparecer com o artigo definido, quanto sem o artigo definido, como no paradigma (16a-b) abaixo.

$\begin{array}{llllllllll}\text { 16. a. Kanhgág } & \text { kar } & \text { ag } & \text { vỹ } & \text { ĩn } & \text { régre } & \text { ag } & \text { han } & \emptyset . \\ \text { kaingang } & \text { total } & \text { D.pl } & \text { m.s } & \text { casa } & \text { dois } & \text { D.pl } & \text { fazer } & \text { ASP } \\ \text { 'Todos os kaingangs fizeram as duas casas.' } & & & \end{array}$

$\begin{array}{lllllll}\text { b. Kanhgág } & \text { kar } & \text { vỹ } & \text { in } & \text { régre } & \text { han } & \emptyset . \\ \text { kaingang } & \text { total } & \mathrm{m} . \mathrm{s} & \text { casa } & \text { dois } & \text { fazer } & \text { ASP } \\ \text { 'Todos os kaingangs fizeram duas casas.' }\end{array}$

Contudo, quando kar e os numerais co-ocorrem com o artigo definido, eles não podem, na sua distribuição na sentença, seguir o artigo definido, como atestado pela agramaticalidade do exemplo abaixo:

$\begin{array}{lllllllll}\text { 17. * Kanhgág } & \text { ag } & \text { kar } & \text { vy } & \text { in } & \text { ag } & \text { régre } & \text { han } & \emptyset . \\ \text { kaingang } & \text { D.pl total } & \text { m.s } & \text { casa } & \text { D.pl } & \text { dois } & \text { fazer } & \text { ASP } \\ \text { 'Todos os kaingangs fizeram as duas casas.' } & & & \end{array}$


Um fato que reforça ainda mais a hipótese de que $\boldsymbol{t} \mathbf{i} / \boldsymbol{f i}$ e $\boldsymbol{a g} / \boldsymbol{f a g}$ funcionam também como artigo definido é que, quando se comportam como pronomes pessoais, eles têm que anteceder kar e os numerais. Note os exemplos abaixo:

18. a. Ag kar vỹ ĩn ag hanhan $\emptyset$. eles total m.s casa D.pl fazer-PLR ASP 'Eles todos fizeram as casas.'

b. *Kar ag vỹ in ag hanhan $\emptyset$. total eles m.s casa D.pl fazer-PLR ASP 'Todos eles fizeram as casas.'

19. a. Ag régre vỹ ĩn ag hanhan $\emptyset$. eles dois m.s casa D.pl fazer-PLR ASP 'Eles dois fizeram as casas.'

b. *Régre ag vỹ in ag hanhan $\emptyset$. dois eles m.s casa D.pl fazer-PLR ASP 'Dois eles fizeram as casas.'

O mesmo se passa com outros pronomes pessoais, como os de primeira e segunda pessoa:

20. a. ẽg kar vỹ ĩn ag hanhan $\emptyset$ nós total m.s casa D.pl fazer-PLR ASP

'Nós todos fizemos as casas.'

b. *Kar ẽg vỹ in ag hanhan $\varnothing$. total nós m.s casa D.pl fazer-PLR ASP 'Todos nós fizemos as casas.'

21. a. Ãjag regre vỹ ĩn ag hanhan $\emptyset$. vocês dois m.s casa D.pl fazer-PLR ASP 'Vocês dois fizeram as casas.' 

b. *Regre ãjag vỹ ĩn ag hanhan $\emptyset$. dois vocês m.s casa D.pl fazer-PLR ASP
'Dois vocês fizeram as casas.'

Por ora, dado que neste capítulo a intenção é de apresentar alguns pontos gramaticais do Kaingang que contribuirão para uma maior compreensão dos dados por parte do leitor, acreditamos que os dados ilustrados acima são o suficiente.

Em resumo, as características gramaticais do Kaingang apresentadas acima foram as seguintes:

- $\quad$ A ordem padrão dos constituintes é S O V, com a precedência de $\mathrm{O}$ sobre V sendo fixa;

- A maioria dos verbos não apresenta flexão de tempo, e são, de modo geral, os adjuntos adverbiais temporais, em interação com as partículas aspectuais, que contribuem para o estabelecimento de relações de anterioridade, posteridade e simultaneidade ao momento de fala;

- $\quad$ O DP apresenta a ordem nome-determinante;

- $\quad$ Os artigos definidos são pospostos ao nome;

- A expressão kar e os numerais podem se combinar com artigos definidos, e, quando isso ocorre, eles antecedem o artigo. 


\section{CAPÍtULO 2: A ESTRUTURA INTERNA DOS DPS COM KAR EM KAINGANG.}

\subsection{Considerações Iniciais.}

Neste capítulo, investigaremos a estrutura interna dos DPs com kar no Kaingang Paranaense. Proporei uma interpretação de kar não como quantificador universal, mas como um modificador, e sustentarei que os artigos definidos na língua, além de formarem indivíduos a partir de um conjunto, também têm a função de realizar restrição de domínio, i.e., de restringir a denotação de uma expressão nominal a um conjunto de indivíduos salientes no contexto.

De maneira a situar a investigação no debate em semântica formal sobre determinantes e restrição de domínio no nível do DP e confrontar meus dados com línguas, sobretudo o Basco e o Grego, cujas estruturas dos DPs/QPs parecem ser bastante semelhantes as do Kaingang, discutirei a proposta desenvolvida em Giannakidou (2004), Etxeberria (2005, 2008, 2009) e Giannakidou \& Etxeberria (2009) para a restrição de domínio no Basco e no Grego. Segundo os autores, no que se refere à restrição de domínio via artigo definido, ela parece ocorrer (i) aplicando o artigo definido ao argumento nominal, i.e., o NP, e (ii) aplicando o artigo definido ao quantificador $(\mathrm{Q})$, formando um constituinte com ele. Na análise dos autores, a restrição (ii), com a aplicação do artigo definido à expressão quantificacional, ocorre em Grego e Basco (línguas não relacionadas geneticamente). Tendo por base dados dessas duas línguas, esses autores propõem a generalização de que em certas línguas a restrição contextual de domínio via artigo definido aplicado à expressão quantificacional é bastante sistemática. Nessas línguas, o artigo definido, quando restritor de domínio (domain restrictor), seria um tipo de função preservadora de tipo semântico, um modificador adjungido ao quantificador, que fornece uma variável $C$ contextual cujo valor é um conjunto não vazio saliente no contexto.

Baseados na ideia de que o artigo definido como restritor de domínio é uma função preservadora de tipo, e não um determinante de tipo $\langle<e, t>, e>$, i.e., uma função $\max$, Giannakidou (2004), Etxeberria (2005, 2008, 2009) e Giannakidou \& Etxeberria (2009) se opõem à proposta de Matthewson (1998, 2001) - formulada a partir de evidências em St'át'imcets, língua da família Salish, falada no Canadá - de modificação 
da teoria padrão dos Quantificadores Generalizados (QG). A hipótese forte de Matthewson (2001) é de que, translinguisticamente, a expressão quantificacional não se combina com um predicado de tipo $\langle\mathrm{e}, \mathrm{t}\rangle$, mas com um argumento de tipo $\langle\mathrm{e}\rangle$. Giannakidou (2004) e Etxeberria \& Giannakidou (2009), em defesa da análise padrão dos quantificadores, propõem uma reconsideração das propriedades especiais do St'át'imcets, e sustentam que nessa língua D também funciona como um restritor de domínio.

O Kaingang parece fornecer, à primeira vista, evidências em apoio ao programa de que a restrição de domínio é realizada por constituintes linguísticos (na forma de uma variável $\mathrm{C}$ saturada por um conjunto especificado no contexto), e, em particular, ao refinamento desse programa proposto por Giannakidou (2004), Etxeberria (2004, 2005, 2009) e Giannakidou \& Etxeberria (2009) de que a restrição de domínio pode afetar abertamente o determinante quantificacional, formando com ele um constituinte, tal como no Grego e Basco.

Contudo, o comportamento de kar em determinados contextos sentenciais sugere que ele não parece apresentar sempre um padrão de comportamento que se espera de um determinante quantificacional. Kar parece se comportar mais como um modificador do que um quantificador quando em construções com um argumento nominal. Com base nessas evidências, hipotetizamos, seguindo a proposta de Lasersohn (1999) para all, que kar seja um modificador com a função de regular os desvios pragmáticos das sentenças em relação as suas condições de verdade.

Assim, neste capítulo, que está dividido em 9 seções, a discussão procederá da seguinte maneira. Na seção 2.2, trato da distribuição de kar na sentença. Apresento também sentenças em que kar co-ocorre com o artigo definido ag e sentenças em que o artigo definido está ausente. Com base na interpretação dada, pelas falantes, de sentenças acompanhadas de contextos, argumento que a presença do artigo definido em DPs com kar força uma leitura restringida ao contexto, i.e., em que a denotação da expressão nominal é um conjunto de indivíduos saliente no contexto. Em vista disso, defendo que em Kaingang a restrição de domínio pode ser realizada via artigo definido.

$\mathrm{Na}$ seção 2.3 apresento uma visão geral e rápida da teoria padrão dos quantificadores generalizados. A seção 2.4 será dedicada à proposta alternativa de Matthewson (2011). Na seção 2.5, abordaremos, de forma mais detalhada, a proposta de Giannakidou (2004), Etxeberria (2004, 2005, 2009) e Giannakidou \& Etxeberria (2009) de que o determinante definido, translinguisticamente, pode funcionar como uma função 
preservadora de tipo que fornece uma variável contextual C. Nesta seção serão apresentados exemplos do Grego e do Basco contidos nos artigos dos autores. Em seguida, na seção 2.6, com base apenas nos dados apresentados nas seções 2.2 e 2.5, argumentarei que o Kaingang poderia também ser compreendido uma língua em que o determinante definido funciona como restritor de domínio se aplicando ao quantificador, se assumirmos que kar seja um quantificador universal.

Contudo, na seção 2.7, apresento evidências consistentes de que em Kaingang o determinante definido não modifica uma expressão quantificacional, como propõem Etxeberria \& Giannakidou (2009) para o Basco e o Grego. Em Kaingang, o artigo definido parece tomar como complemento um NP modificado por kar, de forma que kar seria, na verdade, um modificador com a função de regulador de desvios pragmático, à là Lasersohn (1999), como será proposto em 2.8. Por isso, argumento que construções como kanhgág kar ag (todos os kaingangs) sugerem que o artigo definido ag, em Kaingang, é aplicado diretamente ao argumento nominal fornecendo (i) uma variável contextual $\mathrm{C}$ e (ii) denotando um indivíduo plural saliente no contexto e elemento do valor de C. Em vista disso, proporei que o artigo definido em Kaingang é simultaneamente um restritor de domínio e um operador max. O que significa que entendo que em Kaingang a função referencial do determinante definido não é suprimida quando ele funciona como restritor de domínio, análise defendida por Etxeberria \& Giannakidou (2009) para o Basco e o Grego. Por fim, na última seção, 2.9, apresentarei as considerações finais e discutirei se a análise defendida para kar pode também ser expandida para o Basco e o Grego e o St'át'imcets.

\subsection{O DP com kar.}

Como já ilustrado no primeiro capítulo, quando kar co-ocorre com um artigo definido, ele não pode anteceder o artigo. Desse modo, ao contrário da estrutura [NP kar ag], [NP ag kar] é agramatical em Kaingang:

$\begin{array}{lll}\text { 22. a. gĩr } & \text { kar } & \text { ag } \\ \text { criança } & \text { total } & \text { D.pl }\end{array}$




$$
\begin{array}{clc}
\text { b. }{ }^{*} \text { gĩr } & \text { ag } & \text { kar } \\
\text { criança } & \text { D.pl } & \text { total }
\end{array}
$$

DPs com kar podem ocorrer com e sem o artigo definido. Note o paradigma abaixo:

$\begin{array}{llllll}\text { 23. a. Kanhgág } & \text { kar } & \text { ag } & \text { vỹ } & \text { vẽnh gringrén } & \text { tĩ }^{15} \\ \text { kaingang } & \text { total } & \text { D.pl } & \text { m.s } & \text { dançar-PLR } & \text { ASP } \\ \text { 'Todos os kaingangs dançam' } & & \end{array}$

$\begin{array}{lllll}\text { b. Kanhgág } & \text { kar } & \text { vỹ } & \text { vẽnh gringrén } & \text { tĩ } \\ \text { kaingang } & \text { total } & \text { m.s } & \text { dançar-PLR } & \text { ASP } \\ \text { 'Todos kaingangs dançam' } & & \end{array}$

No paradigma (23a-b), encontramos diferenças de interpretação entre as duas sentenças. (23a), que ocorre com artigo definido, somente recebe a interpretação de que um grupo de kaingangs específico costuma dançar. Já (23b), em que o artigo definido está ausente, pode ser interpretada tanto como se referindo a um grupo específico dos kaingangs quanto se referindo aos kaingangs em geral.

Em língua natural, sentenças podem ser construídas para falar tanto sobre conjuntos de indivíduos em particular quanto para afirmar ou negar algo de um conjunto em geral. Em Kaingang, dado que sentenças como (23a) somente podem afirmar algo sobre um conjunto específico de indivíduos, parece que nestas sentenças o artigo definido é que está forçando a leitura específica. Considerem os pares de sentenças abaixo, e seus respectivos contextos apresentados às informantes:

24. Gilda produz um enunciado geral sobre a mortalidade dos kaingangs.

$\begin{array}{llll}\text { a. Kanhgág } & \text { kar } & \text { kãgter } & \text { tĩ. } \\ \text { kaingang } & \text { total } & \text { morrer-PLR } & \text { ASP } \\ \text { 'Todos kaingangs morrem' } & & \end{array}$

\footnotetext{
${ }^{15}$ Partícula aspectual que expressa a ideia de habitualidade.
} 


$\begin{array}{llllc}\text { b. \#Kanhgág } & \text { kar } & \text { ag } & \text { kãgter } & \text { tĩ. } \\ \text { kaingang } & \text { total } & \text { D.pl } & \text { morrer-PLR } & \text { ASP } \\ \text { 'Todos os kaingangs morrem' } & & \end{array}$

25. Houve um acidente com um ônibus que transportava índios de várias etnias para um encontro entre comunidades indígenas. No ônibus havia 4 kaingangs e todos eles morreram no acidente. Gilda, ao informar sua amiga do acontecimento, comenta:

a. Kanhgág kar ag kãgter $\quad$ a

kaingang total D.pl morrer-PLR ASP

'Todos os kaingangs morreram'

(boa no contexto dado)

b. Kanhgág kar kãgter $\quad$.

kaingang total morrer-PLR ASP

'Todos kaingangs morreram'

(ok no contexto dado, mas preferem 25a)

\section{Leitura não restrita (o conjunto de todos os cachorros)}
a. \# Kasor kar ag kyrkyr tĩ.
cachorro total D.pl latir-PLR ASP
'Todos os cachorros latem.'
b. Kasor kar kyrkyr tĩ.
cachorro total latir-PLR ASP
'Todos cachorros latem.'

27. Leitura restrita (o conjunto dos cachorros saliente no contexto)

\footnotetext{
${ }^{16} \mathrm{O}$ sinal \# significa que a sentença não descreve a situação apresentada para o informante. Ou seja, a sentença não é agramatical, ela apenas não é adequada para o contexto apresentado.
} 
$\begin{array}{ccllc}\text { a. Kasor } & \text { kar } & \text { ag } & \text { kyrkyr } & \varnothing . \\ \text { cachorro } & \text { total } & \text { D.pl } & \text { latir-PLR } & \text { ASP }\end{array}$

'Todos os cachorros latiram.'

b.Kasor kar kyrkyr $\quad$.

cachorro total latir-PLR ASP

'Todos cachorros latiram.'

(ok no contexto dado, mas preferiram 27a)

28. a. Kanhgág kar ag vỹ ãjãg krẽ to ha ni Maringá tá.

kaingang total D.pl m.s pron.pos.pl crianças gostar ASP Maringá lá.

'Em Maringá todos os kaingangs gostam dos seus filhos.'

b. Kanhgág kar vỹ ãjãg krẽ to ha ni Maringá tá.

kaingang total m.s pron.pos.pl crianças gostar ASP Maringá lá.

‘Todos kaingangs gostam dos seus filhos'

29.

Cenário 1: Cristina, uma kaingang, em uma reunião dos kaingangs com funcionários do Estado sobre demarcação de terras indígenas, comenta com sua amiga, também na reunião, sobre os funcionários do Estado que lá estavam:

Cenário 2: Cristina e sua amiga conversam sobre os homens brancos e como eles aprendem rápido. Christina comenta:

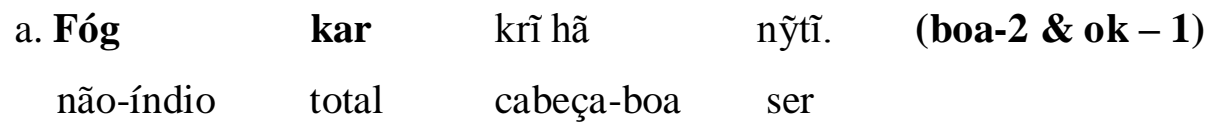

'Todos não-índios são inteligentes'
b. Fóg kar ag krĩ hã nỹtĩ. (boa-1 \& ruim-2)
não-índio total D.pl cabeça-boa ser

'Todos os não- índios são inteligentes' 
30.

Cenário 1: Cristina vive em uma reserva que deveria ser muito maior do que é. Fazendeiros da região grilaram parte das terras da comunidade de Cristina. Conversando com uma amiga sobre esses fazendeiros, Cristina comenta:

Cenário 2: Cristina comenta com uma amiga sobre a dificuldade de todos os índios reconquistarem parte de suas terras:

$\begin{array}{lllllllll}\text { a. Fóg } & \text { kar } & \text { ag } & \text { kanhgág } & \text { kar } & \text { ag } & \text { mỹ } & \text { ga } & \text { tóvanh } \\ \text { não-índio } & \text { total } & \text { D.pl } & \text { kaingang } & \text { total } & \text { D.pl } & \text { para } & \text { terra } & \text { entregar }\end{array}$

ké tũ nĩ.

part.fut NEG ASP

'Todos os não-índios não entregarão terras para todos os kaingangs'

(boa-1 \& ruim-2)

b. Fóg kar kanhgág kar mỹ ga tóvanh ké tũ nĩ.

Não-índio total kaingang total para terra entregar part.fut NEG ASP

'Todos não-índios não entregarão terras para todos kaingangs'

(ok- $1 \&$ boa-2)

Os exemplos (24a) e (26b) podem ser construídos como uma afirmação sobre os kaingangs e os cachorros em geral, enquanto (25a), (27a), (28a), (29b) e (30a) devem ser construídos como afirmações sobre conjuntos de kaingangs, cachorros e homens brancos salientes no contexto. A rejeição de (24b) pelos informantes, por exemplo, como sentença construída genericamente, ou seja, como afirmação da mortalidade dos kaingangs em geral, e a preferência por (25a) como sentença sobre um conjunto particular de kaingangs, sugere que a presença do determinante definido ag em estruturas como kanhgág kar ag restringe o domínio sobre o qual opera kar, i.e., é usado quando o falante pretende se referir a um conjunto saliente no contexto. Já a ausência de ag em estruturas como kanhgág kar permite interpretações em que o domínio é irrestrito, i.e., quando o falante pretende predicar algo de um conjunto em geral, como 
no caso de (24a), em que a mortalidade é afirmada como uma propriedade de todos os kaingangs ${ }^{17}$.

O fenômeno ilustrado em (25a) é uma estratégia de restrição de domínio (i.e., em que o nome kanhgag denota não o conjunto de todos os kaingangs no universo, mas um conjunto dependente do contexto do discurso) que parece ser realizada via introdução do artigo definido. Essa estratégia de restrição de domínio feita por um constituinte foi proposta em vários trabalhos na literatura sobre o assunto (Westerståhl 1984, 1985; Giannakidou 2004; Etxeberria 2005, 2008, 2009; Giannakidou \& Etxeberria 2009, etc), e tem estimulado o debate acerca do que ficou conhecido como $o$ problema da restrição de domínio do quantificador (se o papel que o contexto desempenha na restrição de domínio está ou não previsto na forma lógica de determinados constituintes linguísticos). Problema esse que é um caso especial de uma questão bem maior, que é o problema da dependência contextual, i.e., "o problema de explicar como o contexto contribui para a interpretação [...], para o processo de determinar o que um falante significou ao realizar um enunciado linguístico em uma determinada ocasião" (Stanley \& Szabó 2000: 219).

Como já argumentado na introdução desta dissertação, antes de investigar se o artigo definido em Kaingang se combina com kar (expressão que veicula uma idéia de totalidade), e não diretamente com o nome, apresentaremos propostas na literatura que deram uma solução composicional para línguas que parecem apresentar o mesmo problema e confrontar os dados dessas línguas com os dados do Kaingang. Mas antes, na próxima seção (2.3), discorreremos brevemente sobre a Teoria Padrão dos Quantificadores, referência necessária para melhor compreendermos as propostas de solução para o problema composicional em línguas que o artigo definido parece primeiramente se adjungir a uma expressão quantificacional. Após a seção 2.3, trataremos, na seção 2.4, da análise alternativa de Matthewson (2001) à teoria padrão. E, então, na seção 2.5, focaremos, com detalhe, a hipótese de Giannakidou (2004), Etxeberria (2004, 2005, 2009) e Giannakidou \& Etxeberria (2009) de que a restrição de

\footnotetext{
${ }^{17}$ Notem que não estamos afirmando que a ausência do determinante $a g$ necessariamente resulta em uma leitura não restrita (e os dados acima mostram isso). O que sustentamos é que a presença de ag nas construções acima força uma leitura contextual. Não há nada que restrinja uma língua que realiza a restrição de domínio de forma aberta de também poder realizá-la de forma encoberta. Em Basco, por exemplo, que possui 4 quantificadores universais, o universal oro pode realizar restrição de domínio de forma encoberta, tal como every do Inglês. Segundo Etxeberria (2005), oro restringe o seu domínio quantificacional de forma encoberta no NP. Para mais detalhes, ver Etxeberria (2005: 266-267).
} 
domínio pode afetar abertamente a expressão quantificacional, formando com ele um constituinte, tal como no Grego e Basco.

\subsection{A Teoria Padrão dos Quantificadores Generalizados.}

A tese em semântica formal de que os QPs denotam quantificadores generalizados (Montague 1974, Barwise \& Cooper 1981, Westerståhl 1985, Partee 1987, entre muitos outros), i.e., conjuntos de conjuntos ${ }^{18}$, iniciou, sobretudo a partir da década de 80, um produtivo programa de pesquisa centrado nas estruturas quantificacionais em línguas naturais, desde sua estrutura interna, passando pelo seu uso no discurso, até o seu comportamento de escopo. Embora nas duas primeiras décadas o foco fosse basicamente sobre as estruturas quantificacionais em Inglês, a partir, principalmente, da segunda metade da década de 90 e primeira década de 2000, pesquisas translinguísticas sobre quantificação se desenvolveram rapidamente (Bach et AL. 1995; Matthewson 1998, 2001, 2008; Giannakidou 2004; Etxeberria \& Giannakidou 2009, dentre outros). Estudos em línguas tipologicamente das mais variadas apresentaram resultados e fundamentaram hipóteses de que modificações na teoria padrão precisavam ser realizadas de modo a contemplar os padrões de quantificação encontrados entre as línguas.

Sob a análise padrão, em uma semântica guiada por tipos (sendo que $e$ representa indivíduos, $t$ valores de verdade e et conjuntos de indivíduos), determinantes quantificacionais de tipo $\langle\langle\mathrm{e}, \mathrm{t}\rangle,\langle\mathrm{e}, \mathrm{t}\rangle, \mathrm{t}\rangle\rangle$ se combinam com um NP predicado de primeira ordem de tipo $\langle e, t\rangle$ e, mediante aplicação funcional, criam um quantificador generalizado, que denota um conjunto de conjuntos, de tipo $\langle<\mathrm{e}, \mathrm{t}\rangle, \mathrm{t}\rangle$, como em (31b).

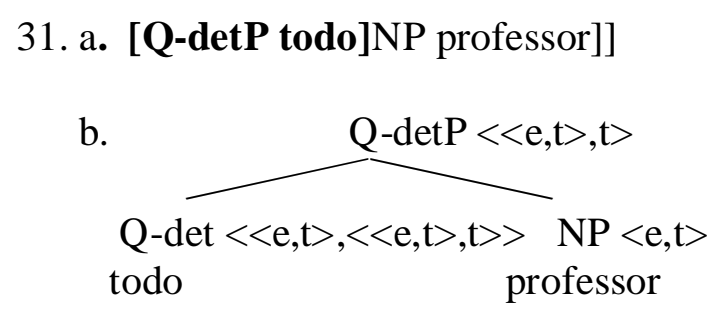

\footnotetext{
${ }^{18} \mathrm{Um}$ QP universal como todo homem denota um conjunto de conjuntos. Assumindo que a denotação de todo é uma relação entre conjuntos, então, ao atribuirmos o valor homem à variável $\mathrm{P}$, e compormos o $\mathrm{QP}$ todo homem, a denotação de todo homem será $\{\mathrm{X}$ : homem $\subseteq \mathrm{X}\}$, e assim chegamos onde queríamos: o conjunto de todos os $\mathrm{X}$ tal que homem é um subconjunto de $\mathrm{X}$.
} 
Como representado em (31b), o quantificador se combina composicionalmente com o NP professor e gera um QP. O NP argumento de Q fornece o domínio sobre o qual o quantificador opera, e Q denota uma relação entre a extensão do NP e a extensão do VP.

$\mathrm{Na}$ teoria QG, portanto, Q denota uma função que cria um argumento quantificacional a partir da aplicação de Q a um predicado de primeira ordem. Essa função, em muitas línguas, é abrigada no núcleo de uma projeção funcional $\mathrm{QP}^{19}$, e o predicado de primeira ordem é abrigado no núcleo de uma projeção lexical NP, que é complemento de Q.

\subsection{Uma análise alternativa (Matthewson 2001).}

Baseada em dados da quantificação nominal em St'át'imcets (Lilooet Salish), Matthewson $(1998,2001)$ sugere que a quantificação, translinguisticamente, procede em dois passos e não em um, como na teoria padrão. Em St'át'imcets ${ }^{20}$, nas estruturas quantificacionais sempre há a presença de um determinante que se liga ao NP e que consiste "de duas partes descontínuas, um proclítico ( $t i$ para singular; $i$ para plural) [...] um enclítico ...a que se liga ao primeiro elemento lexical no sintagma” (Matthewson 2001: 3). Observem o exemplo a seguir:

\begin{tabular}{|c|c|c|}
\hline 32. Léxlex & [tákem i & smelhmúlhats-a] \\
\hline inteligente & D.pl & mulher(pl)-D] \\
\hline
\end{tabular}

(Matthewson 2001: 150)

Com isso, em St'át'imcets, e, segundo a hipótese forte de Matthewson (2011), em todas as línguas que possuem quantificação nominal, os dois passos da quantificação

\footnotetext{
${ }^{19}$ Há autores que adotam uma projeção funcional uniforme para todos os determinantes, inclusive para os quantificadores universais. Assim, toda composição D+NP preencheria uma projeção DP. Muito debate tem ocorrido a respeito deste tópico, e há argumentos fortes em ambas as abordagens. Em consonância com Beghelli e Stowell (1997) e Etxeberria \& Giannakidou (2009) adotaremos a abordagem que atribui uma projeção QP às estruturas nucleadas por determinantes quantificacionais.

${ }^{20}$ Assim como Matthewson, em certas passagens nos referiremos ao St'át'imcets como Salish, que é a sua família. Isso se deve unicamente pela simplicidade ortográfica.
} 
são: (i) um determinante $\mathrm{D}$ de tipo $\langle<\mathrm{e}, \mathrm{t}\rangle$, e $>$ se combina com um predicado de tipo $\langle e, t\rangle$ e cria um DP de tipo $\langle$ e $\rangle$, e (ii) o DP é tomado como um argumentocomplemento por um Q-det de tipo $\langle\mathrm{e},\langle\langle\mathrm{e}, \mathrm{t}\rangle, \mathrm{t}\rangle\rangle$, e essa combinação, resultante da segunda aplicação funcional, cria um QP $\langle<e, t>, t>$, como ilustrado em (33b):

$$
\begin{array}{rlc}
\text { 33. a. tákem } & \mathbf{i} & \text { smelhmúlhats-a } \\
\text { todos } & \text { D-pl } & \text { mulher (pl)-D }
\end{array}
$$

'Todas as mulheres'

b.

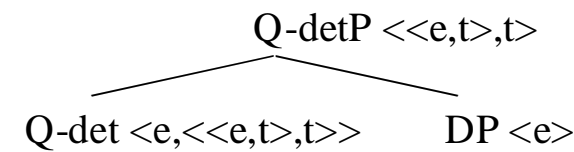

$$
\text { tákem }
$$
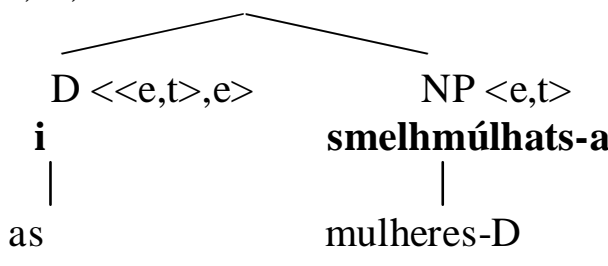

Como podemos observar no exemplo (33b), Matthewson (2001) propõe uma nova sintaxe para os QPs: a composição do QP exige duas aplicações funcionais. Mas também Matthewson (2001) propõe uma nova semântica para os determinantes quantificacionais: Q agora não denota uma relação entre conjuntos, i.e., entre predicados de primeira ordem, mas uma relação entre um indivíduo e um conjunto. $\mathrm{O}$ tipo semântico de Q é agora <e, <<et>,t>> e o domínio dos quantificadores passa a ser um indivíduo e não um conjunto.

Antes de discorrermos, contudo, sobre os problemas, segundo Etxeberria \& Giannakidou (2009), com essa nova proposta da formação dos QPs, abordaremos também a crítica dos autores à hipótese de Matthewson $(1998,1999)$ de que D em Salish não codifica definitude. Pensamos ser importante tratarmos, ainda que rapidamente, de questões morfológicas e semânticas relacionadas com os determinantes, a partir do comportamento dos DPs em Salish, para esclarecer ao leitor, mais à frente, como questões morfológicas se relacionam com a função semântica do determinante como um restritor de domínio, e como a restrição de domínio em Salish pode ser capturada pela análise de Etxeberria \& Giannakidou (2009). 


\subsubsection{Os DPs em Salish.}

Matthewson (1998, 2001) sustenta que os determinantes de um DP em St'át'imcets, embora sejam do mesmo tipo semântico de um determinante definido como the do Inglês, i.e., de tipo <<et>,e>, possuem propriedades que os distinguem de the. Algumas dessas propriedades, segundo Matthewson (1998:26), são as seguintes:

34. a. Os determinantes em Salish não codificam definitude;

b. Os determinantes em Salish não codificam especificidade;

c. Os determinantes em Salish codificam asserção de existência.

Etxeberria \& Giannakidou (2009) observam que Matthewson (1998), seguindo Diesing (1992), colapsa especificidade e definitude ao afirmar que ambas as propriedades são pressuposicionais. Contudo, tal afirmação é muito controversa. ${ }^{21}$ Como sustenta Ionin (2006), a pressuposição de existência é parte do pano de fundo conversacional compartilhado entre falante e ouvinte, enquanto a especificidade tem a ver com a referência do falante, i.e., quando o falante usa um indefinido tendo em mente um indivíduo ou conjunto de indivíduos, basta que o falante esteja ciente da especificidade. Não é necessário, como no caso da pressuposição, que o ouvinte tenha um indivíduo ou conjunto de indivíduos em mente. Assim, enquanto os definidos pressupõem existência e denotam um indivíduo previamente mencionado no discurso, os indefinidos introduzem informação nova, asseveram existência e, quando usados de forma específica, carregam a condição de que o falante tenha um indivíduo em mente.

Matthewson (1999) defende que os determinantes em Salish não são morfologicamente ambíguos entre definidos e indefinidos. Por não apresentarem, segundo a autora, várias propriedades relacionadas aos definidos, os determinantes em

\footnotetext{
${ }^{21}$ Em grande parte da vasta literatura sobre os definidos são apresentadas três propriedades que geram a definitude semântica: referência (pressuposição de existência), familiaridade (denota entidades previamente mencionadas no discurso) e unicidade (Frege 1892; Russell 1905; Strawson 1950; Heim 1982; Elbourne 2007, dentre outros). Uma descrição definida é usada para se referir a um indivíduo singular ou plural saliente no contexto. A unicidade da referência pode ser capturada usando iota, no caso do definido singular e $\max$ no caso do definido plural. Segundo Heim (1982), os definidos carregam a instrução para o ouvinte localizar a representação para um indivíduo familiar previamente mencionado, enquanto o indefinido instrui o ouvinte a cria uma representação para um novo indivíduo. Tal observação de Heim (1982) é capturada pelo que ela define como condição de familiaridade/novidade, que não é senão a definição de que os definidos são pressuposicionais e os indefinidos não são.
} 
Salish são classificados como indefinidos ${ }^{22}$. Contudo, como muito bem atenta Etxeberria \& Giannakidou (2009), a maioria das propriedades que Matthewson (1998, 1999 e 2001) apresenta como caracterizadoras dos determinantes em Salish são muito mais "reminiscentes de definitude do que indefinitude" (Etxeberria \& Giannakidou 2009: 10). Matthewson caracteriza os determinantes em Salish como dêiticos, e, portanto, sempre ancorados no aqui e agora do discurso e profundamente ligados ao contexto. $^{23}$ Tanto é que em Salish os DPs nunca recebem, segundo Matthewson (1998), uma Leitura de Conceito Individual (Individual Concept Reading). Uma sentença como

\begin{tabular}{|c|c|c|c|}
\hline 35. Sécsec & {$[\mathrm{ti}$} & kel7áqsten-s-a & ti United.States-a] \\
\hline idiota & $\mathrm{D}$ & lider-3sg.poss-D & D Estados Unidos-D \\
\hline
\end{tabular}

(Demirdache 1997: 5)

só pode ser interpretada como se referindo ao atual presidente dos Estados Unidos no momento em que a sentença é enunciada. Assim, (35) não pode significar algo como: "quem quer que seja o presidente dos Estados Unidos em qualquer tempo é um idiota" 24 . O fato de uma sentença como (35) em Salish só poder ser referir extensionalmente ao objeto saliente no discurso, no caso, o presidente dos Estados Unidos no momento em que a sentença é enunciada, demonstra "que a inabilidade dos DPs em Salish em denotar conceitos individuais é mais compatível com uma análise onde D em Salish é semanticamente definido, mas sugere que ele é mais como um demonstrativo, e não pode receber a interpretação intensional que exigiria que ele se referisse a objetos fora do discurso" (Etxeberria \& Giannakidou 2009: 10). Mais próximo dos demonstrativos porque, vale lembrar, os demonstrativos nominais, embora semanticamente definidos, não permitem uma leitura intensional justamente porque

\footnotetext{
${ }^{22}$ Em Mathewson $(1998,2001) \mathrm{D}$ é uma choice function de tipo <<et,>,e〉, à la Kratzer 1996. Uma função contextual que cria um indivíduo a partir de um conjunto.

${ }^{23}$ Para um aprofundamento dessa idéia, ver Demirdache (1997).

${ }^{24}$ Em Kaingang, descrições definidas podem receber Leitura de Conceito Individual. Por exemplo, em
}

$\begin{array}{lllllll}\text { i. Apucaraninha kujá } & \text { fi } & \text { vỹ } & \text { rãnhrãj pe há } & \text { tĩ. } \\ \text { apucaraninha curandeira } & \text { D.sg } & \text { m.s } & \text { trabalhar } & \text { muito ? } & \text { ASP.hab } \\ \text { 'A curandeira do Apucaraninha trabalha bastante.' } & & \end{array}$

pode haver a leitura de que "quem quer que seja a curandeira do Apucaraninha em qualquer tempo trabalha muito. O que evidencia que $t i / f i$ e $a g / f a g$, por não estarem necessariamente ancorados no aqui e agora do discurso, não sejam demonstrativos, mas sim artigos definidos. 
estão sempre ancorados no aqui e agora do discurso. Por isso, o fato de D em Salish sempre ser dêitico o torna mais semelhante a um demonstrativo do que a um indefinido.

Etxeberria \& Giannakidou (2009) atentam ainda para outros três fatos em apoio à idéia de que D em Salish também codifica definitude semântica. Em um contexto mais neutro, uma sentença como (36) recebe leituras tanto indefinidas quanto definidas:

$$
\begin{aligned}
& \text { 36. q’wez-1́lc [ti smúlhats-a] } \\
& \text { dancar [D.sg mulher-D] }
\end{aligned}
$$

'A/uma mulher dançou'

(Matthewson 2001: (3a))

Um segundo fato é que DPs em Salish podem tanto introduzir um elemento novo no discurso, como um DP indefinido, quanto se referir a um elemento previamente introduzido no discurso, como um DP definido:

$\begin{array}{lllr}\text { 37. húy'-lhkan } \quad \text { ptakwlh, } & \text { ptákwlh-min } & \text { lts7a } \\ \text { indo-1sg. } & \text { contar.estória } & \text { contar .estória-appl } & \text { aqui } \\ \text { [ti } \quad \text { smém'lhats-a] } & & \\ \text { D.sing } & \text { mulher(vermelho)-D } & \end{array}$

$\begin{array}{lll}\text { wa7 ku7 } & \text { ílal láti7 } & \text { [ti smém'lhats-a.] } \\ \text { prog quot } & \text { chorar deit } & \text { D.sg mulher(vermelho)-D }\end{array}$

'Eu vou contar uma estória, uma estória sobre uma garota. A garota estava chorando lá.' (Mathewson 1998: 17)

O terceiro fato é que os DPs em Salish forçam uma leitura de escopo largo quando em interação com quantificadores universais, numerais, operadores de negação, em sentenças condicionais, etc. A título de ilustração, observem o comportamento de escopo dos DPs em Salish em uma sentença condicional e em uma com negação:

$\begin{array}{lccl}\text { 38. a. cuz' } & \text { tsa7cw } & \text { kw-s Mary } & \text { lh-t'íq-as } \\ \text { ir-FUT } & \text { feliz } & \text { D-NOM } & \text { Mary HYP-chegar-3CONJ }\end{array}$ 


\section{ti qelhmémen'-a. \\ D velho.pessoa(DIMIN)-D}

'Mary ficará feliz se um velho vier.'

(Matthewson 1999: 90)
b. $\exists \mathrm{x}$ [elder (x) \& [come (x) $\rightarrow$ feliz (Mary)]] (escopo largo)
c. $*[\exists x[$ elder $(\mathrm{x}) \&$ come $(\mathrm{x})]] \rightarrow$ feliz (Mary) (escopo estreiro)
39. a. cw7aoz kw-s áz'-en-as [ti sts'úqwaz'-a $]$
NEG D-NOM comprar-TR-3ERG [D. fish-D]
kw-s Sophie.
D-NOM Sophie
'Sophie não comprou um peixe.'

(Matthewson 1999: 91)
b. $\exists x[$ fish (x) \& $\neg[\operatorname{comprar}(\mathrm{x})($ Sophie) $]]$
$(\exists>\neg)$
c. $* \neg[\exists x[$ fish $(\mathrm{x}) \& \operatorname{comprar}(\mathrm{x})($ Sophie $)]] \quad(\neg>\exists)$

(38a) somente é verdadeira em um contexto em que existe um velho específico cuja chegada alegrará Mary, e (39a) somente quando existe um peixe que era para ser comprado, mas Sophie não o comprou. Tipicamente, em função da pressuposição de existência que os determinantes definidos carregam, eles induzem escopo largo nas sentenças em que ocorrem. Do mesmo modo, como ilustrado em (38a) e (39a), em Salish os determinantes que Matthewson $(1998,1999)$ considera indefinidos, em termos de escopo, comportam-se mais como definidos. ${ }^{25}$

\footnotetext{
${ }^{25}$ O argumento de Matthewson (1999) é que Salish codifica lexicalmente a distinção proposta por Kratzer (1998) para o indefinido $a$ (um, algum) em Inglês entre interpretação por função-escolha (choicefunction) e interpretação existencial. Com a diferença de que, ao contrário da proposta de Kratzer, segundo a qual o valor para o indefinido interpretado especificamente é dada pelo contexto, Matthewson sustenta que em Salish os indefinidos interpretados por função-escolha receberiam a leitura aparentemente específica em função de serem sempre fechados por um operador $\exists$ sobre função-escolha que teria sempre escopo largo. Matthewson propõe assim uma hipótese para Salish hibrida entre a análise de choice-function de Reinhart (com a variação interpretativa dependendo do escopo do operador existencial) para todos os indefinidos, e de Kartzer, que mantém que os indefinidos são ambíguos entre função-escolha e existencial clássico. Assim, Salish teria um item lexical para o indefinido interpretado
} 
Assim, com base no próprio comportamento de D em Salish, Etxeberria \& Giannakidou (2009) afirmam que sustentar que um determinante é definido ou não com base quase apenas em uma indistinção morfológica não significa muito. O que deve contar é se tal determinante codifica semanticamente definitude e indefinitude. Embora, como os autores demonstraram muito bem, o determinante em Salish não seja morfologicamente definido, i.e, não há um artigo especificamente definido na língua, ele "carrega propriedades associadas com definitude semântica" (Etxeberria \& Giannakidou 2009: 11), como, por exemplo, indivíduos salientes no contexto. Contudo, o mesmo determinante pode se referir a novos objetos, uma propriedade dos indefinidos.

Em virtude das propriedades dos determinantes em Salish apresentadas acima, os autores hipotetizam que Salish seja uma língua - por não distinguir morfologicamente entre indefinidos ou definidos, mas codificar semanticamente propriedades de ambos - onde "haja um único elemento lógico com diferentes condições de aplicação pragmática" (Etxeberria \& Giannakidou 2009: 11$)^{26}$.

Na próxima subseção, falaremos sobre alguns problemas, segundo Etxeberria \& Giannakidou (2009), de ordem empírica com a hipótese forte de Matthewson (2001) de que o domínio dos quantificadores nominais nas línguas naturais é de tipo <e>, i.e., um indivíduo, e não de tipo <e.t>, i.e., um conjunto, como na teoria padrão.

\subsubsection{Alguns problemas com a hipótese de que o domínio de $Q$ é de tipo semântico e.}

A proposta de Matthewson (2001) prevê que Q-dets deveriam se combinar com DPs de tipo $\langle e>$ trans-linguisticamente. Contudo, em muitas línguas essa previsão parece não ser confirmada. Observem os exemplos abaixo com Inglês, Espanhol, Grego, Português:

$$
\begin{aligned}
& \text { 40. Inglês: } \\
& \text { a. * every the girl } \\
& \text { lit: 'todo o garota' }
\end{aligned}
$$

por função escolha, e um item lexical para o indefinido interpretado existencialmente, que se comporta como os indefinidos de polaridade, como any do Inglês e qualquer do Português.

${ }^{26}$ Os autores não especificam que isso seja uma forma de ambigüidade. Mas pela argumentação, tudo leva a crer que sim. 
b. * most the girls

lit: 'maioria dos garotos'

c. * many the girls

lit:'muitas as garotas'

d. * three the girls

lit: 'três as garotas'

41. Espanhol:
a. * cada los chicos
lit.: 'cada os garotos'
b. * muchos los chicos
lit.: 'muitos os meninos'
c. * tres los chicos
d. lit.: 'três os meninos'

(Etxeberria \& Giannakidou 2009)

42. Grego:
a. * kathe to aghori
lit.: 'todo o garoto'
b. * merika ta aghoria
lit.: 'muitos os garotos'
c. * tria ta aghoria
lit.: 'três os garotos'

(Etxeberria \& Giannakidou 2009)

\section{Português:}
a. * muitos os garotos
b. * cada o garoto
c. $*$ dois os garotos

Muitos dos exemplos acima de construções agramaticais, assim que a preposição partitiva é acrescida, tornam-se gramaticais, como many of the boys, three of the boys, muitos dos garotos, três dos meninos, etc. O que reforça a hipótese em Ladusaw (1982) de que em línguas em que a preposição of é introduzida antes de um DP ela funciona 
como um operador de mudança de tipo que transforma o DP de tipo 〈e $\rangle$ em um predicado, ou seja, um argumento de tipo <et> para que ele possa ser tomado como domínio de um quantificador ${ }^{27}$. O partitivo funcionaria como um operador que transforma indivíduos em conjunto de indivíduos. E, além de funcionar como um operador de mudança de tipo, o partitivo também restringe o domínio do quantificador a um conjunto saliente no contexto, de forma que o quantificador opere sobre um conjunto saliente em intersecção com a extensão do NP.

A análise de Matthewson $(1998,2001)$ de que o domínio de Q é um indivíduo implica na negação da proposta de Ladusaw (1982) para os partitivos como operadores de mudança de tipo que asseguram que $\mathrm{Q}$ receba um predicado de primeira ordem como input. Matthewson (2001), ciente dessa implicação, assume que os partitivos são semanticamente vácuos, e seu emprego ocorre por questão de caso. Com base em Salish, língua sem marcação aberta de caso e sem elemento partitivo, Matthewson (2001) hipotetiza que os partitivos seriam um mecanismo presente nas línguas que possuem alguma marcação aberta de caso e inexistente nas línguas sem marcação aberta de caso. Contudo, Zulu, língua sem marcação aberta de caso, ainda assim possui uma preposição partitiva (Adams 2005).

Além do mais, um problema em abandonar a proposta de Ladusaw (1982) em proveito da de Matthewson (2001) é que, com isso, não apenas descartamos a explicação semântica para a razão do uso do partitivo em línguas como Inglês, línguas românicas, etc., mas também não conseguimos explicar por que em algumas construções nessas línguas o partitivo é opcional, fato estranho se assumirmos que o partitivo é empregado somente por razão de marcação de caso genitivo (Etxeberria \& Giannakidou 2009).

Por fim, mais um problema com a análise em Matthewson (2001), segundo (Etxeberria \& Giannakidou 2009), é que ela prevê que o complemento de determinantes quantificacionais sempre será um DP. Todavia, línguas como o Basco e o Grego, assim como algumas construções do próprio Salish, são evidências da existência de construções [D[Q]]:

44. a. Salish

\footnotetext{
${ }^{27}$ Para mais detalhes, ver Ladusaw (1982) e Partee (1987).
} 
i tákem-a smúlhats ${ }^{28}$

D.pl todos-D mulher

(Matthewson 2001:5)

b. Basco

mutil guzti-ak

[[Q-det $] D]$

garoto todos-D.pl

(Etxeberria 2005:37a)

c. Grego

o kathe fititis

D.sg todo estudante

(Giannakidou 2004: 32b)

Além disso, em Basco [[[NP]D]Q-det] é agramatical:

45. a. Basco

$$
\begin{array}{cl}
* \text { mutil-ak } & \text { guzti }^{29} \\
\text { garoto-D.pl } & \text { todos }
\end{array}
$$

$[[[N P] D] Q-d e t]$

(Etxeberria 2005: (37a))

Concluindo esta subseção, exemplos oriundos de línguas tipologicamente diversas parecem demonstrar que não há evidências suficientes para adotar a hipótese forte de que o domínio dos quantificadores nominais em línguas naturais é um argumento de tipo <e>, i.e., um indivíduo. Mesmo a língua que serviu de base empírica para essa hipótese, i.e., a língua St'át'imcets, não se comporta, segundo Etxeberría \& Giannakidou (2009), como prevê essa hipótese, uma vez que em St'át'imcets são possíveis construções quantificacionais [D[Q]]. Assim, tanto a hipótese forte de que translinguisticamente o domínio do quantificador é um indivíduo, quanto a hipótese fraca de que ao menos em St'át'imcets o complemento de Q é um argumento de tipo $<\mathrm{e}$, resultam, para Etxeberría \& Giannakidou (2009), em previsões precipitadas.

\footnotetext{
${ }^{28}$ Embora em Salish [Q[DP]] seja muito mais comum, com quantificadores universais [D[Q]] é uma opção. Contudo, [D[Q]] parece não se adequar à proposta de Matthewson $(1998,2001)$ de que o domínio de $\mathrm{Q}$ é um argumento de tipo <e>.

${ }_{29}^{29}$ Em Basco, em construções partitivas a restrição de domínio é nominal. Para mais detalhes, ver Etxeberria (2005), subseção 3.1.2.
} 
Na próxima seção, discorreremos sobre as duas formas de restringir abertamente o domínio do quantificador via artigo definido: sobre NP ou sobre Q. Em seguida, mostraremos como Etxeberria \& Giannakidou (2009) estendem a hipótese de D como um restritor contextual de domínio em Basco e Grego para o comportamento da quantificação universal em St'át'imcets.

\section{$2.5 \mathrm{D}$ como função restritora de domínio.}

Desde o trabalho de von Fintel (1994), a hipótese de que a restrição de domínio se dá em LF, em oposição à abordagem de que a restrição é puramente pragmática (Bach 1999), vem ganhando mais suporte empírico, principalmente com evidências de línguas que realizam a restrição contextual de domínio abertamente via D. Segundo von Fintel (1994), os quantificadores possuem um argumento domínio em LF cujo valor é contextualmente fornecido. Notem o seguinte cenário em que a sentença (47) é enunciada:

46. Cenário: Falante $X$ relata ao falante $Y$ o que ocorreu na festa dos professores no dia anterior:

47. a. Every professor danced.

todo professor dançar-PAST

'Todo professor dançou.'

(adaptado de von Fintel 1994)

b. $\forall \mathrm{x}$ [professor C ] dançaram (x)

Em (47a), o argumento nominal (professsor) de every não é o conjunto dos professores no universo, mas o conjunto dos professores que participaram da reunião. $\mathrm{O}$ valor de C será um conjunto saliente dos professores, como ilustrado na forma lógica em (47b). Assim, (47a) fala sobre um conjunto particular de professores que dançaram.

Notem que em (47a), exemplo do Inglês, a restrição se dá de forma encoberta. Contudo, como ilustraram Etxeberria (2005), Giannakidou (2004) e Etxeberria \& Giannakidou (2009) com o Basco e o Grego, há evidências empíricas de que a restrição pode ocorrer também de forma aberta via $\mathrm{D}$ operando sobre $\mathrm{Q}$, o que demonstra que a 
restrição contextual de domínio entre as línguas difere não somente com respeito a se a restrição é feita de forma encoberta ou aberta, mas também onde a restrição opera sintaticamente.

Com isso, além de lançarem luz sobre o debate teórico a respeito de se a restrição contextual de domínio é feita de forma aberta ou encoberta, ou ainda das duas formas, dados do Basco e Grego também clarificam o debate teórico quanto a se o restritor de domínio opera sobre a expressão nominal ou diretamente sobre o próprio quantificador.

Em Basco e Grego o restritor forma um constituinte com o quantificador. Considerem novamente os exemplos (44b-c) repetidos aqui como (48a-b):

48. a. Basco

$\begin{array}{lll}\text { mutil } & \text { guzti-ak } & \text { [[Qdet]D] } \\ \text { garoto } & \text { tods-D.pl } & \end{array}$

(Etxeberria 2005: 37a)

b. Grego

$\begin{array}{ll}\text { o kathe fititis } \\ \text { D.sg todo } & \text { estudante }\end{array}$

[D[Qdet]]

(Giannakidou 2004: 32b)

Etxeberria \& Giannakidou (2009) propõem que D em (48a-b) funciona como um modificador, uma função que, por meio de adjunção ou incorporação de D ao quantificador, modifica o quantificador fornecendo uma variável contextual $\mathrm{C}$ como domínio. Assim, é proposta a seguinte extensão para D modificando Q:

49. $[[\mathrm{D}]]=\lambda \mathrm{Z}_{\text {et,ett }} \lambda \mathrm{P}_{\text {et }} \lambda \mathrm{S}_{\text {et }} \mathrm{Z}(\mathrm{P} \cap \mathrm{C})(\mathrm{S}) ; \mathrm{Z}$ a relação denotada por Q-det

(Etxeberria \& Giannakidou 2009: 18)

Em (49), D toma um quantificador, que denota uma relação entre conjuntos, e o modifica de modo a restringir o seu primeiro argumento, sendo $\mathrm{Z}$ uma relação entre uma variável C (em intersecção com um predicado $\mathrm{P}$ ) e um predicado $\mathrm{S}$.

Notem que, embora D esteja adjungido sintaticamente a Q, seu efeito semântico é de modificar o argumento NP, i.e., a variável contextual $\mathrm{C}$ sempre intersecta com o 
NP argumento. Assumindo, portanto, a denotação (49), ${ }^{30}$ uma quantificação universal restringida em Basco se comporia da seguinte forma:

50. a.

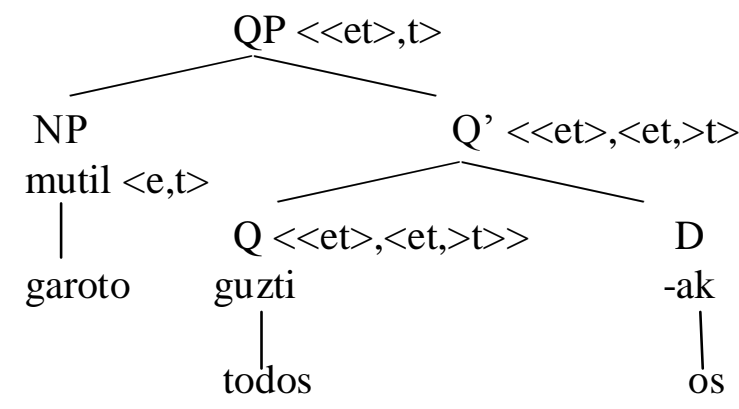

b. $[[$ mutil guzti-ak $]]=($ mutil $)[\operatorname{guzti}(\mathrm{C})]$

c. $[[$ guzti $]]=\lambda P \lambda S . \forall x: P(x) \rightarrow S(x)$

d. [[ak]] $=\lambda Z_{\text {et,ett }} \lambda P_{\text {et }} \lambda S_{\text {et }} Z(P \cap C)(S) ; Z$ a relação denotada por Q-det

e. $[[$ guzti-ak]] $=\lambda \mathrm{P} \lambda \mathrm{S} . \forall \mathrm{x}(\mathrm{P}(\mathrm{x}) \cap \mathrm{C}(\mathrm{x})) \rightarrow \mathrm{S}(\mathrm{x})$

Como pode ser observado, o primeiro argumento da relação $\mathrm{Z}$ é restringido. Assim, se a extensão de guzti é $\lambda \mathrm{P} \lambda \mathrm{S} \forall \mathrm{x}: \mathrm{P}(\mathrm{x}) \rightarrow \mathrm{S}(\mathrm{x})$, i.e., um quantificador com o domínio não restringido contextualmente, guzti-ak (todos os) contém a variável $C$ cujo valor é um conjunto saliente no contexto e em intersecção com o primeiro argumento da extensão de guzti. Ak, portanto, modifica o determinante quantificacional.

Um fato importante de ser mencionado é que quando a contextualização ocorre no nível do quantificador, como ocorre com os quantificadores universais em Basco e Grego, a adição de outro determinante definido resulta agramatical, como nos exemplos abaixo:

51. a. Basco

$$
\begin{array}{ll}
\text { *iskasle-ak } & \text { guzti-ak } \\
\text { estudante-D.pl } & \text { todos-D.pl }
\end{array}
$$

\footnotetext{
${ }^{30}$ D como restritor de domínio seria, segundo Etxeberria \& Giannakidou (2009), uma função adicional que $\mathrm{D}$ pode ter em uma dada língua. O que não significa que $\mathrm{D}$ como restritor substitua a função referencial, i.e., de operador iota. Apenas é assumido que D adjungido a Q preserva o tipo semântico do constituinte QP e, por isso, perde a sua função referencial, mas preserva as propriedades de familiaridade e saliência. Suprimida a função referencial de D, a sua única contribuição para o QP será a de restritor de domínio. "D e Q terminam na mesma posição. Dessa coexistência, sugerimos que D perde a sua habilidade referencial (formador de <e>): se não fosse assim terminaríamos com um núcleo que seria ao mesmo tempo <et,e $>$ e <et,ett $>$. A emergência de D então se segue como um 'side effect' de evitar esse conflito de tipos, e a habilidade referencial de D é negociada pela função somente pragmática de restringir domínio (Etxeberria \& Giannakidou 2009: 23).
} 
(Etxeberria 2005: (80)

b. Grego

$\begin{array}{llll}* 0 & \text { kathe } & \mathbf{0} & \text { fititis } \\ \text { D.sg } & \text { todo } & \text { D.g } & \text { estudante }\end{array}$

(Etxeberria \& Giannakidou 2009: (69))

A razão da agramaticalidade de (51a-b) parece ser o fato de que "a restrição de domínio já é cumprida através do artigo definido que se compõe com o quantificador forte" (Etxeberria 2005: 263) ${ }^{31}$. A repetição da restrição de domínio seria um caso de redundância, por isso o seu bloqueio. Uma vez que a restrição de domínio não acrescenta nenhum conteúdo descritivo novo - "diferentemente, por exemplo, de uma modificação adjetival ou outra que acrescenta uma diferente descrição com cada aplicação e estreita o domínio do NP de forma informativa" (Etxeberria 2005: 263) - a reduplicação de D é proibida ${ }^{32} 33$.

\subsubsection{St'át'imcets explicado por Etxeberria \& Giannakidou (2009).}

Em uma língua como St'át'imcets, em que artigo definido também se adjunge ao NP, ele também não precisa ser uma função formadora de indivíduo. D pode ser um modificador que preserva o tipo do seu argumento e o modifica fornecendo a variável contextual C, como na extensão (52):

\footnotetext{
31 De acordo com Milsark (1977 e 1979) os quantificadores fortes são aqueles que não são nem simétricos, nem intersectivos, e que não podem ocorrer em sentenças existenciais. Isto é, quantificadores como every, all, each, most, etc. Já os quantificadores fracos são, por sua vez, os simétricos, intersectivos e que podem ocorrer em sentenças existenciais. Tais quantificadores são, por exemplo, os numerais, os indefinidos, many, etc.

${ }^{32}$ Em Kaingang a adição de outro determinate definido também resulta agramatical:

i. $\quad$ Kanhgág ag kar ag

Kaingang D.pl total D.pl

33 Segundo Etxeberria (2005), a agramaticalidade de (51a-b) não pode ser explicada recorrendo à incompatibilidade de tipos. Em Basco, mesmo em uma estrutura partitiva, como

i. $\quad$ *ikasle-eta-tik guzti-ak Estudante-D.pl.ABL-todos-D-pl
}

que geraria o argumento correto (<et>) como domínio de guzti, a reduplicação de D é proibida. O que reforça a argumentação de que a agramaticalidade de estruturas com dois Ds é por razões de redundância. 
De maneira que St'át'imcets seria uma língua em que as duas formas de restrição de domínio, i.e, D aplicado diretamente ao NP ou aplicado a Q, ocorreriam de forma aberta. ${ }^{34}$ Assim, uma estrutura [Q[D[NP]]] em St'át'imcets se comporia da seguinte forma ${ }^{35}$ :

53.

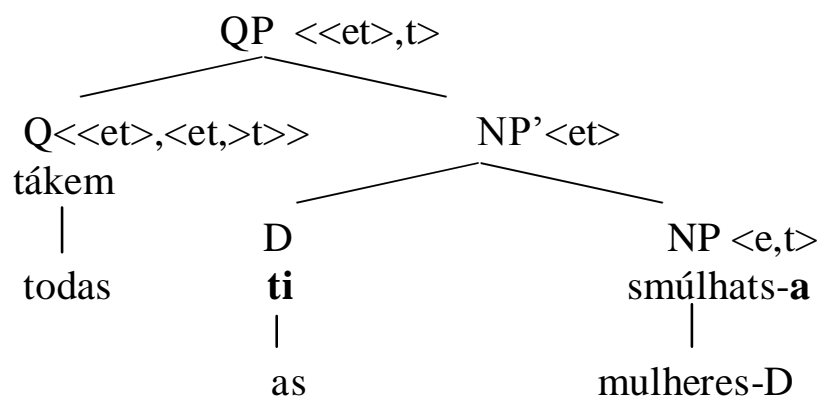

Como podemos ver, D é aplicado ao NP smúlhats e gera um NP' que preserva o tipo semântico de smúlhats e cuja denotação é um conjunto saliente no discurso que intersecta com a denotação do NP. Em seguida, o quantificador universal tákem toma como domínio o valor da variável $\mathrm{C}$ introduzida pelo restritor $\mathrm{D}$. Como pode ser observado em (46), tákem continua sendo um quantificador clássico, i.e., uma função de tipo <et, ett> que estabelece um relação entre conjuntos.

$\mathrm{Na}$ próxima seção, argumentaremos que os dados do Kaingang Paranaense apresentados na seção 2.2, quando comparados com os dados do Basco, Grego e St'át'imcets, nesta seção, sugerem, se assumirmos que kar seja um quantificador, que a restrição de domínio em Kaingang pode funcionar tal como proposto por Etxeberria (2005), Giannakidou (2004) e Etxeberria \& Giannakidou (2009) para essas línguas.

\footnotetext{
${ }^{34}$ Quanto à idéia de D como restritor de domínio em St'át'imcets, ver Gillon (2006; 2009).

${ }^{35}$ Um ponto crucial que o leitor deve manter em mente é que da proposta de Etxeberria \& Giannakidou (2009) não se segue que $\mathrm{D}$, quando funcionando como restritor de domínio, necessariamente tem que ser um determinante morfologicamente definido. Em Grego e Basco, línguas que possuem distinção morfológica entre definido e indefinido, D como restritor é expresso pelo determinante definido. Assim, a previsão é de que se uma língua codifica morfologicamente no sistema $\mathrm{D}$ a distinção pragmática entre familiaridade e novidade, somente o determinante que codifica familiaridade, i.e., o definido, poderá também funcionar como um restritor de domínio. Já em línguas sem distinção morfológica entre definitude e indefinitude, que expressam ambas as propriedades por meio de um mesmo $\mathrm{D}$, como, segundo os autores, o St'át'imcets, este D será o veículo de restrição de domínio.
} 


\subsection{Restrição de domínio em Kaingang: evidência para a hipótese de Etxeberria e Giannakidou?}

Se assumirmos que kar seja uma expressão quantificacional, podemos atrubuir ao Kaingang a mesma solução composicional formulada por Etxeberria (2005), Giannakidou (2004) e Etxeberria \& Giannakidou (2009) para o Basco, Grego e St'át'imcets, dado que no Kaingang, assim como nessas línguas, o artigo definido se adjungiria a uma expressão quantificacional. O Kaingang seria, portanto, mais uma evidência translinguística de uma língua que realiza a restrição de domínio do quantificador universal via aplicação do artigo definido a uma expressão quantificacional. Na tabela abaixo, distribuímos novamente os exemplos nas 4 línguas, colocando-os agora lado a lado, de modo a facilitar a visualização para o leitor do ponto em comum entre elas que queremos destacar:

54.

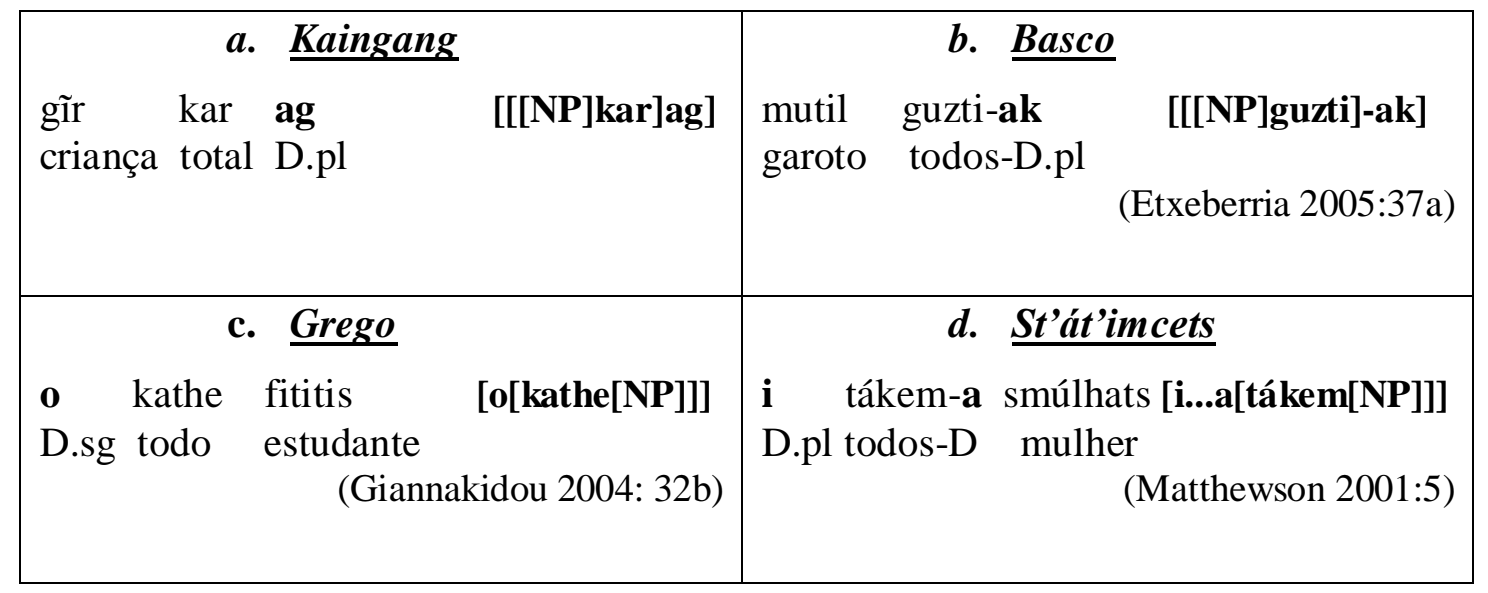

Com isso, com base nas evidências apresentadas nesta seção, seguindo Etxeberria (2005) e Etxeberria \& Giannakidou (2009), podemos hipotetizar que em Kaingang, tal como em Basco e Grego, o determinante ag pode funcionar como um modificador de $\mathrm{Q}$, um restritor de domínio que preserva o tipo semântico do determinante quantificacional ao qual se adjunge. $\mathrm{D}$ sintaticamente ligado à $\mathrm{Q}$ resultaria em uma projeção QP com a mesma estrutura ilustrada (50a-e): 
55.a.

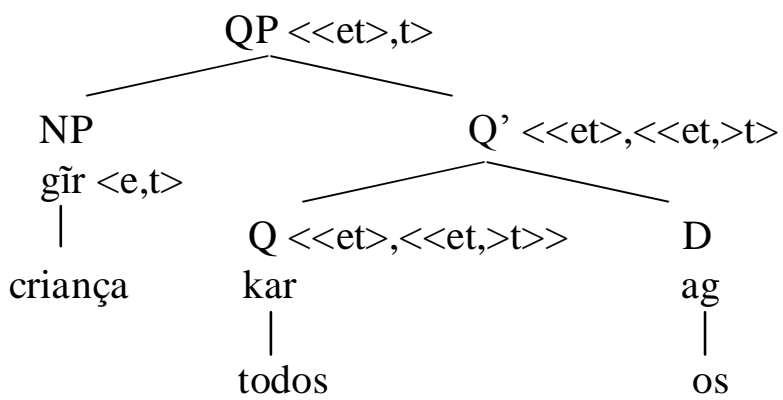

$$
\begin{aligned}
& \text { b. }[[\text { kar }]]=\lambda P \lambda S . \forall x P(x) \rightarrow S(x) \\
& \text { c. }[[a g]]=\lambda Z_{\text {et,ett }} \lambda P_{\text {et }} \lambda S_{\text {et }} Z(P \cap C)(S) ; Z \text { a relação denotada } Q^{\prime} \\
& \text { d. }[[\text { kar ag] }]=\lambda P \lambda S . \forall x(P(x) \cap C(x)) \rightarrow S(x) \\
& \text { e. }[[\text { gir kar ag] }]=(\text { gir })[\operatorname{kar}(C)]=\lambda S . \forall x(\text { girr }(x) \cap C(x)) \rightarrow S(x)
\end{aligned}
$$

$A g$, portanto, funcionaria, em estruturas de quantificação universal, como um operador de restrição de domínio pressuposicional - i.e., pressupõe um conjunto não vazio $^{36}$ - adjungido a Q. Em estrutura de quantificação universal, o artigo definido, na

36 Um ponto importante, em suporte de que em Kaingang é o artigo definido qu realiza a restrição de domínio, é a noção, relacionada com restrição de domínio, de que quantificações sobre conjuntos restritos são pressuposicionais, no sentido de que o conjunto saliente não pode ser vazio. Um conjunto saliente não vazio é, portanto, condição, à la Heim \& Kratzer (1998), para o uso feliz de quantificadores universais ${ }^{36}$. Tanto em Basco quanto em Kaingang, a negação de um conjunto não vazio, como em (i) e (ii) soa contraditória:

Basco

i. Akats guzti-ak aurkitzen badituzu, sari bat emango dizut. erros todos-D.pl.abs encontrar if-aux. dar um recompensa aux 'Se você encontrar todos/a maioria dos erros, eu te darei uma recompensa.

\# Baina gerta liteke bat-ere akats-ik ez egotea. mas happen aux um-também erros-part não ser-nom mas pode não haver erros'

(Exteberria \& Giannakidou 2009: (64))

Kaingang

ii. Problema kar ag kan rã,

problema todos D.pl achar

'Ache todos os problemas,

Kỹ inh ã mỹ nén ũ nẽm.

então 2. pron.pes.sg para presente um dar.

e lhe darei algum presente.

\#Hãrá hẽn ri ke mũn problema vẽnh ke tũ nĩ. mas talvez problema aparecer part.fut. NEG ASP Mas talvez não tenha nenhum problema'

Desse modo, construções com $\boldsymbol{k a r}$ ag parecem ser usadas em contextos em que um conjunto saliente não vazio é estabelecido. Como em Etxeberria \& Giannakidou (2009), “determinantes pressuposicionais pressupõem um conjunto não vazio, i.e., eles vêm com uma pressuposição de existência [...] Note, 
coexistência com Q, perderia sua função referencial, i.e., de formadora de indivíduo, e surgiria como um D somente com a função pragmática de restringir o domínio do quantificador. $^{37}$

Desse modo, o Kaingang seria mais uma evidência translinguística da possibilidade de restrição aberta de domínio via D se combinando diretamente sobre Q, como sustentam Etxeberria (2005) e Etxeberria \& Giannakidou (2009) para o Basco e o Grego.

\subsection{E se em Kaingang NP+kar+ag for um DP ao invés de QP, e kar um modificador?}

Em resposta a observações de que ao invés de criar uma projeção QP, pode ser que os quantificadores fortes em Basco criem um DP, Etxeberria \& Gianakidou (2009) argumentam que se assim fosse, deveria ser correta a predição de que em Basco pode ocorrer a conjunção de dois [NP+Q] sob um único $\mathrm{D}$, da mesma forma que é possível juntar dois NPs ou AdjPs sob um mesmo D, como atestado nos exemplos (56) e (57) abaixo:

$$
\begin{aligned}
& \text { 56. Ikasle eta irakasle-ak azterketa garaian daude. } \\
& \text { estudante e professor-D.pl.abs exame período aux } \\
& \text { 'Os estudantes e os professores estão no período de exames.' }
\end{aligned}
$$

(Etxeberria 2005: 37a)

contudo, que embora all, every, both, the e each geralmente parecem estar associados com domínios não vazios, somente com both, the, e each o domínio não vazio é uma pré-condição para o uso feliz. Com every e all, pode nem haver um acarretamento: abaixo vemos que podemos negar o domínio não vazio sem contradição" (Etxeberria \& Giannakidou 2009: 23):

$$
\begin{aligned}
& \text { iii. If you find every mistake, I'll give you a bonus; } \\
& \text { se você achar todo erro, eu darei você um bônus. } \\
& \text { but there may be no mistake at all. } \\
& \text { mas existir pode ser nenhum erro } \\
& \text { 'Se você achar todo erro, eu te darei um bônus. Mas pode ser que não exista nenhum }
\end{aligned}
$$

${ }^{37}$ Para mais detalhes sobre este processo, ver nota 28. 


\section{Maiak zaldi haundi eta elefante txki-ak ikusi ditu.}

Maia-erg cavalo grande e elefante pequeno-D.pl.abs ver aux

'Maia viu os cavalos grandes e os elefantes pequenos'

(Etxeberria 2005: 37b)

Contudo, segundo Etxeberria \& Giannakidou (2009), em Basco, a conjunção de duas sequências de [NP+Q] sob um único artigo é agramatical:

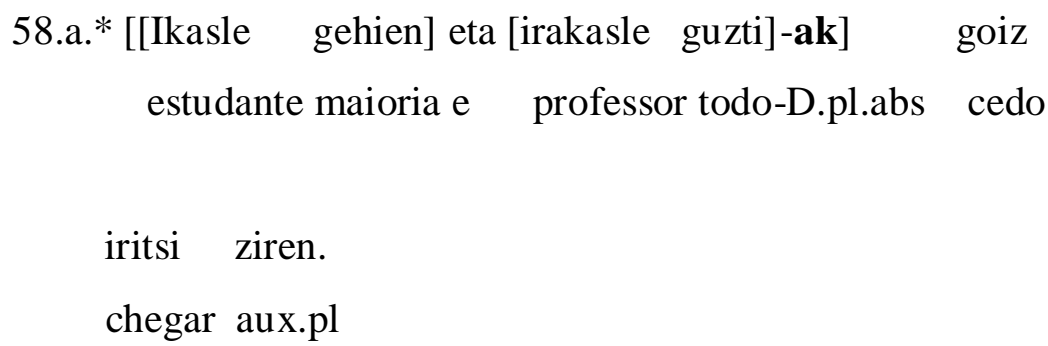

'A maioria dos estudantes e todos os professores chegaram cedo.'

(Etxeberria \& Giannakidou 2009:22)

$\begin{array}{cll}\text { b. *[[Neska bakoitz }] \text { eta [ mutil guzti }]-\mathbf{e k}] & \text { sari bat } \\ \text { garota cada e goroto todo-D.pl.erg } & \text { premio um }\end{array}$

$\begin{array}{ll}\text { irabazi } & \text { zuten. } \\ \text { ganhar } & \text { aux.pl }\end{array}$

'Cada garota e todos os garotos ganharam um prêmio'.

(Etxeberria \& Giannakidou 2009:22)

Baseados em exemplos como (58a-b), Etxeberria \& Gianakidou (2009) defendem, portanto, que em Basco Qs fortes geram QPs e não DPs nucleados por D, de maneira que nesta língua quando D se combina com Q ele consiste em uma função que restringe o domínio quantificacional.

No Kaingang Paranaense, em contrapartida, é gramatical a conjunção de duas sequências de [NP+Q] sob um mesmo $\mathrm{D}$, do mesmo modo que é possível juntar dois NPs sob um mesmo D, como ilustrado nos exemplos abaixo:

$\begin{array}{cccccc}\text { 59. [[Proféso] } & \text { mré } & \text { [gĩr] } & \text { ag] } & \text { junjun } & \emptyset . \\ \text { professor } & \text { e } & \text { criança } & \text { D.pl } & \text { chegar-PLR } & \text { ASP }\end{array}$


'Os professores e as crianças chegaram.'

$\begin{array}{rlllllll}\text { 60. [[Proféso } & \text { kar] } & \text { mré } & \text { [gĩr } & \text { kar] } & \text { ag] } & \text { junjun } & \emptyset^{38} \text {. } \\ \text { professor } & \text { total } & \text { e } & \text { criança } & \text { total } & \text { D.pl } & \text { chegar-PLR } & \text { ASP }\end{array}$

'Todos os professores e todas as crianças chegaram.'

Além do mais, no Kaingang Paranaense não somente dois [NP+Q] podem ocorrer sob um mesmo D, mas também dois NPs sob um mesmo Q:

$\begin{array}{ccccclc}\text { 61. [[[Proféso] } & \text { mré } & \text { [gĩr] } & \text { kar] } & \text { ag] } & \text { junjun } & \emptyset . \\ \text { professor } & \text { e } & \text { criança } & \text { total } & \text { D.pl } & \text { chegar-PLR } & \text { ASP }\end{array}$

'Todos os professores e todas as crianças chegaram'

As sentenças 59, 60 e 61 são evidências sintáticas que - juntas com o fato semântico de kar ser neutro quanto à propriedade de distributividade e não possuir uma força quantificacional, como defenderemos no capítulo 3 - dão suporte à nossa hipótese de que não somente kar pode ser interno a uma projeção DP, mas que ele pode se comportar como um modificador 394041 .

${ }^{38}$ Em Kaingang também é gramatical que cada $[\mathrm{NP}+\mathrm{Q}]$ em uma conjunção possa aparecer com um D, como abaixo:

i. [[[Proféso kar] ag] mré $\quad$ [gĩr $\quad$ kar] $\mathbf{a g}]$ junjun $\emptyset$ professor todos D.pl e criança todos D.pl chegar-PLR ASP

'Todos os professores e todas as crianças chegaram'

Notem que (59) e (i) são sentenças sinônimas.

${ }^{39}$ Mais suporte em favor dessa hipótese, assumindo que os numerais em Kaingang possam ser modificadores, vem do fato de que no Kaingang Paranaense dois cardinais também podem ocorrer sob um mesmo D. Observem:
i. $\quad$ [[Proféso régre] mré [gĩr tãgtu] ag] junjun $\emptyset$.
Professor dois e criança três D.pl chegar-PLP ASP
'Os dois professores e as três crianças chegaram.'

Contudo, não investigamos se os numerias na língua se comportam como modificadores. Apenas queremos sugerir que, se isso for o caso, será mais uma evidência em favor da nossa hipótese de que kar é um modificador.

${ }^{40}$ Partee (1995), comentando a hipótese de Gil (1995) de que o significado de all, e da sua contraparte em outras línguas, seja mais básico do que every, sugere que "talvez como um reflexo da sua própria [propriedade] de ser básico, all não seja necessariamente um determinante" (PARTEE 1995: 582). Segundo Partee, em muitas línguas, "às vezes $[$ all $]$ parece mais um adjetivo do que um determinante quando em construções com um substantivo" (PARTEE 1995: 582). Embora somente tenhamos encontrado exemplos em que kar modifica substantivos, preferimos ser cautelosos quanto a hipotetizar que kar seja um adjunto adnominal ou um adjetivo. Isso porque entendemos que para tanto mais testes 


\subsubsection{Duas propostas na literatura de interpretar all como modificador.}

\subsubsection{Proposta de Brisson (1998, 2003).}

O fato de os comportamentos sintáticos e semânticos de kar serem muito próximos de all, também é mais uma evidência de que kar pode ser meramente um modificador.

Brisson (2003) desenvolve uma hipótese empiricamente bem sustentada de que o comportamento excepcional de all em relação a every e each - i.e, co-ocorrência com predicados coletivos, ter por complemento um DP plural, etc - decorre do fato de all não ter uma força quantificacional própria, mas sim um modificador. Ele interagiria com um operador distributivo disparado por certos predicados verbais ${ }^{42}$, de forma a descartar a não maximalidade de DPs definidos plurais. Sua única função seria a de desfazer a não maximalidade dos plurais definidos.

Landman $(1989,1996)$ e Brisson (2003) defendem que (62) não acarreta (63).

$\begin{array}{clllll}\text { 62. The } & \text { girls } & \text { jumped } & \text { in } & \text { the } & \text { lake. } \\ \text { D } & \text { garotas } & \text { pular-PAST } & \text { em } & \text { D } & \text { lago }\end{array}$

'As garotas pularam no lago.'

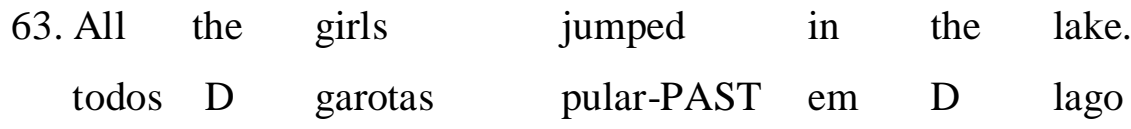

'Todas as garotas pularam no lago'

(Brisson 2003: 130)

teriam que ser realizados sobre a distribuição de kar, sobretudo se a intenção seja de ver se ele se comporta como um adjetivo. Assim, preferimos deixar subespecificado que tipo de modificador kar é.

${ }^{41}$ (59), (60) e (61) apresentam um problema composicional. A conjunção de proféso e gĩr não denota a intersecção de [[proféso]] e [[gĩr]]. Para uma solução elegante deste propblema composicional, ver Heycock \& Zamparelli (2005).

${ }^{42}$ Entre tais predicados estão inclusive os exemplos clássicos de predicados coletivos, como cercar a escola, reunir-se, etc. Está além do escopo desta dissertação discutir esta hipótese de que junto com os predicados distributivos, muitos predicados coletivos possuem um operador $\mathrm{D}$ e que a leitura coletiva de tais predicados decorre da posição que este operador distributivo ocupa. Mas que fique claro para o leitor que na proposta de Brisson (2003) os verbos de atividade coletiva e os verbos de accomplishments envolvem quantificação distributiva, e, por isso, podem co-ocorrer com all. Para detalhes desta proposta, ver as seções 5 e 7 do artigo da autora. 
Para os autores, (62) não é sinônimo de (63). (62) seria, na verdade, mais fraca, e permitiria exceções (não maximalidade).

Com o intuito de dar conta dessa não maximalidade, Brisson (2003) sustenta, em parte baseada em Schwarzschild (1996), que um operador distributivo disparado pelos predicados verbais é sempre acompanhado de uma variável que seleciona um domínio dependente do contexto, e que essa variável, chamada por Schwarzchild (1996) de Cov, toma a forma de um cover do universo do discurso. A definição proposta é seguinte:

\section{Definição de Cover:}

$X$ covers $Y$ sse:

a. $\mathrm{X}$ é um conjunto de subconjuntos não-vazios de $\mathrm{Y}$

b. $\forall y \in Y \exists x \in X[y \in x]$

(Brisson 2003: 135)

Por exemplo, para avaliar as condições de verdade de uma sentença como (62), repetida abaixo como (65), tendo em vista a definição de cover acima, precisamos atribuir um valor a Cov, e, para isso, precisamos de um universo de discurso U.

$\begin{array}{clllll}\text { 65. The } & \text { girls } & \text { jumped } & \text { in } & \text { the lake. } \\ \text { D } & \text { garotas } & \text { pular-PAST } & \text { em } & \text { D lago }\end{array}$

'As garotas pularam no lago'

66. $\forall \mathrm{x}[\mathrm{x} \in[[\mathrm{Cov}]] \& \mathrm{x} \subseteq[[$ the.girls $]] \rightarrow \mathrm{x} \in[[j u m p e d . i n . t h e . l a k e]]]$

67. $U=\{a, b, c, s, t,\{a, b\},\{a, c\},\{a, s\},\{a, t\},\{a, s, t,\} \ldots\}$

[[the girls] $]=\{a, b, c\}$

$J=\{\{a\},\{b\},\{c\},\{s, t\}\}$

$\mathrm{K}=\{\{\mathrm{a}\},\{\mathrm{c}\},\{\mathrm{b}, \mathrm{s}, \mathrm{t}\}\}$

Suponha que um contexto em que todas as garotas (sendo elas $\mathbf{a}, \mathbf{b}$ e c) pularam no lago atribua o valor $\mathrm{J}$ a Cov. Neste caso, (65) será interpretada como se tivéssemos usado um operador distributivo padrão, pois cada garota em $\mathrm{J}$ (cover atribuído a Cov) ocupa um conjunto unitário (singleton). Por exemplo, o contexto que atribuiria $\mathrm{J}$ a Cov seria um em que a, b e c sejam garotas e pularam no lago, e $\mathbf{s}$ e $\mathbf{t}$ sejam garotos e não 
pularam no lago. Em contrapartida, se o valor é K, b não ocupa um conjunto unitário, pois b está em um conjunto com dois elementos que não são garotas: por exemplo, em um contexto em que a garota $\mathbf{b}$ não pulou no rio e ficou jogando vôlei com os garotos $\mathbf{S}$ e t, que também não pularam no rio. Brisson (2003) chama esse contexto de ill-fitting cover, porque não se adéqua perfeitamente ao conjunto das garotas: não há um conjunto de subconjuntos unitários cuja união é equivalente ao conjunto das garotas. Contudo, quer o valor seja J, quer seja K, (65) será verdadeira.

Já all, "interagindo com a quantificação introduzida pelo operador distributivo, para descartar a não maximalidade que o operador D normalmente permite" (BRISSON 2003:141), descarta os valores que são ill-fitting cover, i.e, all exige que o valor de Cov seja um good-fitting cover: um conjunto cuja união dos seus subconjuntos unitários seja equivalente ao conjunto das garotas, no caso de (67). Observem a definição da autora de good-fit (Brisson 2003: 141):

\section{Definição de good-fit:}

Para algum cover do universo de discurso Cov e alguma denotação X do DP, Cov é um a good-fit em relação a $\mathrm{X}$ sse $\forall \mathrm{y}[\mathrm{y} \in \mathrm{X} \rightarrow \exists \mathrm{Z}[\mathrm{Z} \in \mathrm{Cov} \& \mathrm{y} \in \mathrm{Z} \& \mathrm{Z} \subseteq$ $\mathrm{X}]]$

(Brisson 2003: 141)

All é mais como uma pressuposição ou um operador sensitivo ao foco (Brisson 2003). A contribuição de all ao significado é chamada pelo autor de "domain-adjusting meaning”. A presença de um "domain-adjusting meaning” disparada pela introdução de all é derivada ao lado do significado comum da sentença. Observem abaixo como all em uma sentença funcionaria no modelo de Brisson (2003):

69. a. All the musicians played the piano. todos D músicos tocar-PAST D piano 'Todos os músicos tocaram o piano'

70. $\forall \mathrm{x}[\mathrm{x} \in[\mathrm{Cov}] \& \mathrm{x} \subseteq[$ the.musicians $]] \rightarrow \mathrm{x} \in[$ [played the piano $]]$, $\boldsymbol{A l l}(\mathrm{Cov})$ (the musicians) 


$$
\begin{aligned}
& \mathrm{U}=\{\mathrm{a}, \mathrm{b}, \mathrm{c}, \mathrm{s}, \mathrm{t},\{\mathrm{a}, \mathrm{b}\},\{\mathrm{a}, \mathrm{c}\},\{\mathrm{a}, \mathrm{s}\},\{\mathrm{a}, \mathrm{t}\},\{\mathrm{a}, \mathrm{s}, \mathrm{t},\} \ldots\} \\
& \text { [[the.musicians]] }=\{\mathrm{a}, \mathrm{b}, \mathrm{c}\} \\
& \mathrm{J}=\{\{\mathrm{a}\},\{\mathrm{b}\},\{\mathrm{c}\},\{\mathrm{s}, \mathrm{t}\}\} \\
& \mathrm{K}=\{\{\mathrm{a}\},\{\mathrm{c}\},\{\mathrm{b}, \mathrm{s}, \mathrm{t}\}\} \\
& \mathrm{L}=\{\{\mathrm{a}\},\{\mathrm{b}\},\{\mathrm{c}, \mathrm{s}, \mathrm{t}\}\}
\end{aligned}
$$

All interage com o contexto para limitar o conjunto de valores possíveis para Cov. Em U, somente J será o valor de Cov. O operador distributivo disparado pelo verbo terá força quantificacional universal sobre o conjunto denotado por the musicians, como em (70), e all será um modificador com função pragmática de um operador de exaustividade, i.e, um operador que selecionaria como valor para Cov um conjunto em que todos os seus elementos estejam na extensão do predicado verbal. Isto é, a função de all em (69) é de "assegurar que o valor atribuído a Cov seja adequado em relação ao DP sujeito" (Brisson 2003: 142). É por isso que no universo de discurso acima, o único conjunto que pode ser selecionado por all é J. Por exemplo, J seria o valor para Cov em (69) num contexto em que os músicos $\mathbf{a}, \mathbf{b}$ e $\mathbf{c}$ tocaram o mesmo piano, enquanto $\mathbf{s}$ e $\mathbf{t}$ são os amigos (que não são músicos) dos músicos que assistiram eles tocando. Já K não poderia ser o valor para Cov de (69), porque no contexto de K b, que é músico, estaria no conjunto dos que estão assistindo e não tocaram. Da mesma forma, L não poderia ser o valor para Cov de (69), porque, no contexto de L, o músico c estaria entre os que estão assistindo e não tocaram.

Em resumo, Brisson (2003) propõe um significado para all em que ele não tem força quantificacional e é um modificador que "interage com um operador [distributivo] D e tem a função de descartar a interpretação não maximal dos DPs plurais com os quais o operador D e all estão associados (Brisson 2003: 182).

\subsubsection{A proposta de Lasersohn (1999).}

Uma segunda proposta em termos pragmáticos para o comportamento de itens como all foi modelada por Lasersohn (1999). Partindo do truísmo de que quando precisões exatas não são exigidas, as pessoas, em geral, aceitam, sem maiores problemas, enunciados que desviam em pequenos graus da verdade, Lasersohn (1999) observa que o grau de desvio permitido não é somente determinado pela pragmática das 
situações de enunciação. Determinadas palavras que podem ocorrer nas sentenças enunciadas desempenham um papel importante quanto ao grau de aceitabilidade do desvio das sentenças em relação à sua verdade. Palavras como all, exactly, perfectly, etc., teriam por função reduzir a aceitabilidade do nível de desvio da verdade. Por exemplo, a sentença (71) pode permitir, de acordo com os propósitos práticos do falante que a enuncia, que alguns indivíduos da cidade que permaneçam acordados sejam ignorados ${ }^{43}$.

$\begin{array}{ccl}\text { 71. The townspeople } & \text { are } & \text { asleep. } \\ \text { D habitantes } & \text { estar-PRES-pl } & \text { adormecido } \\ \text { 'Os habitantes estão dormindo' } & \end{array}$

(Lasersohn 1999: 522)

Já em uma sentença como (72), parece que a introdução de all aumenta o nível de precisão requerida para que (72) seja aceita: praticamente nenhuma exceção é tolerada.

\begin{tabular}{|c|c|c|c|c|}
\hline 72. All & the & townspeople & are & asleep. \\
\hline todos & $\mathrm{D}$ & habitantes & estar-PRES-PL & adormecido \\
\hline
\end{tabular}

(Lasersohn 1999: 523)

All seria, assim, um operador (slack operator) que controla o quanto de desvio da verdade da sentença é pragmaticamente permissível. 'Pragmaticamente permissível' porque a diferença de significado entre (71) e (72) não é uma diferença de condições de verdade, mas tão somente no quanto, por assim dizer, de 'afrouxamento pragmático' (pragmatic slack) é tolerado. (71) e (72) são, no que diz respeito a condições de verdade, equivalentes, i.e., (71) e (72) são verdadeiras se, e somente se, todos os moradores da cidade estão dormindo. A diferença entre ambas é de ordem pragmática, pois, de modo geral, (71) é enunciada em contextos em que as pessoas costumam falar de forma mais imprecisa, e (72) em contextos em que uma maior precisão é requerida. Por exemplo, no contexto em que alguns moradores da cidade estão acordados, tanto

\footnotetext{
${ }^{43}$ Baseado na situação formulada por Lasersohn (1999) em que um grupo de ladrões intentam entrar durante a noite enquanto os moradores estão dormindo.
} 
(71) quanto (72) são falsas. Contudo, em função de propósitos práticos, como no caso de ladrões que queiram efetuar um roubo na cidade, o desvio de (71) em relação à verdade será pragmaticamente mais tolerado (Lasersohn 1999).

Para Lasersohn (1999), a tolerância com (71) em um contexto como o descrito, não sugere que a quantificação em (71) não seja universal, mas quase universal (notquite-universal), como propõe Brisson (1998, 2003). Evidências de que (71) possui uma força quantificacional ${ }^{44}$ vêm de sentenças como (73), que soam contraditórias.

73. \#Although the $\begin{aligned} & \text { townspeople } \\ & \text { are }\end{aligned}$
$\begin{aligned} & \text { habitantes } \\ & \text { estar-PRES-pl }\end{aligned}$
adormecido,
algum de eles estar-PRES-pl acordado
'Embora os habitantes estejam dormindo, algums deles estão
acordados.'

(Lasersohn 1999: 523)

Além do mais, the $+N P$ pode ser usado em contextos em que qualquer exceção é relevante. Imagine uma situação em que 2 cientistas estão testando uma possível fórmula para um medicamento em uma comunidade de 20 ratos. A reação que os cientistas esperam, para que o experimento seja bem sucedido, é que ao aplicar a substância nos 20 ratos, todos os animais adormeçam ${ }^{45}$. Suponha, ainda, que o experimento foi aplicado apenas por João, um dos dois cientistas, pois neste dia Pedro, o outro cientista, estava indisposto e não foi ao laboratório. Assim que o experimento deu certo, João ligou para Pedro para lhe informar do sucesso do resultado e de pronto diz:

$\begin{array}{ccll}\text { 74. The } & \text { animals } & \text { are } & \text { asleep. } \\ \text { D } & \text { animais } & \text { estar-PRES-pl } & \text { adormecido }\end{array}$

'Os animais estão dormindo'

\footnotetext{
${ }^{44}$ Força introduzida, segundo (Link 1987), por um operador distributivo encoberto no VP.

${ }^{45}$ Exemplo de Lasersohn (1999), mas com mais detalhes acrescentados por nós.
} 
Em uma situação como esta parece que Pedro interpretaria que os 20 ratos dormiram. De maneira que o contexto descrito para a enunciação de (74) sugere "que a sentença [74] pode permitir algum afrouxamento, mas isso não significa que toda situação pragmática explorará o afrouxamento que a sentença disponibiliza" (LASERSOHN 1999: 523). Ou seja, o contexto dos cientistas parece bloquear não o uso de (97), mas apenas o seu uso impreciso, i.e., em uma situação em que alguns ratos não tenham dormido com a aplicação da substância.

Em função da sensibilidade das sentenças à introdução de expressões como all, é razoável hipotetizar, segundo Lasersohn (1999), que algum tipo de procedimento composicional está envolvido quando da aplicação destas expressões. Em vista disso, Lasersohn (1999) propõe o seguinte modelo para formular a semântica de all: a cada expressão $\beta$ de uma língua é atribuída uma denotação, que é usada para calcular suas condições de verdade. Além disso, o contexto pragmático associa a esta denotação um conjunto de objetos do mesmo tipo semântico da denotação. Cada um desses objetos difere da denotação somente em questões que são ignoráveis em termos pragmáticos. Assim, uma expressão como the townspeople denota um conjunto de indivíduos ${ }^{46}$. $\mathrm{O}$ contexto pragmático, por sua vez, associará com esse conjunto denotado por the townspeople um conjunto de conjuntos de indivíduos. No contexto dos ladrões, esses conjuntos se diferenciam do conjunto dos habitantes em aspectos pragmaticamente irrelevantes: alguns não possuirão indivíduos cujas propriedades preocupam pragmaticamente os ladrões. Indivíduos acordados, mas desatentos, por exemplo, não os impedem de enunciar the townspeople are asleep.

O conjunto denotado por uma expressão será ordenado de modo a formar um ponto central da ordenação. Por exemplo, “a ordenação relevante sobre o conjunto associado com a expressão the townspeople será aquela que mais se aproxima do conjunto dos moradores da cidade" (LASERSOHN 1999: 526). O conjunto que o contexto associa à denotação de uma expressão $\beta$ Lasersohn denomina de halo pragmático (pragmatic halo), de modo a expressar figurativamente a ideia de que em torno da denotação de $\beta$ há uma espécie de agrupamento circular (circular cluster), que consiste no conjunto, junto com sua relação de ordenação, que o contexto pragmático associa com a denotação de $\beta$. O halo pragmático de the townspeople seria, então, um conjunto de conjuntos de indivíduos que diferem do conjunto dos moradores da cidade

\footnotetext{
${ }^{46}$ Para ser mais fiel a Lasersohn (1999), que modela indvíduos plurais como conjuntos, optamos por nos referir a expressões como the townspeople como denotando um conjunto.
} 
apenas de maneiras irrelevantes pragmaticamente e que estão ordenados de acordo com a sua proximidade em relação ao conjunto dos moradores da cidade.

All também terá um halo pragmático. All denotaria uma função de identidade e o seu halo "um conjunto de funções sobre grupos de indivíduos (aproximando-se da função de indentidade)" (LASERSOHN 1999: 548). E o halo de all the $N$ é derivado formando um conjunto cujos elementos são os valores que as funções do halo de all retornam quando aplicadas ao ponto central do halo de the $N$, i.e., a denotação de the $N$. Em the townspeople, o ponto central será o próprio conjunto dos moradores da cidade.

Para capturar a intuição dos falantes de que todo conjunto no halo de all the townspeople também estará no halo de the townspeople, Lasersohn (1999) estipula que as funções de all devem mapear qualquer conjunto $\mathrm{X}$ no subhalo do halo de $\mathrm{X}$. Assim, se um conjunto $\mathrm{X}$ estiver no halo de all the $N$, também estará qualquer conjunto Y que esteja tão perto do conjunto denotado por the $N$ quanto $\mathrm{X}$ está.

Imaginem, por exemplo, que num contexto em que um grupo de ladrões intentam entrar numa cidade durante a noite para realizar um grande roubo, o halo pragmático de the towns people na sentença the townspeople are asleep seja o conjunto de conjuntos $\{\mathrm{X}, \mathrm{W}, \mathrm{Y}, \mathrm{Z}\}$ ordenados de acordo com a sua proximidade da denotação de the townspeople, que seria o conjunto $\mathrm{X}$. Sendo

$$
\begin{aligned}
\text { 75. } X & =\{\mathrm{x}: \mathrm{x} \text { é habitante da cidade }\} \\
\mathrm{W} & =\{\mathrm{x}: \mathrm{x} \text { é habitante da cidade, mas não é amigo dos ladrões }\} ; \\
\mathrm{Y} & =\{\mathrm{x}: \mathrm{x} \text { é habitante da cidade, mas não é cego }\} \\
Z & =\{\mathrm{x}: \mathrm{x} \text { é habitante da cidade, mas não é novo na cidade }\} .
\end{aligned}
$$

Agora, suponha que o halo de all the townspeople seja o subconjunto $\{\mathrm{X}, \mathrm{W}\}$ de $\{\mathrm{X}, \mathrm{W}, \mathrm{Y}, \mathrm{Z}\}$. Se assumirmos que o conjunto mais próximo de $\mathrm{X}$ é $\mathrm{W}$, mas que $\mathrm{Y}$, que está fora do halo de all the townspeople, seja o único conjunto saliente no contexto quando da enunciação da sentença (72) - all the townspeople are asleep - então (72) não será considerada próxima da verdade o suficiente neste contexto. Contudo, como o leitor pode notar, (71) - the townspeople are asleep - será considerada adequada, uma vez que Y é elemento do conjunto do halo de the townspeople ${ }^{47}$.

\footnotetext{
${ }^{47}$ Para seguir a formalização dos halos, ver apêndice I no final deste capítulo.
} 
Sendo o conjunto mais próximo do conjunto denotação de the townspeople o conjunto dos moradores que não são amigos dos ladrões, a sentença (72) - all the townspeople are asleep - seria usada num contexto em que somente os colaboradores dos ladrões podem estar acordados. Neste caso, o uso de all regularia a aceitabilidade do nível de desvio da verdade.

\subsubsection{Observações sobre as duas propostas.}

Como pode ser notado, tanto a proposta de Brisson (2003) quanto a de Lasersohn (1999) conseguem, fazendo uso da pragmática, propor uma semântica para all que explique o seu comportamento peculiar em relação aos quantificadores every e each. O fato de all poder ocorrer com predicados coletivos e tomar um DP como complemento decorre do fato de all não ser um quantificador universal, e, por isso, não possuir força quantificacional e tampouco propriedade de distributividade. Para Brisson (1999) all é um operador de exaustividade e para Lasersohn (1999) all é um operador que regula o desvio pragmático em relação à verdade da sentença na qual ele ocorre.

Embora não haja critérios de ordem empírica para avaliar a superioridade de uma proposta em relação à outra, pois ambos os modelos expliquam all o classificando como um modificador, entendemos que a proposta de Lasersohn (1999) parece ter ao menos vantagens teóricas sobre a de Brisson (1999), basicamente por duas razões. Primeiro porque a teoria de Lasersohn dá conta de explicar as leituras não maximais de sentenças como the girls ate a sandwich - i.e., sem que todas tenham comido um sanduiche - sem que seja necessário atribuir condições de verdade distintas para sentenças com all e sem all, e, portanto, significados distintos. Como detalhado na subseção 2.7.1.2, Lasersohn sustenta que, na verdade, as leituras não maximais em sentenças sem all são desvios da verdade das sentenças "licenciados porque os participantes do discurso acham conveniente ignorar distinções e detalhes irrelevantes" (LASERSOHN 1999: 526). A força quantificacional da sentença continua a mesma. The girls are asleep, por exemplo, possui força quantificacional universal, e as suas condições de verdade exigem que todas as garotas tenham dormido, sendo o desvio em relação a essas condições de verdade puramente uma questão de ordem pragmática. Em segundo lugar, porque, no modelo de Lasersohn, a análise em termos de regulador de desvios pragmáticos pode ser estendida trivialmente para outras expressões, como 
exactly, perfectly, etc., e no modelo de Brisson não nos parece tão claro que o mesmo possa ser feito ${ }^{48}$.

Por isso, dada as vantagens teóricas que entendemos que o modelo de Lasersohn (1999) apresenta, na próxima seção procuraremos recorrer a sua proposta para modelar o uso de kar (todos) no Kaingang Paranaense. Mas que fique bem claro que com isso não estamos sustentando que a proposta de Brisson seja insuficiente para explicar o comportamento de kar.

Por fim, antes de iniciar a próxima seção, em que trataremos kar como um regulador de desvíos pragmáticos, queremos prevenir o leitor de que, apesar de kar se comportar, de modo geral, como all, o fato de ele ocorrer interno ao DP e não externo ao DP, como no caso de all, exigirá que realizemos algumas adaptações da proposta de Lasersohn (1999), de maneira que ela possa ser implementada com mais precisão para descrever os dados do Kaingang.

\subsection{Kar como regulador de desvios pragmáticos.}

Relembrando o que foi apresentado na seção 2.2, em Kaingang NP+kar pode ser usado em construções genéricas, i.e., em enunciados sobre um conjunto de indivíduos em geral. Em contrapartida, o acréscimo do determinante definido ag para formar expressões $N P+k a r+a g$ é usado somente em construções restritas, i.e., em enunciados sobre um conjunto particular de indivíduos saliente no contexto. A sentença (27a), aqui repetida como (76), em que o artigo definido ag está presente, consiste em uma afirmação sobre um conjunto particular de Kaingangs que têm o habito de dançar, por exemplo, os kaingangs que moram na cidade de Maringá.

76. Kanhgág kar ag vỹ vẽnh gringrén tĩ
kaingang total $\quad$ D.pl m.s dançar-PLR ASP
'Todos os kaingangs dançam'

\footnotetext{
${ }^{48} \mathrm{O}$ que pode significar que o modelo de Lasersohn consegue abarcar uma quantidade maior de fenômenos, e, por isso, possui um poder explicativo maior. Contudo, para que tal posição seja defendida, faz-se necessário investigar se o modelo de Brisson pode ser estendido também para dar conta dos termos tratados por Lasersohn (1999).
} 
Em Kaingang o termo kar - ao contrário de all do inglês, que parece ser realizado como um adjunto fora do DP (Sportiche 1988) - aparece dentro do DP. Assumiremos que kar seja um modificador e que, dado que não encontramos exemplos em que kar seja realizado fora do DP, a expressão kanhgág kar ag pode ser representada como tendo a seguinte estrutura:

77. a. [[[kanhgág [kar]] ag DP] ${ }^{49}$

b.

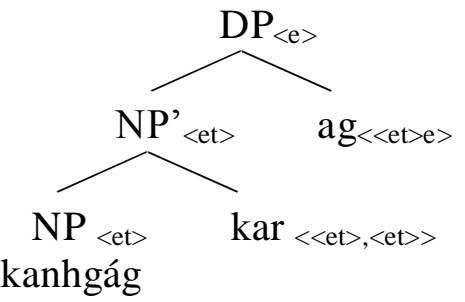

A proposta de Lasersohn (1999) para all como regulador de desvio pragmático apresenta exemplos de sentenças cujo conjunto denotado pelo DP é pressuposto, pelo autor, como um conjunto de indivíduos saliente no contexto, embora o autor não deixe isto claro. Mas como os exemplos são com sentenças circunstanciais, e all sempre ocorrendo externo a um DP com determinante definido, entendemos que Lasersohn (1999) assume que a denotação de the $+N$, ao menos nos exemplos do texto, seja um conjunto particular previamente mencionado no discurso. Do que se segue que o halo pragmático da denotação do DP é o halo do conjunto saliente no discurso. Lasersohn (1999) não trata de sentenças em que all opera diretamente sobre um nome plural, sentenças que em Inglês parecem forçar uma leitura genérica, como em (78):

78. All languages have over twenty color words.
todas línguas ter-PRES mais-de vinte cor palavras
'lit: 'Todas línguas têm mais de vintes palavras para cores'

(Beghelli \& Stowell 1997: 100)

Do mesmo modo, a ausência do determinante definido em Kaingang em sentenças tanto com kar quanto sem, permite leituras genéricas, como em (79) e (80):

\footnotetext{
49 Estamos ignorando aqui projeções que possam existir entre D e N, como, por exemplo, NumP, pois não afetarão a nossa análise.
} 
79. Kanhgág kar vỹ vẽnh gringrén tĩ.

kaingang total m.s dançar-PLR ASP

lit: 'Todos kaingangs dançam'

80. Kanhgág vỹ vẽnh grén tĩ.

kaingang m.s dançar ASP

lit:'Kaingang dança'

Entendemos que podemos modelar não somente sentenças em Kaingang com leitura restringida contextualmente, mas também com leitura genérica, utilizando-se da proposta composicional de Lasersohn (1999) para os halos pragmáticos.

Comecemos então com a leitura genérica. Para isso, devemos assumir que o termo kanhgág em (79) e (80) denota o conjunto dos kaingangs em geral. O halo pragmático da denotação de kanhgág será o conjunto de conjuntos de kaingangs que diferem, somente de maneiras que são pragmaticamente irrelevantes, do conjunto dos kaingangs, i.e, um conjunto de "membros cujas propriedades estranhas não são pragmaticamente uma preocupação" (Lasersohn 1999: 526). Tais membros são ordenados de acordo com sua proximidade em relação à denotação de kanhgág. Suponham que o halo da denotação de kanhgág nas sentenças (79) e (80) seja o seguinte conjunto:

81. $\mathbf{K}=\{\{\mathrm{x}$ : $\mathrm{x}$ é kainhang $\},\{\mathrm{x}$ : $\mathrm{x}$ é kaingang, mas não é paralítico $\},\{\mathrm{x}: \mathrm{x}$ é kaingang, mão não é bebê $\},\{x$ : x é kaingang, mas não é muito idoso $\}$.

Agora, recordando que todo conjunto no halo da denotação de kanhgág kar também estará no halo da denotação de kanhgág, suponha que ao enunciar (79), o falante $j$ tolere os kaingangs que são paralíticos. E suponham que o halo de kanhgág kar seja um conjunto $K^{\prime}$ que preserve como elementos somente os seguintes conjuntos:

82. $K^{\prime}=\{\{\mathrm{x}$ : x é kaingang $\},\{\mathrm{x}$ : x é kaingang, mas não é paralítico $\}$. 
Assim, (79) enunciada pelo falante $j$ poderá ser considerada uma sentença suficientemente próxima da verdade se todos os kaingangs dançam, exceto os paralíticos. Já se alguns kaingangs bebês e kaingangs bem idosos não dançarem por razões físicas ou de idade, embora (79) enunciada por $j$ não seja considerada próxima da verdade o suficiente, (80) será. Por isso, como já demonstrado na seção anterior, pode haver contextos em que (80) é considerada pragmaticamente permitida, mas (79) não ${ }^{50}$.

E quanto a sentenças em que a presença do determinante $a g$ restringe a denotação de uma expressão nominal a um conjunto saliente no contexto? Como podemos modelar os halos pragmáticos dessas sentenças? Lembrem que em Basco e Grego, segundo Etxeberia (2005) e Etxeberria \& Gianakidou (2009), quando D toma um Q como complemento ele o modifica fornecendo uma variável contextual $\mathrm{C}$ cujo valor será um conjunto saliente no contexto. Neste processo, D preserva o tipo semântico de Q, mas perde sua função referencial, i.e, não é mais um operador max, uma vez que passa a ser um modificador de quantificadores fortes.

Embora num primeiro momento o Kaingang parecesse mais uma evidência translinguística para a hipótese dos autores, um estudo mais detalhado do comportamento de kar nos levou a hipotetizar que, na verdade, kar é um modificador que pode ocorrer interno a uma projeção DP. Como já ilustrado com certa exaustão, em Kaingang, sempre que ocorrerem expressões complexas da forma kanhgág kar ag elas denotarão um conjunto de indivíduos em particular. E isso é de se esperar, uma vez que nessas sentenças ag é o operador max e restritor de domínio, introduzindo, por isso, uma variável contextual C. O que significa que em uma sentença como (27a), repetida aqui como (83):

$\begin{array}{lllll}\text { 83. Kasor } \quad \text { kar } & \text { ag } & \text { kyrkyr } & \emptyset . \\ \text { cachorro total } & \text { D.pl } & \text { latir-PLR } & \text { ASP } \\ \text { 'Todos os cachorros latiram.' } & & \end{array}$

assumindo que $a g$ tenha a denotação

$$
\text { 84. }[[\mathrm{ag}]]=\lambda \mathrm{P} \cdot \max \{\mathrm{x}: \mathrm{C}(\mathrm{x}) \cap \mathrm{P}(\mathrm{x})\}
$$

\footnotetext{
${ }^{50}$ Para uma formalização do halo de kanhgág kar, dado o contexto modelado para (79), ver apêndice II no final deste capítulo.
} 
ag introduz uma variável contextual $\mathrm{C}$ e fecha sob o operador max o conjunto que satura C, gerando, assim, o indivíduo plural máximo a partir dos elementos deste conjunto, que sempre será um conjunto de cachorros salientes no contexto.

O resultado da aplicação de ag a kasor kar, será a seguinte estrutura:

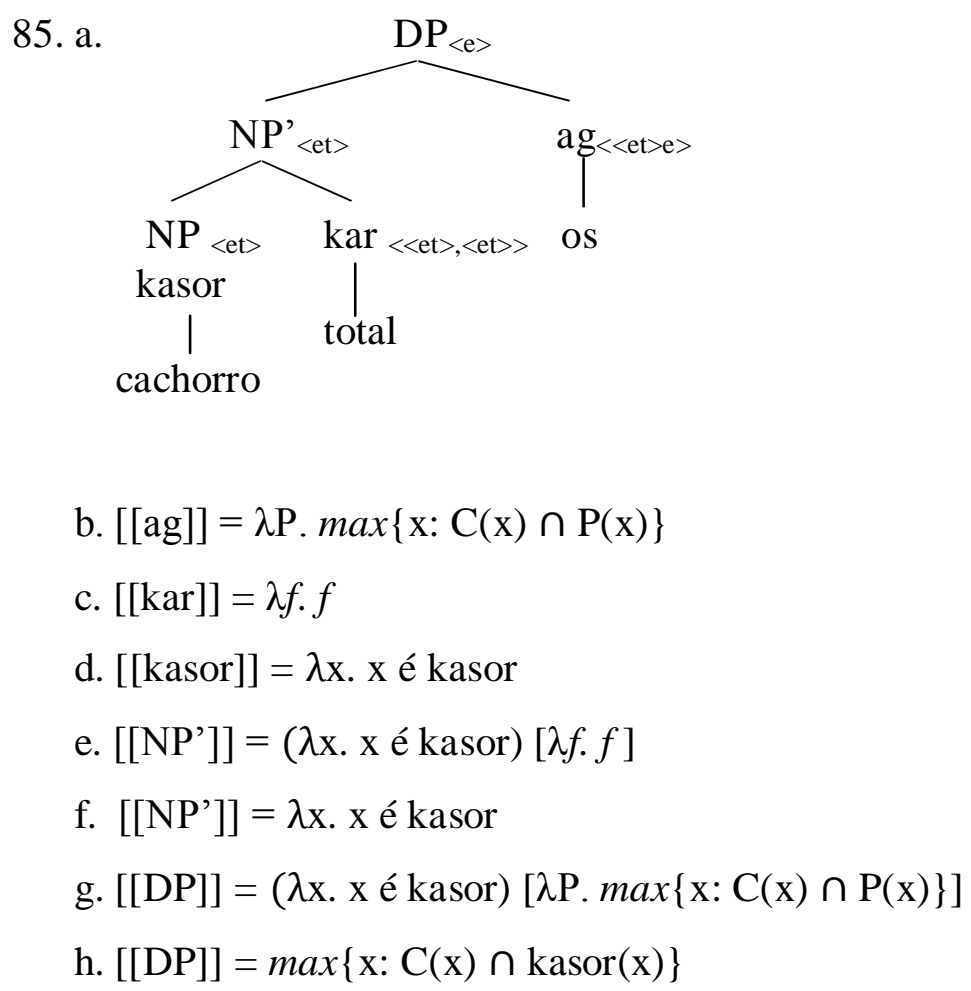

Como pode ser observado, kar, como mera função identidade, não alterará em nada as condições de verdade de uma sentença em que a estrutura (83) ocorra, como em (85). E é isso mesmo o que queremos. Sendo a denotação de $k a r \lambda f . f$, então[[kasor kar]] $=([[$ kasor $]])[[$ kar $]]=[[$ kasor $]]$. E a denotação da variável $\mathrm{C}$ introduzida pelo artigo definido ag em (85) será um conjunto dos cachorros salientes no contexto.

Desse modo, assumindo que em (85) o contexto pragmático associa ao valor da variável contextual $\mathrm{C}$, introduzida na forma lógica pelo artigo definido $a g$, um conjunto de conjuntos ordenados em relação à denotação de $\mathrm{C}$ - i.e., o halo pragmático do valor de $\mathrm{C}$ - todo conjunto no halo de kar kanhgág estará também no halo do valor da variável C.

Mesmo que seja trivial especificar o halo de $\mathrm{C}$ (variável cujo valor é fixado pelo contexto), o faremos de maneira a especificar ainda mais ao leitor a distinção entre (79) e (83) no modelo de halos pragmáticos. 
Imaginem que o halo do valor de $\mathrm{C}$ em (83) seja o seguinte conjunto A de conjuntos:

86.A $=\{\{x: x$ é cachorro da aldeia $\},\{x$ : x é cachorro da aldeia, mas não está gravemente doente $\},\{x: x$ é cachorro da aldeia, mas não é filhote $\},\{x: x$ é cachorro da aldeia, mas não é muito manso\} \}.

Agora, suponham que o halo de kanhgá kar seja $\{\{\mathrm{x}$ : $\mathrm{x}$ é cachorro da aldeia $\}$, $\{x: x$ é cachorro da aldeia, mas não está gravemente doente $\}$. Neste caso, (83) será considerada pragmaticamente permissível, por exemplo, em uma situação em que todos os cachorros da aldeia latiram, exceto o(s) que estava(m) gravemente doente(s) ${ }^{51}$.

Em resumo, demonstramos que a proposta de halos pragmáticos desenvolvida em Lasersohn (1999) pode muito bem dar conta, no caso do Kaingang, tanto de construções genéricas quanto de construções particulares em que kar ocorre. Enquanto em uma construção genérica o halo pragmático será o halo de um conjunto de indivíduos em geral, em uma construção particular, em função da introdução de uma variável contextual $\mathrm{C}$ pelo artigo definido ag, o halo pragmático será o halo de um conjunto particular de indivíduos. De maneira que, em uma leitura genérica, o halo pragmático de $N$ kar será um conjunto do(s) conjunto(s) mais próximo(s) de um conjunto de indivíduos em geral; e em uma leitura particular o halo de $N$ kar será um conjunto do(s) conjunto(s) mais próximo(s) de um conjunto contextualmente saliente de indivíduos.

\subsection{Considerações finais.}

Neste capítulo tratamos da estrutura interna dos sintagmas nominais em Kaingang nas quais ocorre a expressão kar. Observamos que, em Kaingang, o determinante ag pode tomar $N P+k a r$ como complemento, e que quando isso ocorre, a leitura é sempre de um conjunto restringido no contexto. Com base na hipótese desenvolvida em Etxeberria (2005), Giannakidou (2004) e Etxeberria \& Giannakidou (2009) para estruturas semelhantes no Basco e Grego - segundo a qual o determinante

\footnotetext{
${ }^{51}$ Para uma formalização do halo de kasor kar ag dado o contexto modelado para (83), ver apêndice III.
} 
definido, nessas línguas, toma uma expressão quantificacional como complemento e desempenha a função de restringir contextualmente o domínio da quantificação apresentamos, num primeiro momento, dados que sugerem que o Kaingang seja mais um evidência translinguística para a hipótese dos autores. Contudo, um olhar mais detalhado do comportamento de kar - como, por exemplo, a possibilidade da conjunção de duas sequências de kar sob um mesmo D, etc - levou-nos a hipotetizar que, ao invés de kar e mais uma expressão nominal criarem uma projeção Q-detP, como proposto pelos autores para Basco e Grego, kar consiste em um modificador originado interno a um NP. E quando o determinante $a g$ é introduzido, o que se cria é uma projeção DP.

Na seção 2.8, apresentamos dados que sugerem que kar não se comporta como um quantificador. Com base nesses dados, propusemos uma análise alternativa de kar. Hipotetizamos, no esteio da proposta de Lasersohn (1999) para all do Inglês, que kar não é um quantificador universal, mas sim um modificador com a função de regular o quanto de desvio da verdade é pragmaticamente permissível. Esta análise aplicou o mecanismo de halos pragmático proposto por Lasersohn (1999): “conjuntos que se aproximam da denotação de uma expressão e que são fixados em parte pragmaticamente, ignorando detalhes e distinções irrelevantes, e em parte estruturalmente, a partir do uso de expressões reguladoras" (LASERSOHN 1999: 548). Assim, $N+k a r$ seleciona apenas o(s) conjunto(s) pragmaticamente mais próximo(s) do conjunto denotação de $N$.

Em seguida, estendemos a análise de Lasersohn (1999) para dar conta tanto de sentenças com leitura genérica quanto particular. Além disso, como resultado da proposta de que kar seja apenas um modificador, sustentamos que em Kaingang ag, quando operando sobre $N+k a r$ não perde a sua função referencial, como no caso do Basco e Grego, segundo Etxeberria \& Giannakidou (2009). De maneira que em Kaingang, em estruturas $N+k a r+a g$, o determinante também funciona como restritor contextual, mas continua sendo um operador de tipo $\langle<$ et, $>$ e $>$, i.e., formando indivíduo a partir de um conjunto. Mais especificamente, mostramos que o determinante definido em Kaingang não é ambíguo entre uma função de artigo definido clássico, i.e., formadora de indivíduo a partir de um conjunto, e de restritor contextual de domínio, como sugerem Etxeberria \& Giannakidou (2009) para os determinantes definidos em Baco e Grego.

Dado as conclusões a que chegamos neste capítulo, gostaríamos, para fechá-lo, de levantar algumas questões, a título de reflexão, quanto à viabilidade e problemas de 
se estender a análise que propomos para o Kaingang, também para o Grego, Basco e St'át'imcets. A pergunta de partida é a seguinte: seria possível, após termos analisado kar como modificador, voltarmos para o Grego, Basco e St'át'imcets e (i) tratarmos da mesma forma as expressões dessas línguas assumidas pelos autores como quantificadores fortes (ii) e assumir que nelas o determinante definido não perde a sua função formadora de indivíduo e continua sendo um artigo definido clássico?

Lembrem que na proposta de Etxeberria (2005) e Etxeberria \& Giannakidou (2009) o determinante restringe uma expressão quantificacional (um quantificador forte). Por isso, os autores assumem que ele perde sua função max. Mas e se essas expressões tratadas como quantificadores forem, na verdade, modificadores?

O caso do Grego parece mais complicado, já que os únicos dados apresentados em Etxeberria \& Giannakidou (2009) são dados em que o determinante e o nome são singulares e a expressão tratada como quantificador universal, kathe, parece ser inerentemente distributiva, como no exemplo (51b), repetido abaixo como (87):.

\section{Grego \\ o kathe fititis \\ D.sg todo estudante \\ 'Todo estudante'}

Além de ser inerentemente distributivo, segundo Etxeberria \& Giannakidou (2009) kathe não pode ocorrer sem o determinante definido $o$ e não é possível duas sequências de $N+k a t h e$ sob um mesmo determinante definido. O que reforça a hipótese de que (86) seja uma projeção QP.

Já no Basco, tal como no Kaingang, o determinante e a expressão tratada como quantificador são plurais, e guzti (todos), expressão mais presente nos dados em Etxeberria \& Giannakidou (2009), assim como kar, não é inerentemente distributivo. Contudo, o complicado é que no Basco há três expressões universais não distributivas e plurais: guzti, den e oro (Etxeberria 2005). Dessas três, apenas oro pode aparecer sem determinante:

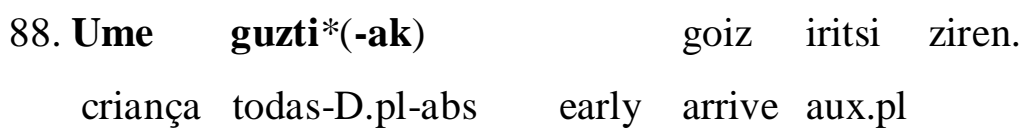


'Todas (as) crianças chegaram cedo.'

(Etxeberria 2005: 252)

89. Jarraitzaile den*(-ek) abeslari-a-r-en sinadura
fã $\quad$ todos-D.pl-erg cantor-D.sg-ep-gen assinatura-D.sg-abs

nahi zuten.

querer aux.pl

'Todos (os) fãs quiseram a assinatura do cantor.'

(Etxeberria 2005: 252)

90. Ikasle oro-k lan bat egin zuen ikasgai-a estudante todos-erg trabalhar um-abs fazer aux.sg disciplina-D.sgabs

gaindi-tze-ko.

passar-nom-gen

'Todos estudantes devem escrever um artigo para passar na disciplina .'

(Etxeberria 2005: 253)

A partir da variação na necessidade dessas expressões aparecerem ou não com $\mathrm{D}$, e do fato de que oro não somente pode aparecer sem D, mas também aparecer com um DP, i.e., um nome modificado por um determinante definido, como em (91), Etxeberria (2005) sustenta que oro pode ser ambíguo entre um quantificador universal e um modificador de DP com a função semântica de um operador de maximalidade.

$$
\begin{aligned}
& \text { 91. Ikasle-ak oro } \\
& \text { estudante-D.pl.abs todos } \\
& \text { 'Todos os estudantes' }
\end{aligned}
$$

Segundo Etxeberria (2005), uma propriedade específica de oro, que reforça a hipótese da sua ambiguidade, é que quando D está presente, é D que obrigatoriamente 
tem que se combinar com a expressão nominal, ao contrário de guzti e den, que sempre têm que se combinar com D. Sentenças nas quais ocorre a estrutura (91) sempre receberão uma leitura restringida contextualmente, i.e., o conjunto dos estudantes sempre será um conjunto de indivíduos salientes no contexto. Já quando oro se combina apenas com a expressão nominal, tanto leituras restritas quanto genéricas são permitidas; o que leva Etxeberria (2005) a hipotetizar que quando oro se comporta como um quantificador universal em uma sentença com leitura restringida, a restrição de domínio é realizada de forma encoberta.

Contudo, entendemos que não é necessário assumir a hipótese da ambiguidade de oro, pois se pode muito bem sustentar que oro seja um modificador como all, que pode tanto se combinar com uma expressão nominal quanto com um DP. Poderíamos defender que all seja ambíguo também, mas não vemos necessidade disso. Como demonstramos na seção 2.8, o modelo de Lasersohn (1999) dos halos pragmáticos, que assume que all seja um modificador com a função de regular desvios pragmáticos quanto às condições de verdade das sentenças, pode dar conta de modelar tanto leituras particulares quanto genéricas. Tanto kar quanto all são mantidos como modificadores em ambas as leituras. O que é uma vantagem clara, já que nenhuma forma de ambiguidade é necessária para dar conta de ambas as leituras. Assim, ao menos com base nos exemplos apresentados em Etxeberria (2005), entendemos que podemos assumir que oro seja em todas as suas ocorrências um modificador. Já quanto à guzti e den, parece mais difícil defendermos que sejam também modificadores. Além de guzti e den terem que obrigatoriamente se combinar com $\mathrm{D}$, e, por isso, somente receberem leituras restringidas contextualmente, é impossível juntar duas sequências de $N P+$ guzti/den sob um mesmo D.

Em Etxeberria (2005) e Etxeberria \& Giannakidou (2009) não há uma explicação da razão da obrigatoriedade de guzti e den sempre ocorrerem com D. O que se depreende da análise dos autores é que guzti e den, em função de se combinarem com $\mathrm{D}$, recebem sempre leitura restringida, e que, por isso, com essas expressões a restrição de domínio é sempre realizada de forma aberta. Mas parece não haver uma razão evidente para oro, ao contrário de guzti e den, realizar a restrição de domínio de forma encoberta.

Quanto à St'át'imcets, Etxeberria \& Giannakidou (2009) observaram muito bem que a análise de Matthewson (2001), segunda a qual nessa língua os quantificadores se 
combinam com um DP, não dá conta de explicar os casos, existentes em St'át'imcets, em que D se combina com o quantificador, como abaixo:

$$
\begin{aligned}
& \text { 92. qwatsáts [i tákem-a smúlhats] } \\
& \text { partir [D.pl todas-D mulheres] } \\
& \text { 'Todas as mulheres partiram.' }
\end{aligned}
$$

(Mathewson 2001 (5))

Em Matthewson (2001), na $5^{\circ}$ nota de roda pé, a autora se refere a esses casos, que segundo ela somente ocorrem com quantificadores fortes, mas justifica que não analisará essas construções porque elas “estão além do escopo... do artigo" (Matthewson 2001: 151 (5)), e que um tratamento mais detalhados dos quantificadores fortes e fracos em St'át'imcets se encontra na sua tese de 1998. Não tivemos acesso a esse trabalho, mas com base no artigo de (2001), no qual o único dado de uma construção em que D se combina com um "quantificador" é o exemplo da nota 5, em que D se combina com tákem, expressão que parece não ser inerentemente distributiva, e que, como kar e all, se combina com determinantes plurais, poderíamos também argumentar que tákem seja um modificador que se combina tanto com um DP, tal como all, quanto com uma expressão nominal, como kar.

Em St'át imcets, o determinante $i . . . a$, que segundo Etxeberria e Giannakidou (2009) pode se comportar semanticamente tanto como definido quanto como indefinido, não seria ambíguo entre um operador de tipo ete e um restritor de domínio. Tal como ag do Kaingang, ele seria um determinante que forma indivíduos a partir de um conjunto e que introduziria uma variável $\mathrm{C}$ a ser saturada por um conjunto selecionado pelo contexto. Lembrem que o argumento em Etxeberria e Gaiannakidou (2009) é que, quando se combina com um quantificador, o determinante perde sua função referencial e apenas funciona como um operador preservador de tipo que restringe o domínio da quantificação. Com a mesma análise, os autores defendem dar conta das duas construções que ocorrem em St'át'imcets, a saber, a que o quantificador se combina com um DP e a que D se combina um quantificador.

Mas no caso em que o quantificador se combina com um DP, o determinante definido se combina primeiramente com uma expressão nominal, e parece que para esses casos fica um pouco difícil sustentar que D perdeu sua função referencial, uma vez que Q já tomaria um DP formado. Somente nos parece razoável sustentar que Q 
tomaria um DP com um D sem função referencial se $a . . . i$ fosse ambíguo entre operador max e restritor de domínio. O argumento em Etxeberria \& Giannakidou (2009) é que D, nessas línguas, negociaria a sua função referencial, quando se combinando com Q, para que não ocorra incompatibilidade de tipos. No caso em que tákem toma um DP, todavia, não é o D que se combina com Q. Defendendo que tákem seja um quantificador, basta postularmos que quando Q toma um DP em St'át'imcets, um operador encoberto de mudança de tipo transforma o DP de tipo $e$ em tipo et, de forma a poder servir de complemento de um quantificador.

Já se defendermos que tákem é um modificador, além de não precisarmos postular ambiguidade, nem mesmo a um operador encoberto de mudança de tipo será preciso recorrer. O que ocorreria nas duas construções em St'át imcets é que o modificador tákem poderia aparecer tanto interno a um DP, como em Kaingang, quanto se combinando com um DP, como em Inglês.

O que se coloca com toda essa discussão é que se todas essas expressões puderem ser tratadas como modificadores, teremos a vantagem teórica de explicar (translinguisticamente) a restrição de domínio realizada via determinante sem portular uma ambiguidade do artigo definido. Além do mais, uma consequência de tal análise seria um questionamente da proposta dos autores de que há línguas nas quais a estratégia de restrição de domínio se dá com D operando sobre Q e formando com ele um constituinte, e, com isso, a crítica dos autores à proposta alternativa de Matthewson $(1998,2001)$ teria que ser revista em muitos aspectos.

Embora tenhamos encontrado problemas, talvez devido às nossas limitações teóricas, para estender a análise proposta para o Kaingang também para todos os casos em Grego, Basco e St'át'imcets, esperamos que esse breve ensaio de uma tentativa de explicação unificada, sem postular ambiguidades, sirva para destacar problemas ainda em aberto e que aguardam futuras investigações. 


\section{APÊNDICE I}

Lasersohn (1999) deriva, como procuramos demonstrar informalmente, os halos das expressões complexas aplicando operações semânticas a todas as possíveis combinações de objetos nos halos das expressões constituintes.

Assumindo uma teoria composicional, Lasersohn (1999) atribui a toda expressão $\beta$ um conjunto parcialmente ordenado $<\operatorname{Hc}(\beta), \leq \beta, \mathrm{C}>$, que consiste no halo de $\beta$. $\operatorname{Hc}(\beta)$ é um conjunto de objetos relativos a um contexto $\mathrm{C}$ que diferem de $[[\beta]]$, i.e, da denotação de $\beta$ relativo a um modelo. Como demonstrado acima, a $[[\beta]] \in \operatorname{Hc}(\beta)$, i.e, a denotação de uma expressão sempre será um elemento do halo da própria expressão, e os elementos do halo de uma expressão sempre serão do mesmo tipo semântico da expressão. Além disso, no modelo proposto, a extensão de $\beta$ será ıy em $\forall x \in \operatorname{Hc}(\beta), y \leq$ B,c $\mathrm{x}$, i.e., a denotação de $\beta$ é o ponto central do halo, em relação ao qual os outros elementos do halo são ordenados.

O termo all, como já mencionado, é tratado como denotando uma função identidade:

\section{i. $\quad[[$ all $]]=f: f(\mathrm{~g})=\mathrm{g}$}

para todos os grupos ${ }^{52}$ de indivíduos em g. Sendo $\beta$ um termo denotador de grupo, [[all $\beta]]=[[$ all $]]([[\beta]])=[[\beta]]$.

Uma vez que a denotação de all é uma função identidade sobre grupos de indivíduos, o halo de $H c($ all) será um conjunto de funções sobre grupos de indivíduos, que se aproximam da função de identidade. Essa restrição significa que cada uma dessas funções "se diferencia da função de identidade somente de maneiras ignoráveis pragmaticamente" (LASERSOHN 1999: 529). E uma vez que a denotação de uma expressão sempre será um elemento do seu halo, a própria função de identidade, que é denotação de all, é também um elemento do halo de all. Com efeito, o que essas funções fazem é mapear cada grupo g no seu domínio em um g' que difere de g apenas em questões ignoráveis. "Essas funções juntas mapeiam [g] em um conjunto de [grupos] muito próximos, que podemos considerar como um tipo de halo 'extra-apertado' (extratight) em torno de [g]" (LASERSOHN 1999: 529).

\footnotetext{
${ }^{52}$ Lasersohn não distingue no artigo em questão grupo de conjunto. Na parte informal do texto ele sempre se refere à denotação de um DP como sendo um conjunto. Contudo, no apêndice do texto, onde o autor apresenta em detalhe a sua formalização, é usado o termo grupo. Por isso, na parte em que expomos um trecho da formalização do autor, decidimos preservar o termo grupo.
} 
Assim, para calcular o halo de uma expressão com all $\beta$, aplicam-se as funções no halo de all sobre o ponto central do halo de $\beta$, ou seja, sobre a denotação de $\beta$, e juntam-se em um conjunto os valores retornados. Em outros termos, o halo da expressão complexa all $\beta$ é derivado composicionalmente dos halos de suas partes (o halo de all regulador do quanto de desvio é pragmaticamente permissível - e o halo de $\beta$ ). Lasersohn (1999) propõe a seguinte formalização para o halo de all $\beta$ :

$$
\text { ii. } \quad H c(\text { all } \beta)=\left\{\mathrm{x}: \exists \mathrm{y}\left[\forall \mathrm{z} \mathrm{y} \leq_{\beta, \mathrm{C}} \mathrm{z} \& \exists f[f \in H c(\text { all }) \& f(\mathrm{y})=\mathrm{x}]\right\}\right.
$$

y quantificado existencialmente em (ii) é o ponto central do halo de $\beta$, i.e., o conjunto denotado por $\beta$; já $z$, quantificado universalmente, consiste em todos os elementos do halo ordenados em relação ao ponto central y. Basicamente, "a idéia [...] é recobrar o ponto central do halo de $\beta$, aplicando as funções no halo de all [...] sobre esse ponto central" (LASERSOHN 1999: 549). Desse modo, o halo de all the townspeople, por exemplo, consistirá no conjunto de conjuntos(s) do halo de the townspeople "sob alguma função $f$ que pragmaticamente se aproxima da função de identidade" (LASERSOHN 1999: 549) i.e., no conjunto do(s) conjunto(s) mais próximo(s) da denotação de the townspeople.

Notem que a formalização em (ii) junta em um conjunto os valores que as funções no halo de all retornam quando aplicadas ao ponto central $\mathrm{y}^{53}$. O que o operador all faz, portanto, é "reajustar o halo pragmático das expressões com as quais ele se combina" (LASERSOHN 1999: 527). No exemplo (95), all the townspeople elimina do halo da expressão the townspeople os elementos mais distantes do ponto central da denotação da expressão, i.e., os conjuntos mais distantes do conjunto dos moradores da cidade.

\section{APÊNDICE II}

Assumindo, tal como Lasersohn, que a denotação de kar, do ponto de vista das condições de verdade, é semanticamente trivial, pois denota uma função identidade, dado o contexto que formulamos na seção 2.8, os halos de kanhgág e kaingang kar serão respectivamente os seguintes:

\footnotetext{
${ }^{53}$ Vale destacar que, dado que o halo de all é um conjunto de funções que se diferenciam da função de identidade apenas em questões irrelevantes pragmaticamente, Lasersohn (1999), na formalização (99), apenas apresenta a própria função identidade. Uma formalização mais precisa talvez seria uma que conseguisse evidenciar as funções do halo de all retornando os conjuntos mais próximos do ponto central.
} 
i. $\quad H c\left(\right.$ kanhang): $\left\{\exists \mathrm{Y}: \forall Z \mathrm{Y} \leq_{\beta, \mathrm{C}} \mathrm{Z}\right\}$, onde

$\mathbf{Y}=\{\mathrm{x}: \mathrm{x}$ é kaingang $\}$;

$\mathbf{Z}=\{\{\mathrm{x}: \mathrm{x}$ é kainhang $\},\{\mathrm{x}$ : $\mathrm{x}$ é kaingang, mas não é paralítico $\}\}$,

\{x: x é kaingang, mas não é bebê $\},\{x$ : x é kaingang, mas não é muito idoso\},

ii. $\quad \boldsymbol{H c}$ (kanhgág kar) $=\left\{\mathrm{X}: \exists \mathrm{Y}\left[\forall \mathrm{Z} \mathrm{Y} \leq_{\beta, \mathrm{C}} \mathrm{Z} \& \exists f[f \in H c(\right.\right.$ all $) \& f(\mathrm{Y})$

$=\mathrm{X}]\}$, onde

$\mathbf{Y}=\{\mathrm{x}$ : $\mathrm{x}$ é kaingang $\}$;

$\mathbf{Z}==\{\{\mathrm{x}$ : $\mathrm{x}$ é kainhang $\},\{\mathrm{x}$ : $\mathrm{x}$ é kaingang, mas não é paralítico $\}\}$, \{x: x é kaingang, mas não é bebê $\},\{x$ : x é Kaingang, mas não é muito idoso\},

$f$ é alguma função que, quando aplicada sobre o domínio Y, retorna o conjunto ordenado mais próximo de $\mathrm{Y}$, i.e., $\{\mathrm{x}$ : x é kaingang, mas não é paralítico\}

$\mathbf{X}$ é $\{\mathrm{x}$ : x é kaingang, mas não é paralítico $\}$;

Assim, em (ii) kar reajusta o halo pragmático da denotação da expressão kanhgág.

\section{APÊNDICE III}

O halo de kasor kar ag em (83), dado o contexto formulado na seção 2.8, seria o seguinte:

i. $\quad \boldsymbol{H c}\left(\right.$ kasor C kar ag) $=\left\{\mathrm{X}: \exists \mathrm{C} \cap \mathrm{Y}\left[\forall Z: \mathrm{C} \cap \mathrm{Y} \leq_{\beta, \mathrm{C}} \mathrm{Z} \& \exists f[f \in\right.\right.$ $H c$ (all) $\& f(\mathrm{C})=\mathrm{X}]\}$, onde

$\mathbf{C} \cap \mathbf{Y}=\{\{\mathrm{x}: \mathrm{x}$ é cachorro da aldeia $\} \cap\{\mathrm{x}: \mathrm{x}$ é cachorro $\}\}$ 
$\mathbf{Z}=\{\{\mathrm{x}: \mathrm{x}$ é cachorro da aldeia, mas não está gravemente doente $\}$, $\{\mathrm{x}$ : $\mathrm{x}$ é cachorro, mas não é filhote $\},\{\mathrm{x}$ : $\mathrm{x}$ é cachorro da aldeia, mas não é muito manso \} \};

$f$ é alguma função que, quando aplicada sobre o domínio $\mathrm{C}$, retorna o conjunto ordenado mais próximo de $\mathrm{C}$, i.e., $\{\mathrm{x}$ : x é cachorro da aldeia, mas não está gravemente doente\};

$\mathbf{X}$ é $\{\mathrm{x}: \mathrm{x} \text { é cachorro da aldeia, mas não está gravemente doente }\}^{54}$.

\footnotetext{
${ }^{54}$ Além disso, uma vez que toda expressão possui seu halo pragmático (Lasersohn 1999), e a denotação de $a g$ em (83) fecha o valor da variável C sob um operador max, que cria um indivíduo supremum a partir do conjunto de cachorros saliente no contexto, o halo de ag, aplicado ao halo de kasor kar, cria um indivíduo a partir do conjunto $\{\{\{\mathrm{x}$ : $\mathrm{x}$ é cachorro da aldeia $\} \cap\{\mathrm{x}$ : $\mathrm{x}$ é cachorro $\}\}$, mas $\mathrm{x}$ não está gravemente doente\}\}. Com efeito, podemos sugerir que o halo de $\beta+a g$ seja o seguinte:

$$
\text { i. } \quad \mathbf{H c}(\boldsymbol{\beta}+\boldsymbol{a g})=\{\sigma \mathrm{X}: \sigma \mathrm{C} \in(\mathrm{C} \cap \mathrm{Y}) \& \sigma \mathrm{C} \leq \sigma \mathrm{X}\}
$$

Relativo a um contexto pragmático, o halo de $a g \beta$ será o conjunto do(s) indivíduo(s) $\sigma$ soma máxima do(s) $\mathrm{X}$, tal que $\sigma X$ está em relação de ordenação $-\sigma \mathrm{C} \leq \sigma \mathrm{X}$ - com o ponto central do halo, que é a extensão $\sigma$ da variável $\mathrm{C}$, e cujo valor é um conjunto saliente no contexto. Certamente, (i) é trivial, mas apenas o ilustramos de moda a reforçar ainda mais para o leitor que no modelo proposto por Lasersohn (1999) podemos derivar composicionalmente o halo de todas as expressões que compõem uma sentença. Assim, do mesmo modo que a denotação de um DP definido plural é um conjunto que pode ser mapeado em um indivíduo plural, o halo pragmático de um DP definido plural pode também ser mapeado de um conjunto em um indivíduo plural.
} 


\section{CAPÍTULO 3: O COMPORTAMENTO DE KAR NA SENTENÇA E SUA INTERAÇÃO COM OUTROS TERMOS E O OPERADOR DISTRIBUTIVO INTRODUZIDO VIA REDUPLICAÇÃO VERBAL.}

\subsection{Considerações iniciais.}

Neste capítulo observaremos o comportamento da expressão kar (todos) na sentença. Verificaremos as leituras de sentenças com DPs nos quais ocorre kar. Atentaremos para sentenças com $N P+k a r a g$ em interação com indefinidos, numerais, operador de negação, assim como os tipos de predicados verbais com os quais $N P+k a r+a g$ pode co-ocorrer. Também investigaremos a interação de $N P+k a r+a g$ com um operador distributivo introduzido via reduplicação verbal, de forma a entender quando leituras distributivas e/ou coletivas são permitidas.

Assim, este capítulo está organizado da seguinte maneira. Na seção 3.2, apresentaremos a metodologia empregada nos testes com as informantes nativas. $\mathrm{Na}$ seção 3.3, investigaremos o comportamento de kar nas sentenças e sua interação com o operador distributivo introduzido via reduplicação verbal. Na seção 3.4, proporemos, com base nas leituras atribuídas às sentenças pelos informantes, que o operador distributivo tem escopo sobre todo o VP, distribuindo o predicado verbal a cada indivíduo atômico na extensão do DP sujeito. Por fim, na seção 3.5, faremos as considerações finais.

\subsection{A Metodologia dos testes.}

Os dados e generalizações nesta seção resultaram de trabalho de campo realizado basicamente com duas informantes bilíngues (não linguistas) falantes nativas do Kaingang Paranaense, e fluentes em Português Brasileiro: Gilda Kuitá, de meiaidade, e Cristina Bandeira, de aproximadamente 30 anos. Gilda é professora aposentada de Kaingang e Cristina cursa o Ensino Superior de Enfermagem.

Os dados foram coletados espaçadamente durante o período de um ano. Uma parte dos dados foi coletada durante a estadia de 10 dias na reserva Kaingang do Apucaraninha, localizada na confluência dos rios Apucarana e Apucaraninha com o rio 
Tibagi, município de Londrina, PR. A outra parte, no município de Maringá, também no estado do Paraná, onde uma das informantes reside.

O método empregado consiste em elicitar dos informantes julgamentos sobre condições de verdade das sentenças, de modo a verificar se determinado número de sentenças apresentam mais de uma possível leitura. Parte-se do pressuposto metodológico de que, quando elicitado para julgar se uma dada sentença pode ser verdadeira em um dado contexto modelado, o informante se comporta (i) como quem pretende enunciar algo verdadeiro e como quem (ii) acredita que a sentença que ele enuncia seja verdadeira quando ele a enuncia ${ }^{55}$.

Basicamente, um contexto é primeiramente descrito ou ilustrado com desenhos, como em (93), contexto para testar leitura distributiva. Em seguida, uma sentença potencialmente ambígua é apresentada ao informante, como (94), e perguntado a ele se a sentença pode ser verdadeira naquele contexto. As duas informantes, por exemplo, rejeitaram a sentença (93) no contexto (94),

93. Contexto: Tem 3 kaingangs. Cada um dos 3 construiu, individualmente, 3 casas, de forma que 9 casas foram construídas.

$\begin{array}{cccccccc}\text { 94. Kaingag } & \text { kar } & \text { ag } & \text { vỹ } & \text { in } & \text { tãgtũ } & \text { han } & \emptyset \\ \text { kaingang } & \text { total } & \text { D.pl } & \text { m.s } & \text { casa } & \text { três } & \text { fazer } & \text { ASP } \\ \text { 'Todos os kaingangs fizeram } & \text { (coletivamente) três casas' }\end{array}$

Além da descrição de um contexto, sempre que possível, adicionamos desenhos feitos no computador, de maneira a clarificar ainda mais o contexto no qual queríamos testar uma sentença. Por exemplo, o contexto (93) foi ilustrado com a figura abaixo:

\footnotetext{
${ }^{55}$ Sobre questões metodológicas envolvendo uma semântica de condições de verdade, ver, por exemplo, o livro Inquiries into Truth and Interpretation, de Donald Davidson (2001)
} 

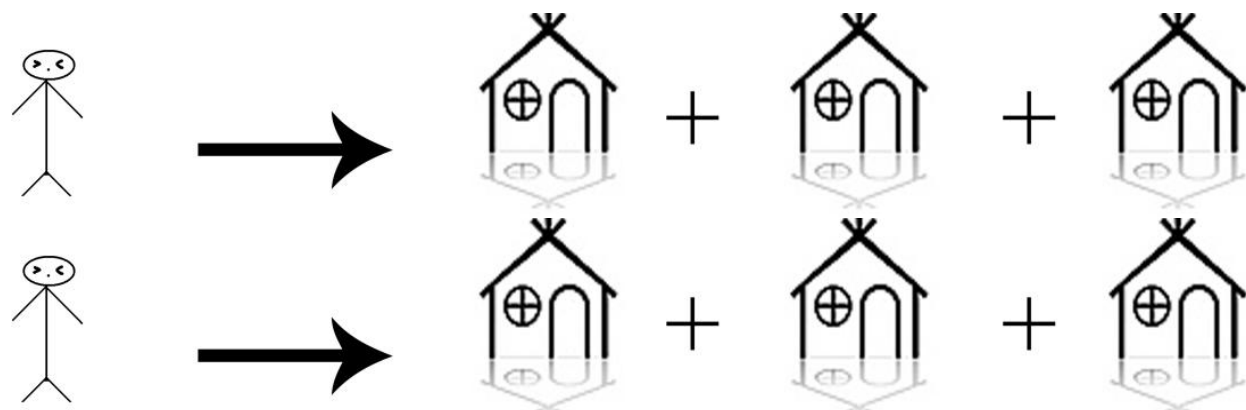

象
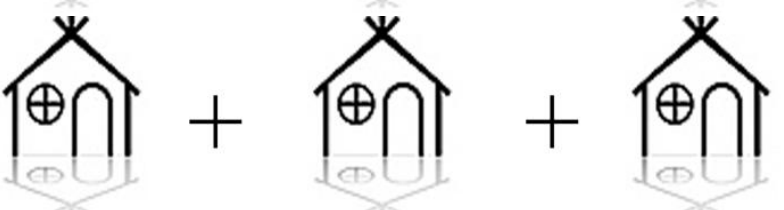

Assim, resultados como os de acima, induzem a firmação de que a leitura distributiva apresentada no contexto (93) é rejeitada em uma sentença como (94).

Passemos agora aos dados.

\subsection{A expressão kar e sua interação com outros elementos na sentença.}

Como defendido no capítulo 2, o termo kar é um constituinte que sempre carrega a ideia de totalidade. A sua presença na sentença exige que todos (ou quase todos) os indivíduos de um conjunto tomem parte em uma ação, e, por isso, sustentamos, no esteio de Lasersohn (1999), que kar é um modificador com a função de regular o quanto de desvio pragmático em relação às condições de verdade da sentença é permitido. Agora olhemos para a sua interação com outros termos na sentença.

\subsubsection{Interação com predicados coletivos.}


Os testes confirmaram a previsão de que, por ser um modificador, uma expressão sem força quantificacional e, portanto, neutra quanto à propriedade de distributividade, $k a r$ pode co-ocorrer com predicados coletivos ${ }^{56}$.

$\begin{array}{rlllll}\text { 95. a. Gĩr kar } & \text { ag } & \text { vỹ } & \text { escola } & \text { gĩn } & \emptyset . \\ \text { criança total } & \text { D.pl } & \text { m.s } & \text { escola } & \text { cercar } & \text { ASP }\end{array}$

'Todas as crianças cercaram a escola'

b. Gĩr kar ag jagnẽ kato tẽ escola tá $\emptyset$. criança total D.pl pron.rec encontrar escola ind.cir ASP 'Todas as crianças se encontraram na escola'

$\begin{array}{llll}\text { c. Gĩr } & \text { kar } & \text { jagnẽ hã } & \text { nỹtĩ. } \\ \text { criança } & \text { total } & \text { semelhante } & \text { ser }\end{array}$

'Todas as crianças são parecidas.'

$\begin{array}{lllllll}\text { d. Gĩr } & \text { kar } \quad \text { ag } & \text { in } & \text { tag } & \text { ki } & \text { jagnẽ } & \text { mré nỹtĩ. } \\ \text { criança } & \text { todos } & \text { D.pl } & \text { casa pron.dem ind.circ pron.rec } & \text { morar } \\ \text { 'Todas as crianças moram juntas nesta casa' } & & \end{array}$

\footnotetext{
56 Somos cientes de propostas que questionam a distinção tradicional entre predicados coletivos, distributivos e mistos, como as proposta de Dowty (1987), Winter (2002) e Brisson (2003). Em Brisson (2003), por exemplo, a agramaticalidade de sentenças como *All the students are a good team resulta do fato de que com all não são possíveis estados coletivos, que "são casos genuínos de predicação de 'grupo", (BRISSON 2001: 170). Para Brisson, a possibilidade de all ocorrer com predicados tradicionalmente considerados coletivos, como reunir-se, cercar, etc., é porque tais predicados disparam um operador distributivo com qual all interage. A leitura coletiva desses predicados resultaria da posição em que o operador distributivo é inserido na árvore sintática e da sua interação com um subcomponente DO da denotação desses verbos, que, no modelo da autora, seria um núcleo aspectual licensiado pelo significado do próprio predicado verbal. A autora argumenta que "uma vez que all é dependente da distributividade [introduzida pelo predicado verbal], ele não é permitido com estados coletivos..." (BRISSON 2001; 171). Assim, em predicados coomo to be a good team, genuínos predicados coletivos, "não há uma distributividade presente para all operar sobre" (Brisson 2003: 170). Como em Kaingang o operador distributivo parece ser introduzido somente via reduplicação verbal, pois até mesmo com predicados classificados como mistos, como construir uma casa, a leitura distributiva só é possível quando o verbo é reduplicado, e como não tivemos tempo de investigar se kar pode ocorrer com predicados, em Kaingang, semelhantes a to be a good team, não trataremos dessas questões aqui. Entendemos que a tipologia tradicional formulada em Vendler (1967) seja suficiente, nas suas linhas gerais, para a análise que realizaremos dos dados apresentados neste capítulo.
} 


\subsubsection{Interação com numerais.}

Em sentenças com kar ocorrendo em um DP sujeito e um numeral em um DP objeto, como em (97), a leitura que descreve a situação A em (96) foi aceita pelos informantes, i.e., a coletiva, mas a distributiva, a que descreve B, foi rejeitada ${ }^{57}{ }^{58}$ :

96.

Cenário A: Há 5 kaingangs e 2 casas. Os 5 construíram as 2 casas juntos.

Cenário B: Há 5 kaingangs e 10 casas. Cada um construiu duas casas.

97. Kanhgág kar ag vỹ ĩn régre han $\emptyset$.
kaingang total D.pl m.s casa dois fazer ASP
'Todos os kaingangs fizeram duas casas'

$(\mathbf{V}-\mathbf{A} / \mathbf{F}-\mathbf{B})$

É importante destacar que sem kar, como em (98),

98. Kanhgág ag vỹ ĩn régre han $\emptyset$.
kaingang D.pl m.s casa dois fazer ASP
'Os kaingangs fizeram duas casas'

também a única interpretação que os informantes deram foi a coletiva. A única diferença percebida entre (97) e (98) é que, como esperado, os informantes não foram tão rigorosos quanto à exigência de que (98) descreva contextos em que nenhum, ou quase nenhum, indivíduo (membro de um conjunto fixado contextualmente) fique fora da construção de duas casas. O que reforça ainda mais a hipótese de que kar seja apenas um modificador, e que sua contribuição não afeta as condições de verdade da sentença, mas que tão somente opera no nível pragmático.

A leitura distributiva foi apenas possível (aliás a única possível) quando houve reduplicação da raiz verbal, han-han he ${ }^{59}$, como em (99):

\footnotetext{
${ }^{57}$ Os informantes não aceitaram nem mesmo uma leitura cumulativa de (97).

${ }^{58}$ Nesta seção, usaremos $\mathrm{V}$ para quando a sentença for verdadeira em um dado cenário, e $\mathrm{F}$ para quando ela for falsa.
} 


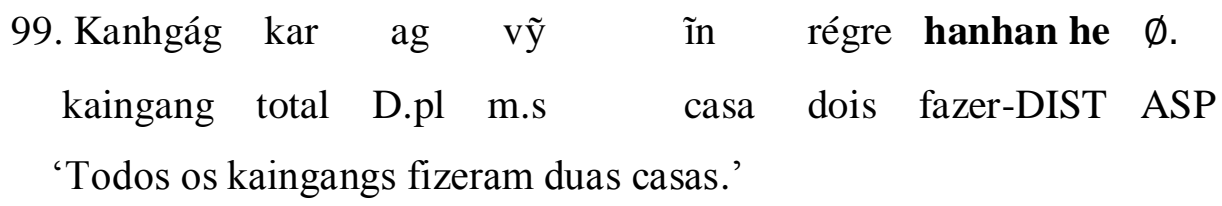

(F-A/V-B)

Como notou Gil (1995), em muitas línguas a maioria das interpretações distributivas é forçada por mecanismos morfossintáticos disponíveis nas línguas. Em Kaingang, como muitas línguas indígenas, por exemplo, a interpretação distributiva é forçada pela reduplicação parcial ou total do verbo, como em (99), que é um mecanismo formal adicionado à complexidade morfossintática de uma construção como (97). Assim, com a reduplicação do verbo han (fazer), a leitura distributiva se torna obrigatória, podendo (99) ser verdadeira em um cenário como B.

Parece que a maioria das formas plurais dos verbos em Kaingang não tem função de concordância com seus argumentos, mas sim de distribuir eventos de acordo com o número de participantes e no tempo ${ }^{60}$. Este fenômeno é um tipo de pluracionalidade, categoria morfológica que indica alguma forma de multiplicidade na leitura semântica do verbo ${ }^{61}{ }^{62}$. De modo geral, os verbos pluracionais em Kaingang são formados por reduplicação completa ou parcial da raiz verbal, e por vezes com acréscimo de mais uma partícula ao morfema reduplicado. Os resultados de testes realizados com os informantes sugerem que o afixo reduplicado é um operador distributivo que opera sobre todo o VP, aplicando o predicado verbal, como na sentença

\footnotetext{
${ }^{59}$ Em alguns verbos, além da reduplicação, há também acréscimo de alguma partícula (complicação morfológica que não afeta a nossa análise), como he em (99). Em mais de um verbo, os informantes não aceitaram a forma pluracional do verbo sem o acréscimo da partícula he: han/hanhan he (fazer); velveve he (ver); kute/kute kute he. Em função disso, deduzimos que em tais verbos he é uma partícula que compõe a sua forma pluracional, mas não sabemos explicar porque em certos verbos ela é obrigatória e em outros é descartada

${ }^{60}$ D'Angelis (2004) foi o primeiro, e, até onde sabemos, o único a notar que em Kaingang a reduplicação verbal denota multiplicidade de eventos.

${ }^{61}$ Newman (1990) distingue entre dois tipos de pluralidade verbal: pluralidade flexional e pluralidade derivacional . Esses dois tipos são definidos como se segue:
}

i. Pluralidade Flexional: concordância com os argumentos da sentença, como no caso do Português, em que o verbo concorda em número com o sujeito (ex: Eles pintaram a casa)

ii. Pluralidade derivacional: pluralidade semântica do evento denotado pelo predicado verbal, e não possui a função de concordância com os argumentos do verbo.

Pluralidade derivacional é o que se denomina mais comumente de pluracicionalidade.

${ }^{62}$ Os marcadores de pluracionalidade, que podem ser tanto morfemas, frequentemente reduplicativos, que se afixam ao verbo, ou uma forma supletiva do verbo, de modo geral indicam multiplicidade de eventos (Cusic 1981; Lasersohn 1995; Ojeda 1998). 
(99), aos indivíduos atômicos na extensão so sujeito. ${ }^{63}$ Nos testes com verbos transitivos - ao menos - o operador distributivo parece operar sobre todo o VP.

Contudo, em Kaingang, encontramos tanto leituras distributivas baseadas nos participantes (Lasersohn 1995) - atribuindo o predicado verbal a cada participante quanto leituras que distribuem os eventos no tempo. Portanto, mais testes precisam ser realizados com outras classes de verbo, pois supomos que, em Kaingang, a variedade de possibilidades de leituras distributivas está intimamente ligada às classes lexicais do verbo.

Para o objetivo principal deste capítulo, todavia, que é o de verificar o comportamento de kar na sentença, a leitura distributiva baseada nos participantes será suficiente. ${ }^{64}$ Além disso, para a explicação dos dados que apresentaremos, não será necessário tratar os verbos como predicados de eventos ligados aos seus argumentos através de papéis temáticos, i.e., não adaptaremos o operador distributivo para tomar eventos. Optamos, por isso, pelo simples princípio metodológico da economia, segundo o qual só se deve introduzir novas entidades quando necessário para explicar os dados. Mas que fique claro que consideramos que para um estudo mais detalhado, em $\underline{\text { Kaingang, do fenômeno da distributividade verbal, em particular, e da pluracionalidade, }}$ em geral, e que leve em conta as várias classes de verbos, uma semântica de eventos será necessária.

Após essa breve, mas importante, justificação da razão de não adotarmos uma semântica de eventos para tratar, no presente capítulo, da interação de kar com verbos reduplicados, voltemos à análise dos dados.

\subsubsection{Interação com verbos de experiência.}

Em sentenças com verbos de experiência em que kar ocorre em um DP objeto, a leitura distributiva somente se torna obrigatória quando o verbo é reduplicado, como em

\footnotetext{
${ }^{63} \mathrm{Em}$ (103), o número de casas é multiplicado pelo número de kaingangs.

${ }^{64}$ Em inglês a distributividade pode ser forçada com a expressão adverbial apice, em Maricopa por meio do afixo -xper sufixado ao verbo, em Turco o numeral núcleo do DP objeto é marcado com o sufixo -er, etc. Para exemplos de sentenças com esses mecanismos formais adicionados, ver Gil (1995).
} 
(101b). Sem reduplicação do verbo, como em (101a), tanto a leitura distributiva quanto a leitura coletiva são possíveis ${ }^{65}$, embora a coletiva seja mais saliente ${ }^{6667}$.

100.

Cenário A: Todas as crianças estavam reunidas no pátio da escola, e o cacique olhou todas elas de uma só vez, i.e, um único evento de olhar.

Cenário B: O cacique recebeu as crianças, uma por uma, numa sala, i.e, vários eventos de olhar as crianças.

$\begin{array}{llllllr}\text { 101a. Pa'i } & \text { vỹ } & \text { gĩ } & \text { kar } & \text { ag } & \text { ve } & \emptyset . \\ \text { cacique } & \text { m.s } & \text { criança total } & \text { D.pl } & \text { olhar } & \text { ASP } \\ \text { 'O cacique olhou todas as crianças' }\end{array}$

(V-A/V-B)

$\begin{array}{llllllr}\text { b. Pa'i } & \text { vỹ } & \text { gĩ } & \text { kar } & \text { ag } & \text { veve he }^{68} & \emptyset . \\ \text { cacique } & \text { m.s } & \text { criança } & \text { total } & \text { D.pl } & \text { olhar-DIST } & \text { ASP } \\ \text { 'O cacique olhou todas as crianças' }\end{array}$

(V-B/F-A)

\subsubsection{Interação com indefinidos.}

Olhemos agora para uma sentença em que kar ocupa um DP objeto e um indefinido ocupa um DP sujeito. Observem o par de sentenças em (103).

${ }^{65}$ Embora os informantes tenham considerado possível uma leitura distributiva para (101a), a interpretação coletiva foi mais saliente.

${ }^{66}$ Em sentenças como $(101 \mathrm{a} / \mathrm{b})$, mas sem $k a r$, as mesmas leituras foram observadas.

${ }^{67}$ É interessante notar que em Inglês, com verbos de experiência, como look (olhar), uma sentença com all+DP na posição de objeto, como em (i), pode receber leituras coletiva e distributiva (Beghelli \& Stowell 1997):

i. The Pope looked at all the members of his flock.

D papa olhar-PAST prep todos D membros de pron.pos rebanho

'O Papa olhou todos os membros de seu rebanho'

(Beghelli \& Stowell 1997: 88)

${ }^{68}$ Daqui em diante, substituiremos a glosa PLR (pluracionalidade) por DIST (distributividade), de modo a especificar na glosa a função que a reduplicação verbal está desempenhando. 
Cenário A: tem 1 kaingang e 3 casas. O kainhang construiu as 3.

Cenário B: 1 kaingang para cada casa.

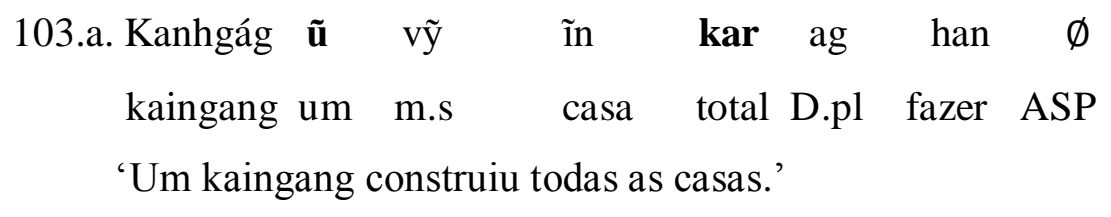

(V-A/F-B)
b. Kanhgág ũ vỹ in kar ag hanhan he $\emptyset$. kaingang um m.s casa total D.pl fazer-DIST ASP
'Um kaingang construiu todas as casas.'

$(\mathrm{V}-\mathrm{A} / \mathrm{F}-\mathrm{B})$

Notem que tanto em (103a) quanto em (103b) a única leitura permitida é de que um único homem construiu todas as casas, como num cenário igual à $\mathrm{A}$. Nem mesmo com a reduplicação verbal a interpretação de escopo inverso de in kar ag foi permitida. O que pode sugerir que a reduplicação verbal não induz uma leitura distributiva de escopo inverso do termo objeto ${ }^{69}$.

Um fato interessante é que em sentenças com numeral ocorrendo em um DP objeto, a reduplicação do verbo também não permitiu leitura distributiva de escopo inverso. Em uma sentença como

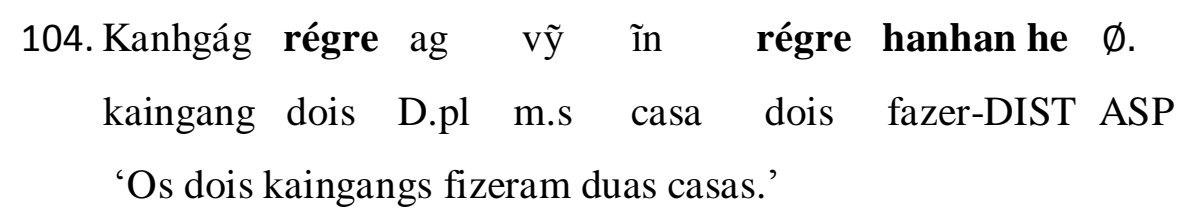

\footnotetext{
${ }^{69}$ Com um indefinido ocupando um DP objeto, e kar um DP sujeito, tal como no exemplo (99), em que um numeral ocupando um DP objeto, a leitura distributiva só foi aceita pelas informantes quando houve reduplicação verbal:

i. Kanhgág kar ag vỹ in $\quad$ u $\quad$ han $\varnothing$.

kaingang total D.pl m.s casa um fazer ASP

'Todos os kaingangs fizeram um casa.'

Assim, em (i) a leitura é de que cada kaingang construiu uma casa.
} 
a única interpretação possível é de que cada kaingang fez 2 casas, totalizando 4 casas. Ou seja, o número de casas foi multiplicado pelo número de kaingangs ${ }^{70}$. Fato que também pode sugerir que a reduplicação verbal não induz uma leitura distributiva de escopo inverso do termo objeto, i.e., que o Kaingaing seja uma língua que não permite leituras distributivas de escopo inverso.

Em (103a) e (103b) - contextos com entonação neutra - a única interpretação permitida, portanto, é com kanhgág ũ tendo escopo sobre in kar ag.

\subsubsection{Interação com um operador de negação.}

DPs com a estrutura $N P+k a r+a g$, quando na posição de objeto, podem tanto ter escopo sobre quanto sob um operador de negação. Considerem a sentença (107):

105.

Cenário A: Manoel ganhou 6 livros há um ano e ainda não leu nenhum deles.

Cenário B: Manoel ganhou 6 livros há um ano e ainda só lei 3.

106. Manoel vỹ vẽnhrá kar ag to ke tũ $\quad$ nĩ.
Manoel m.s livro total $\quad$ D.pl ler
'Manoel não leu todos os livros'

(V-A/V-B,)

Em (106), vẽnhrá kar ag pode ter escopo sobre o operador de negação tũ, resultando em uma interpretação que pode ser verdadeira em um cenário como A (leitura mais saliente para as informantes), i.e., em que Manoel não leu nenhum dos 6 livros que ganhou. Por sua vez, (106) pode também receber uma interpretação em que o

\footnotetext{
${ }^{70}$ Também em Inglês, em uma sentença como

$\begin{array}{llllll}\text { i. A } & \text { boy } & \text { read } & \text { all } & \text { the } & \text { books } \\ \text { um garoto } & \text { ler-PAST } & \text { todos } & \text { D } & \text { livros } \\ \text { 'Um garoto leu todos os livros' } & & & \end{array}$

(adaptado de Beghelli \& Stowell 1997:96)

a única leitura possível é com all the books tendo escopo sob a boy.
} 
operador de negação tũ tem escopo sobre vẽnhrá kar ag, i.e, uma interpretação que pode ser verdadeira em um cenário como B, em que Manoel leu 3 dos 6 livros que ganhou ${ }^{71}$.

\subsubsection{Número gramatical, variável ligada e distributividade verbal.}

Quanto ao número gramatical de kar, o fato de tanto construções como kanhagág kar e kanhgág kar ag, i.e., com ou sem o determinate plural, licenciarem pronomes plurais como variáveis ligadas, parece sugerir que kar seja semanticamente plural.

Considerem os pares de sentenças abaixo:

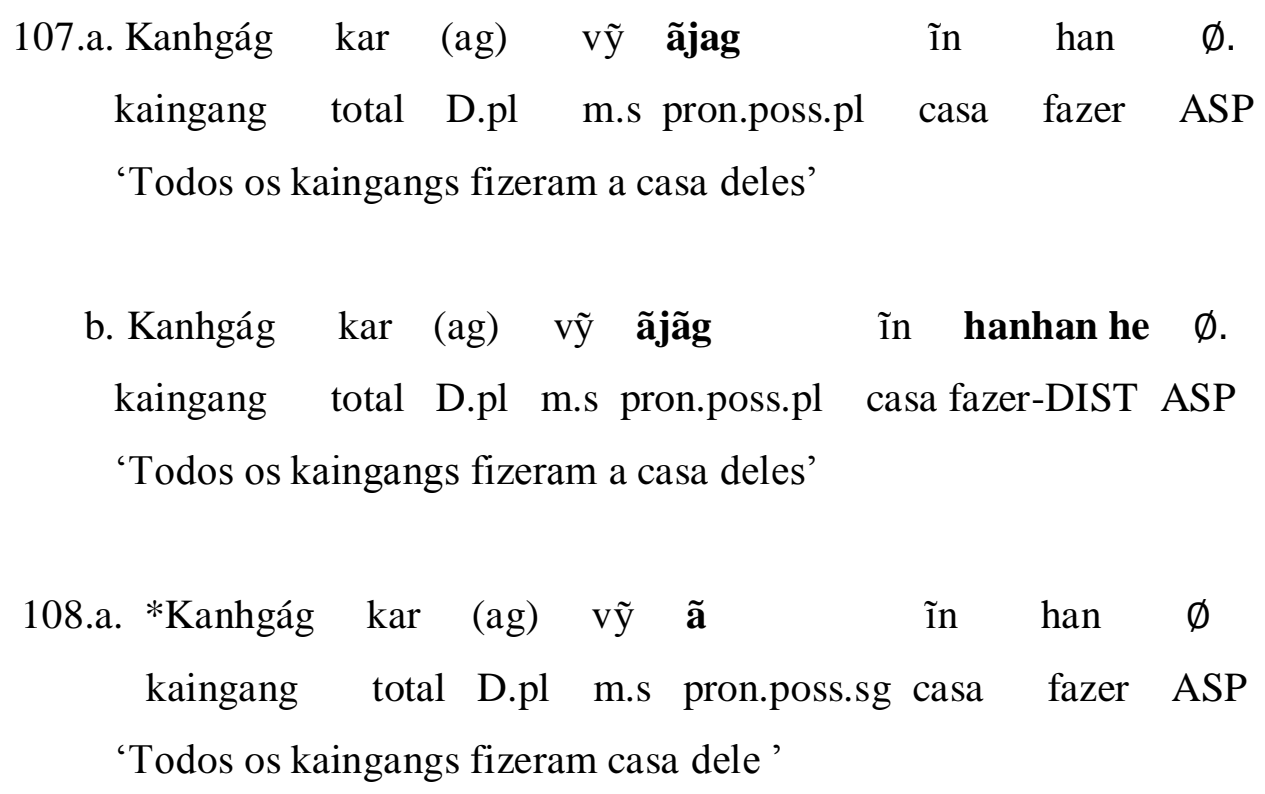

\footnotetext{
${ }^{71}$ Em Inglês, também ambas as leituras são possíveis, como no exemplo abaixo:

i. John didn't read all the books.

João NEG-PAST ler todos D livros

'João não leu todos os livros'

(Begheli \& Stowell 1997: (30b)

Em que all the books pode ter escopo sobre e sob o operador de negação. Não havendo influência de entonação quando realizado o teste da sentença (107), a interpretação que descreve um contexto como A pode sugerir que, semanticamente, kar, além de ser uma função identidade, também pode interagir com outros termos na sentença, gerando ambiguidade de escopo. Todavia, para estarmos mais certos disso, precisamos investigar se em uma sentença como (107), mas sem a presença de kar, ambas as leituras são também possíveis. (107) e (i) podem, assim, ser dados que exijam que a proposta de Lasersohn (1999) sofra algumas modificações para que eles sejam abarcados.
} 


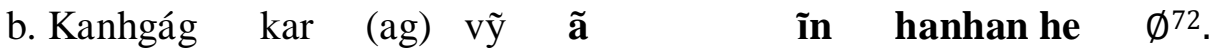 kaingang total D.pl m.s pron.poss.sg casa fazer-DIST ASP 'Todos os kaingangs fizeram casa dele.'}

Notem que em (107b) o verbo foi reduplicado, o que resulta na interpretação de que cada kaingang construiu a sua própria casa. Já (108a), por sua vez, com o pronome no singular e verbo não reduplicado, foi rejeitada pelos falantes.

É importante observar que uma evidência forte para a generalização de que a reduplicação verbal em Kaingang introduz um operador distributivo, ao menos em verbos accomplishment, está no fato de que quando o verbo de uma sentença rejeitada pelos informantes, como (108a), é reduplicado, a sentença é aceita pelos informantes, como em (108b), sugerindo que o pronome pural em (107b) só está ali por razão de mera concordância. Desse modo, em (108b) - ao contrário de (189a) - o pronome singular $\tilde{\boldsymbol{a}}$ pode ser ligado pela expressão plural kanhgág $\boldsymbol{k a r}$ ag, exatamente em uma sentença em que o verbo ocorre na sua forma reduplicada hanhan he (fazer). Já quando o pronome singular $\tilde{\boldsymbol{a}}$, em sentenças com o verbo não reduplicado, como em (108a), é ligado por kanhgág kar ag, essas sentenças são rejeitadas pelos falantes. Enquanto (107a) é verdadeira tanto em contextos em que os kaingangs se ajudaram na construção de suas casas, quanto em contextos em que cada kaingang construiu sua própria casa, (107b) e (107b) - em função da reduplicação verbal - somente são verdadeiras em contextos em que cada kaingang construiu sua própria casa, i.e, as leituras são necessariamente distributivas. Assim, (107b) e (108b) são semânticamente equivalentes.

Casos bem interessantes que também corroboram a hipótese de que a reduplicação verbal em Kaingang introduz um operador distributivo são sentenças com variáveis ligadas em que o nome na posição de objeto aparece tanto na sua forma singular - kosin (filho) - quanto na sua forma plural - krẽ (filhos). Observem as sentenças abaixo:

$$
\begin{aligned}
& \text { 109. a.Kanhgág kar fag vỹ ãjag krẽ } \quad \text { kype } \varnothing \text {. } \\
& \text { kaingang total D.pl m.s pron.poss.pl filhos banhar ASP } \\
& \text { 'Todas as kaingangs banharam seus filhos' }
\end{aligned}
$$

\footnotetext{
${ }^{72}$ No dialeto paranaense os possessivos ã/ãjag podem ser possessivos de segunda e terceira pessoa. Isto é, podem tanto significar dele(s)/dela(s) quanto de você(s). Por isso, decidimos traduzir ã/ãjag como $\operatorname{seu}(s) / \operatorname{sua}(s)$, já que em Português Brasileiro seu(s)/sua(s) também podem significar tanto dele(s)/dela(s) quanto de você( $(s)$.
} 
b.Kanhgág kar fag vỹ ãjãg krẽ kype pe $\varnothing$.

kaingang total D.pl m.s pron.poss.pl crianças banhar-DIST ASP

'Todas as kaingangs banharam sus filhos'

c. *Kanhgág kar fag vỹ $\quad$ a $\quad$ kosin kype $\varnothing$.

kaingang total D.pl m.s pron.poss.sg criança banhar ASP

'Todas s kaingangs banharam seu filho.'

d. Kanhgág kar fag vỹ $\quad \tilde{a} \quad$ kosin $\quad$ kype pe $\varnothing$.

kaingang todos D.pl m.s pron.poss.sg criança banhar-DIST ASP

'Todas as kaingangs banharam seu filho.'

Como o leitor atento terá notado, o único ambiente em que um pronome singular $\tilde{\boldsymbol{a}}$, seguido de um substantivo singular kosin, pode ser ligado pelo DP definido plural kanhgág fag é em (109d), exatamente na sentença em que o verbo ocorre na sua forma reduplicada, kype pe (banhar). Já, em contrapartida, quando o pronome singular $\tilde{\boldsymbol{a}}$, seguido do substantivo lexicalmente singular kosin, foi ligado pelo DP definido plural na sentença com o verbo na sua forma básica, como em (109c), tal sentença foi rejeitada.

(109a) foi considerada verdadeira tanto em contextos em que as mulheres se ajudaram a banhar seus filhos, quanto em contextos em que cada mulher banhou seu(s) próprio(s) filho(s). Por outro lado, (109b), em função da reduplicação verbal, somente foi considerada verdadeira em contextos em que cada mulher banhou seu(s) próprio(s) filho(s), i.e, a leitura é distributiva. E em (109d) a única leitura aceita pelos informantes é a de para cada mulher um filho, i.e, cada mulher banhou seu próprio filho, também leitura distributiva.

Com base nas sentenças em (109a-d), entendemos que a aceitação de (109d), mais a rejeição de $(109 \mathrm{c})$, são fortes evidências de que as formas reduplicadas dos verbos em Kaingang geram leituras distributivas ${ }^{73}$.

\footnotetext{
${ }^{73}$ Sentenças com o pronome na sua forma singular e o nome na sua forma plural, independentemente de o verbo aparecer na sua forma básica ou reduplicada, foram rejeitadas pelos falantes, como em (i) e (ii) abaixo:
}

$$
\text { i. } \quad \text { *Kanhgág } \operatorname{kar} \text { fag vỹ } \quad \text { a } \quad \text { krẽ } \quad \text { kype } \emptyset \text {. }
$$




\subsection{Interpretando o operador distributivo e calculando as condições de verdade de uma sentença.}

Como demonstrado e sustentado na seção precedente, a operação de reduplicação da raiz verbal de verbos transitivos em Kaingang consiste num mecanismo morfossintático que parece introduzir um operador distributivo que tem escopo sobre o VP, atribuindo, com isso, o predicado verbal aos indivíduos na extensão do sujeito ${ }^{74}$.

Em linhas gerais, adotamos a proposta tradicional desenvolvida, sobretudo em Link (1987) e Roberts (1987), que postula um operador distributivo * operando sobre o predicado. Assim, esse operador, que usualmente é representado pela letra D ou *, ocuparia a seguinte posição na representação em árvore do verbo han (fazer):

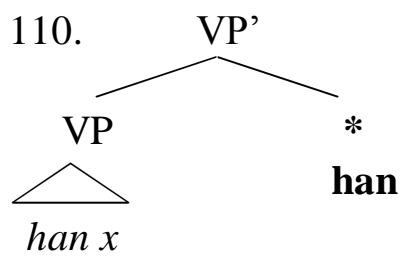

kaingang total D.pl m.s pron.poss.sg crianças banhar ASP

'Todas as kaingangs banharam seus filhos.'

ii. $\quad$ *Kanhgág kar fag vỹ $\tilde{\mathbf{a}} \quad$ krẽ $\quad$ kype pe $\quad$.

kaingang total D.pl m.s pron.poss.sg crianças banhar-DIST ASP

'Todas as kaingangs banharam seus filhos.'

Parece que a rejeição de (i) e (ii) seja por causa da não concordância entre o pronome ã (singular) e o nome krẽ (plural).

${ }^{74}$ Em verbos intransitivos, como jãn (cantar), a sua reduplicação, em uma sentença com sujeito plural, como em (i), pode gerar a leitura que atribui o perdicado verbal aos átomos em kanhgág ag.

(i) Kanhgág ag jãn-jãn $\quad$.

kaingang D.masc.pl cantar-PLR ASP

'Os kaingangs cantaram.'

Em (i) podemos ter a leitura de que, de um grupo de 5 kaingangs, por exemplo, cada um dos 5 cantou. Uma outra interpretação possível - rejeitada pelos informante nos verbos transitivos acomplishments que testamos - é de que o grupo dos 5 kaingangs, cantaram mais de uma vez. Não tratamos dessas leituras aqui por entendermos que para tal mais testes com todas as classes de verbos precisam ser realizadas. Por isso, embora neste trabalho estejamos assumindo a reduplicação verbal como mecanismo, em Kaingang, de gerar leituras distributivas, não sustentamos que a reduplicação nesta língua sfuncione apenas como operador distributivo. Até porque, como muito bem argumentou Lasersohn (1995), grande variedade de interpretações que podem ser atribuídas às marcas de pluracionalidade, por reduplicação ou supleção, demonstra que a semântica desses marcadores pode variar significativamente de língua para língua, e até mesmo no interior de uma mesma língua. 
Formalmente, utilizando o calculo lambda para representar funções, a semântica do operador * é a seguinte:

111.[[*]] $=\lambda$ P. $\lambda X . \forall x: x$ é átomo $\& x \leq X \rightarrow P(x)^{75}$

A paráfrase de (111) é

112.Para um predicado qualquer $\mathrm{P}$ e soma máxima de indivíduos $\mathrm{X}$, se $\mathrm{x}$ é átomo e parte de X, então P se aplica a X.

Assim, em uma sentença como (99), aqui repetida como (113),

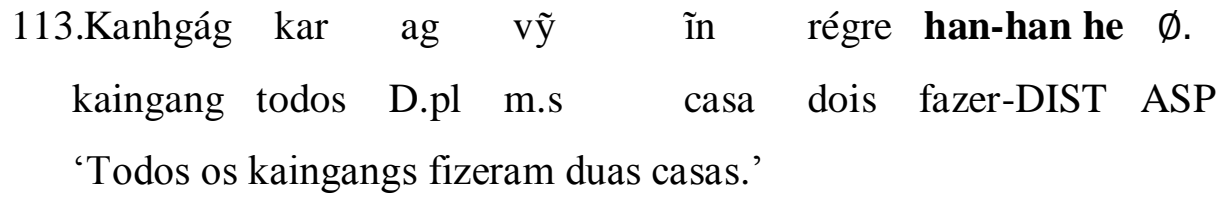

o predicado in régre han-han he (fazer duas casas) é aplicado a cada indivíduo atômico na extensão de kanhgág kar ag (todos os kaingangs). Com isso, em um contexto em que haja 3 kaingangs, haverá 6 casas, sendo que cada um dos 3 kaingangs fez 2 casas. O que significa que, em (113), o operador distributivo toma o predicado ĩn régre han e os indivíduos plurais na extensão de kanhgág kar ag e checa se todas as partes atômicas de kanhgág $\boldsymbol{k a r}$ ag estão na extensão de ĩn régre han.

De forma a ter uma visão mais nítida de como a leitura de (113) é composicionalmente gerada, calculemos, passo a passo, as condições de verdade de (113), aplicando, além da interpretação que demos para o operador distributivo introduzido via reduplicação verbal, as extensões que propusemos, no capítulo 2, para o modificador kar e o determinate definido $a g$ :

\footnotetext{
${ }^{75}$ Notem que o operador distributivo introduz quantificação universal para efetivar a distribuição.
} 
114.

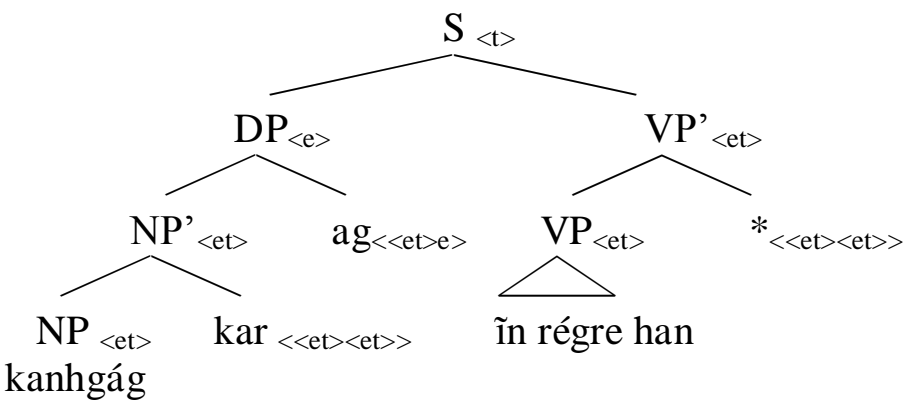

1. $[[\mathrm{S}]]=([[\mathrm{DP}]])\left[\left[\mathrm{VP}^{\prime}\right]\right]$

2. $[[\mathrm{DP}]]=\left[\left[\mathrm{NP}^{\prime}\right]\right]([[\mathrm{ag}]])$

3. $\left[\left[\mathrm{NP}^{\prime}\right]\right]=[[\mathrm{NP}]]([[\mathrm{kar}]])$

4. $\left[\left[\mathrm{VP}^{\prime}\right]\right]=([[\mathrm{VP}]])[[*]]$

5. $\left[\left[\mathrm{VP}^{\prime}\right]\right]=(\lambda \mathrm{x} . \mathrm{x}$ ĩn régre han $)[\lambda \mathrm{P} . \lambda \mathrm{X} . \forall x: x$ é átomo $\& x \leq X \rightarrow P(x)]$

6. [[VP'] $]=\lambda \mathrm{X} . \forall x: x$ é átomo $\& x \leq X \rightarrow x$ ĩn régre han

7. $\left[\left[\mathrm{NP}^{\prime}\right]\right]=(\lambda \mathrm{x} . \mathrm{x}$ é kanhgág) $[\lambda f . f]$

8. $\left[\left[\mathrm{NP}^{\prime}\right]\right]=\lambda \mathrm{x}$. $\mathrm{x}$ é kanhgág

9. $[[D P]]=(\lambda x . x$ é kanhgág $)[\lambda P \cdot \max \{x: C(x) \cap P(x)\}]$

10. $[[\mathrm{DP}]]=\max \{\mathrm{x}: \mathrm{C}(\mathrm{x}) \cap \operatorname{kanhgág}[\operatorname{kar}](\mathrm{x})\}$

11. $[[\mathrm{S}]]=(\max \{\mathrm{x}: \mathrm{C}(\mathrm{x}) \cap \operatorname{kanhgág}[\operatorname{kar}](\mathrm{x})\})[\lambda \mathrm{X} . \forall x: x$ é átomo $\& x \leq X \rightarrow$ x ĩn régre han]

12. $[[\mathrm{S}]]=1$ sse $\forall x: x$ é átomo $\& x \leq \max \{\mathrm{x}: \mathrm{C}(\mathrm{x}) \cap \operatorname{kanhgág}[\operatorname{kar}](\mathrm{x})\} \rightarrow$ $\mathrm{x}$ ĩn régre han

As condições de verdade em (114) são exatamente a que esperávamos: cada kaingang que pertence ao grupo de kaingangs denotado por kanhgág kar ag (todos os kaingangs) fez duas casas. Uma paráfrase precisa de (12) seria a seguinte: para cada kaingang $x$, se $x$ é um indivíduo atômico e $x$ está na extensão da soma máxima de kaingangs salientes no contexto, então x fez duas casas.

Assim, em uma sentença declarativa em que os termos kar e $a g$ e a reduplicação verbal ocorrem, como (113), geramos, aplicando as extensões que propusemos para eles, as condições de verdade que descrevem a interpretação das informantes.

Os dados neste capítulo apontam no sentido de uma análise de kar como modificador neutro quanto à distributividade. Como se pôde notar, com excessão dos 
verbos de experiência, todas as sentenças que apresentamos somente receberam leitura distributiva quando o verbo foi reduplicado. O Kaingang seria uma língua que contém um termo (kar) neutro quanto à distributividade, que expressa uma idéia de totalidade, e que, até onde sabemos, não possui um determinante marcadamente distributivo, como each do Inglês, cada do Português, etc. A distributividade é realizada não por um quantificador distributivo, mas via reduplicação verbal.

A título de conclusão desta seção, sugerimos que tais propriedades do Kaingang localizam a língua, na tipologia das línguas, proposta por Gil (1995), quanto à ausência ou presença de um quantificador distributivo, entre as linguas que possuem termos não distributivos, e não possui quantificadores universais distributivos.

Segundo Gil (1995), não se conhece nenhuma língua na qual existam contrapartes de quantificadores distributivos como each, mas não exista um termo com a semântica de all. E esse fato para o autor é evidência forte para a hipótese de que all, e sua contraparte translinguística, sejam primitivos semânticos, e que os quantificadores distributivos seriam termos marcados. A partir da observação de línguas tipologicamente diversas, como o Inglês, Russo, Tagalog, etc., Gil (1995) propõe a seguinte classificação das línguas quanto aos termos distributivos e não distributivos:

i. Com quantificadores universais distributivos e termos não-distributivos;

ii. com termos não distributivos e não quantificadores universais distributivos; $\mathrm{e}$

iii. com nenhum dos dois termos.

E descarta a seguinte possibilidade:

iv. Com quantificador distributivo e ausência de um termo não distributivo.

O Kaingang seria, portanto, uma língua do tipo (ii) e mais uma evidência translinguística para a hipótese do autor de que termos como kar são primitivos semânticos, portanto não marcados, e que determinantes distributivos, em função de só existirem em línguas que possuem um termo como kar, i.e., que veicula a idéia de 
totalidade e é neutro quanto à distributividade, seriam marcados e derivados dos não $\operatorname{marcados}^{76}$.

\subsection{Considerações finais.}

Neste capítulo, olhamos para o comportamento da expressão kar na sentença. Investigamos as leituras que podem receber sentenças com DP nos quais kar ocorre. Observamos sentenças com $N+k a r$ ag em interação com indefinidos, numerais, operador de negação, assim como os tipos de predicados verbais com os quais $N$ kar ag pode co-ocorrer. Também olhamos para a interação de $N+k a r+a g$ com um operador distributivo introduzido via reduplicação verbal, de forma a entender quando leituras distributivas e/ou coletivas são permitidas.

Os dados mostraram que kar é neutro quanto à distributividade e que leituras distributivas foram atribuídas às sentenças quando houve reduplicação verbal. $\mathrm{O}$ fato de as leituras distributivas atribuírem o predicado verbal aos indivíduos atômicas na extensão do DP sujeito, levou-nos a hipotetizar que a reduplicação verbal em Kaingang, ao menos para verbos accomplishment, introduz um operador distributivo que tem escopo sobre todo o VP.

\footnotetext{
${ }^{76}$ Dado que esta hipótese, sem dúvida, levanta importantes questões sobre o processo de aquisição de quantificadores em línguas naturais, colocamo-nos a seguinte pergunta: se all e kar, e suas contrapartes em outras línguas, não funcionam como quantificadores, que é o que defendemos, mas sim como reguladores de desvios pragmáticos, a hipótese de Gil (1995) poderá ser reforçada, feitas as devidas alterações, já que Gil considera all também um quantificador? Parece-nos que sim. E isso fundamentalmente por uma razão. $\mathrm{O}$ fato de all e kar não se comportarem como quantificadores genuínos, mas como modificadores, talvez decorra justamente de essas expressões serem termos semanticamente primitivos. Essa especulação não é nova. Como já referido na nota (40), Partee (1995) argumenta que o fato de o significado de all ser mais básico do que every, sugere que "talvez como um reflexo da sua própria [propriedade] de ser básico, all não seja necessariamente um determinante" (PARTEE 1995: 582). A generalização de Gil (1995) de que os quantificadores distributivos são marcados e combinam universalidade e distributividade, implica na predição testável de que every e each são mais difíceis de adquirir do que all. Por causa da maior complexidade semântica dos quantificadores universais distributivos, em uma língua que possui all e every/each, a aquisição de all deve preceder a do quantificador universal distributivo. Não conhecemos nenhum estudo que tenha testado esta predição. Contundo, Matthewson (2001) observa que, em uma conversa informal que teve com o linguista Tom Roeper, que estuda aquisição, ele a informou "de que a aquisição de all precede em muito a de every" (Matthewson 2001: 182). Fato que corrobora a predição implícita na hipótese de Gil (1995), e, consequentemente, apresenta mais uma evidência em apoio à própria hipótese.
} 


\section{CONCLUSÃO}

Conforme exposto na introdução desta dissertação, esta pesquisa se propôs a ser mais uma contribuição para os estudos translinguísticos sobre quantificação, definitude restrição de domínio e distributividade, a partir da análise desses fenômenos no dialeto paranaense da língua Kaingang, do troco Macro-Jê, família Jê.

Neste trabalho, descrevemos e analisamos, primeiramente, o comportamento semântico da expressão kar e sua interação com nomes cuja denotação é restringida contextualmente via artigo definido. Defendemos que kar parece se comportar mais como um modificador do que um quantificador quando em construções com um argumento nominal, e que, por isso, não possui uma força quantificacional própria. Hipotetizamos, em consonância com a proposta de Lasersohn (1999) para all, que kar seja um operador com a função de regular os devios pragmáticos das sentenças em relação às suas condições de verdade. Vinculado a esta hipótese e como que resultando dela, argumentamos que o artigo definido no Kaingang Paranaense, quando operando sobre $N P+k a r$ não perde a sua função referencial, como proposto para o caso do Basco, Grego e St'át'imcets, por Etxeberria e Giannakidou (2009), línguas muito semelhantes ao Kaingang no domínio nominal. Assim, concluímos que, no Kaingang Paranaense, o determinante definido não é ambíguo entre um artigo definido clássico e um mero restritor contextual de domínio. Em estruturas $N P+k a r+a g$, o determinante também funciona como restritor contextual, mas continua sendo um operador de tipo et,e, i.e., formando indivíduo a partir de um conjunto. Levantamos também algumas reflexões quanto à possibilidade e os probelmas de se estender a análise do Kaingang Paranaense para o Basco, Grego e St'át'imcets. Com isso, intentamos ensaiar uma análise unificada para as línguas que apresentam uma estrutura em que o determinante definido parece, a princípio, combinar-se com uma expressão quantificacional.

Num segundo momento, com o objetivo de mapear ainda mais a semântica de kar, saímos da estrutura interna do DP em Kaingang e investigamos o comportamento da expressão kar na sentença, i.e, as possíveis leituras que podem receber sentenças com DP nos quais ocorre kar, sobretudo a sua interação com um operador distributivo que parece ser introduzido via reduplicação verbal. O comportamento de kar nas sentenças mostrou que kar é neutro quanto à distributividade, i.e., não força leitura distributiva. As leituras distributivas foram atribuídas às sentenças quando houve reduplicação verbal. E o fato de tais leituras distributivas atribuírem o predicado verbal aos 
indivíduos atômicos na extensão do DP sujeito, levou-nos a hipotetizar que a reduplicação verbal em Kaingang, ao menos para verbos accomplishments, introduz um operador distributivo que tem escopo sobre todo o VP.

Compreendemos que muitas questões relacionadas com nossa investigação ainda precisam ser tratadas em novas pesquisas. Ainda faz-se necessário investigar em Kaingang (i) a existência de outras expressões, tradicionalmente consideradas expressões quantificacionais, como most (a maioria), muitos, poucos, etc., e a (ii) distribuição dessas expressões nas sentenças e sua interação com os determinantes definidos. Entendemos que, com isso, poderemos ter um maior conhecimento da estrutura do DP em Kaingang e uma classificação mais precisa e abrangente das expressões quantificacionais e dos modificadores na língua. Além disso, precisamos investigar com mais detalhe a distribuição de kar, para podermos especificar melhor a sua classificação. Embora não encontramos nenhum exemplo em que kar não ocorra interno a um DP, não o classificamos como um adjunto adnominal ou um adjetivo, por entendermos que mais testes precisam ser realizados para se sustentar qualquer hipótese nesse sentido. Por exemplo, precisaríamos investigar se a distribuição de kar se assemelha à distribuição dos adjetivos em Kaingang. Em função de não termos tido tempo de realizar esta investigação, compreendemos que a solução mais prudente foi deixar kar apenas subespecificado como um modificador.

Quanto ao fenômeno da reduplicação verbal, testes precisam ser realizados com todas as classes de verbo, de maneira a podermos mapear de forma mais exaustiva as possíveis leituras oriundas da reduplicação verbal, e, por sua vez, formularmos uma generalização mais precisa deste fenômeno na língua.

Por último, enfatizamos que nossa principal expectativa é de que, com esta dissertação, tenhamos contribuído, com mais dados translinguisticos, para a investigação do fenômeno da restrição de domínio em língua natural (fenômeno esse que é um caso especial de uma questão maior nas línguas naturais, que é o problema da dependência contextual, i.e., de explicar o papel do contexto na determinação do significado de um enunciado linguístico) e de expressões que veiculam a idéia de totalidade/completude. E que, no escopo dessas duas questões, tentou-se (i) investigar o papel desempenhado por certas expressões liguísticas, como o determinante definido, na restrição de domínio e (ii) e a interação destas expressões com outros termos linguísticos, como termos com um uma função eminentemente pragmática, no caso kar, 
e um operador distributivo, que, em sentenças com leitura restrita, introduziu uma quantificação universal sobre elementos salientes no contexto .

Portanto, no percurso desta dissertação, no marco da semântica formal e tendo por diretriz da investigação a busca por universais semânticos, procuramos relacionar restrição de domínio, modificadores e operador distributivo. 


\section{Referências}

ABREU. E. R. R; SANTOS. L (2009). Os pronomes na língua kaingang e a variação na estrutura frasal. In: CELLI - COLÓQUIO DE ESTUDOS LINGUÍSTICOS E LITERÁRIOS. 3, 2007, Maringá. Anais... Maringá, p. 1334-1343.

ADAMS. N (2005). Quantification and partitivity in Zulu. Ms. University of Chicago.

BARWISE, J. \& COOPER, R (1981). 'Generalized quantifiers and natural language', Linguistics \&Philosophy 4: 159-219.

BEGHELLI. F \& STOWELL. T (1997). 'Distributivity and Negatiopn: the syntax of each and every. A. Szabolcsi(ed). Ways of scope taking, 71-107. Kluwer Academic Publishers. Printed in the Netherlands.

BRISSON, C. (1998). Distributivity, Maximality, and Floating Quantifiers, Doctoral dissertation. Rutgers University.

(2003). 'Plurals, all, and the nonuniformity of collective predication', Linguistics \& Philosophy 26: 129-84.

CARLSON, G (1977), Reference to Kinds in English, Ph.D. dissertation, University of Massachusetts at Amherst. Published in 1980 by Garland, New York.

D’ANGELIS (1998). Traços de modo e modos de traçar geometrias: línguas Macro-Jê \& teoria fonológica . Tese de Doutorado. Campinas: IEL-Universidade estadual de Campinas (Unicamp);

DAVIDSON. D. (2001).Inquiries into truth and interpretations. Oxford University Press, New York.

DEMIRDACHE, H. (1997). 'Predication times in St'át'imcets', in Blight, R. \& M. Moosally (eds.), Texas Linguistic Forum 38: The Syntax and Semantics of Predication. Austin, Texas: University of Texas Department of Linguistics.

DIESING, M. (1992). Indefinites. Cambridge, MA: MIT Press.

DOWTY, D. (1987). Collective predicates, distributive predicates and all. In Proceedings of the 3rd Eastern States Conference on Linguistics, ed. by Fred Marshall, AnnMiller, and Zheng-sheng Zhang, 97-115.Columbus: The Ohio State University, Department of Linguistics.

ELBOURNE, P. (2007). Descriptions. Stanford encyclopedia of Philosophy, Open access encyclopedia.

ETXEBERRIA, U. (2005). Quantification and Domain Restriction in Basque, Doctoral dissertation. University of the Basque Country (UPV-EHU).

(2005) Contextually Restricted Quantification in Basque. Handout for $Q P$ structures, Nominalization, and the role of DP. Saarbücken, Dec. 15-17. 
(2008). 'On quantification in Basque and on how some languages restrict their quantificational domain overtly', in Matthewson, L. (ed.), Quantification: A crosslinguistic perspective. Emerald. 225-276.

ETXEBERRIA, U \& GIANNAKIDOU, A. (2009). Contextual domain restriction across languages: Definiteness, Indefiniteness and the structure of QP. Pending version for Natural Language and Semantics.

von FINTEL, K. (1994). Restrictions on Quantifier Domains. Doctoral dissertation, UMass.

(2004). 'Domain restriction and the arguments of quantificational determiners', in Proceedings of SALT 14. Dept. of Modern Languages, Cornell University, Ithaca, NY, 110-128. The Ohio State University, Columbus, 383-402.

FODOR, J \& SAG(1982). I. 'Referential and Quantificational Indefinites', Linguistics and Philosphy 5, 355-398.

FREGE, G. (1892). 'On Sense and Nominatum', in Martinich, A. P. (ed.), 2001, The Philosophy of Language, Oxford: Blackwell Publishers. 199-211.

GIANNAKIDOU, A. (2004). 'Domain restriction and the arguments of quantificational determiners', in Proceeding of SALT 14. Dept. of Modern Languages, Cornell University, Ithaca, NY, 110-128.

GIL. D (1995). 'Universal Quantifiers and distributivity'. E. Bach, E. Jelinek, A. Kratzer and B. H. Partee (eds), Quantification in Natural Languages, 321-365. Kluwer Academic Publishers. Printed in the Netherlands.

GONÇALVES, S. A. Aspecto no Kaingang. Dissertação de Mestrado. Universidade Estadual de Campinas (Unicamp)

GONÇALVES, S. A. (2009)A expressão do tempo na língua Kaingang. In: ESTUDOS LINGUÍSTICOS, São Paulo, 38 (1): 249-258 jan.-abr.

HEIM, I. (1982). Semantics of Definite and Indefinite Noun Phrases, Doctoral dissertation, MIT.

HEIM, I. \& A. KRATZER (1998). Semantics in Generative Grammar, London: Blackwell.

HEYCOCK, C \& ZAMPARELLI R (2005). 'Friends and Colleagues: Plurality, Coordination, and the Structure of DP'. , in Natural Language Semantics 13:201-270.

IONIN, T. (2006). 'This is definitely specific: Specificity and definiteness in article systems', in Natural Language Semantics 14: 175-234.

KRATZER, A. (1996). 'Scope or Pseudoscope? Are There Wide Scope Indefinites?', ms., University of Massachusetts, Amherst. Also in S. Rothstein (ed.), Events and Grammar, Kluwer, Dordrecht, 1998. 
LADUSAW, W. (1982). 'Semantic constraints on the English partitive construction', in D.Flickinger et al. (eds.), Proceedings of WCCFL 1, 231-242.

LASERSOHN. P. (1995). Plurality, Conjunction, and Events. Dordrecht, Boston: Kluwer Academic Publishers.

(1999). 'Pragmatic Halos'. Language. Volume 75, number 3, September.

LINK, G. (1984). 'The Logical Analysis of Plurals and Mass Terms: A Lattice Theoretical Approach', in Bäuerle, R., C. Schwarze, \& A. von Stechow (eds.), Meaning, Use, and Interpretation of Language, Berlin: Walter de Gruyter. 302-323.

MARTÍ, L. (2003). Contextual Variables. Doctoral dissertation, UConn.

MATTHEWSON, L. (1998). Determiner Systems and Quantificational Strategies: Evidence from Salish, The Hague: Holland Academic Graphics.

Semantics 7:79-134.

(1999). 'On the interpretation of wide-scope indefinites', Natural Language

Language

(2001). 'Quantification and the nature of crosslinguistic variation', Natural

Semantics 9: 145-79.

(2008). Quantification: A crosslinguistic perspective. Emerald.

MILSARK, G. (1977). 'Toward an Explanation of Certain Peculiarities of the Existential Construction in English', in Linguistic Analysis 3-1. 1-28.

(1979). Existential Sentences in English. New York: Garland Publishing

Inc.

MONTAGUE, R. (1974). 'The proper treatment of quantification in ordinary English', in Hintikka J., J. Moravcsik, \& P. Suppes (eds.), Approaches to Natural Language. Dordrecht: D. Reidel.

NASCIMENTO, S.H.L (1995). Aspectos Morfológicos e Sintáticos e Marcação de Caso da Língua Kaingang. Dissertação de Mestrado, Universidade Federal de Santa Catarina.

PARTEE, B. H. (1987). 'Noun phrase interpretation and type-shifting principles', in Groenendijk J.,D. de Jongh, \& M. Stokhof (eds.), Studies in Discourse Representation Theory and the Theory of Generalized Quantifiers. Dordrecht: Foris, 115-43

(1995) 'Quantificational Structures and Compositionality'. E. Bach, E. Jelinek,

A. Kratzer and B. H. Partee (eds), Quantification in Natural Languages, 541-602. Kluwer Academic Publishers. Printed in the Netherlands.

RECANATI, F. (1996). 'Domains of discourse. Linguistics \& Philosophy 19:5. 445475 .

REINHART, T. (2006). Interface Strategies: Optimal and Costly Computations, MIT Press, Cambridge, Massachusetts.

Quantifier Scope: 'How Labor is Divided between QR and Functions', Linguistics and Philosophy 20, 335-397, 1997. 
ROBERT, C. Modal subordination, Anaphora and Distributivity. Uviversity of Massachusetts. dDssertation.

RUSSELL, B. (1905). 'On Denoting', in Martinich, A. P. (ed.), 2001, The Philosophy of Language, Oxford: Blackwell Publishers. 212-220.

SCHWARZSCHILD, R (1996). Pluralities. Dordrecht: Kluwer

STANLEY, J. \& SZABÓ, Z. G. (2000). 'On quantifier domain restriction', Mind \& Language 15: 219-61.

STRAWSON, P. F., (1950). “On Referring,” Mind, 59, 320-334.

TABOSA, L.P (2006). Construções Causativas na Língua Kaingang. Dissertação de Mestrado, Universidade Estadual de Londrina (UEL).

VENDLER, Z (1967). Linguistics in philosophy. Ithaca, N.Y.: Cornell University Press.

WESTERSTAHL, D. (1984). 'Determiners and context sets' In van Benthem, J. and A. ter Meulen (eds), Generalized quantifiers in Natural Language, Foris, Dordrecht. 45-71. (1985). 'Logical constants in quantifier languages', Linguistics \& Philosophy 8:387-413.

WINTER, Y. (1997). 'Choice Functions and the Scopal Semantics of Indefinites', Linguistics and Philosophy 20, 399-466. 